AUTARQUIA ASSOCIADA À UNIVERSIDADE DE SÃO PAULO

\title{
Estudo da preparação de eletrocatalisadores Pt-Sn/C por meio da deposição superficial de Pt sobre Sn/C utilizando diferentes metodologias para aplicação na oxidação eletroquímica do etanol
}

Vilmaria Aparecida Ribeiro

Tese apresentada como parte dos requisitos para obtenção do Grau de Doutor em Ciências na Área de Tecnologia Nuclear - Materiais.

Orientador:

Dr. Estevam Vitorio Spinacé

Co-orientador:

Dr. Almir Oliveira Neto

SÃO PAULO 
INSTITUTO DE PESQUISAS ENERGÉTICAS E NUCLEARES

Autarquia associada à Universidade de São Paulo

\title{
Estudo da preparação de eletrocatalisadores Pt-Sn/C por meio da deposição superficial de Pt sobre Sn/C utilizando diferentes metodologias para aplicação na oxidação eletroquímica do etanol
}

\author{
Vilmaria Aparecida Ribeiro \\ Tese apresentada como parte dos \\ requisitos para obtenção do Grau \\ de Doutor em Ciências na Área de \\ Tecnologia Nuclear - Materiais.
}

Orientador:

Dr. Estevam Vitorio Spinacé

Co-orientador:

Dr. Almir Oliveira Neto

\begin{abstract}
Versão Corrigida
Versão Original Disponível no IPEN
\end{abstract}

SÃO PAULO 
"Talvez não tenha conseguido fazer o melhor, mas lutei para que $o$ melhor fosse feito. Não sou o que deveria ser, mas Graças a Deus, não sou o que era antes". Marthin Luther King 
Assim como o sol nasce, a lua ilumina e as estrelas brilham, em perfeita harmonia, assim me sinto quando penso e estou com minha irmã querida. À Mayara Neves Ribeiro 


\section{AGRADECIMENTOS}

Agradeço a Deus. Ele que esteve sempre ao meu lado durante esta caminhada, muitas vezes o caminho tornou-se difícil e pensei em desistir. Contudo, não teria chegado até aqui sem a ajuda de alguns anjos que Ele me enviou:

À minha família, em particular, aos meus pais e aos meus irmãos, cunhado, cunhada, tias e primos que acreditaram no meu potencial.

Aos meus queridos amigos, Michele B. Tusi, Eliana Paim, Thais A. B. Santoro, Maria José A. Oliveira, Marcelo M. Tusi pelo seu apoio, incentivo e por fazerem a diferença em minha vida.

Meu muitíssimo obrigado a Dra. Doris H. Moreno, por todo cuidado dedicado a mim, durante os dias em que a luz não brilhava tanto.

Meu orientador Dr. Estevam Vitorio Spinacé, por todo o aprendizado, pela sua enorme paciência, dedicação, estímulo e por me ensinar que é errando que se aprende sem perder a esperança no amanhã.

Desejo agradecer ao meu Co-orientador Prof. Dr. Almir Oliveira Neto, pelos ensinamentos, paciência e pela disponibilidade de materiais e equipamentos de seu laboratório.

Obrigado ao meu supervisor André D. Taylor que me recebeu e acompanhoume durante o período em que estive Yale University nos Estados Unidos.

Ao Dr. Fabio C. Fonseca, Dr. Marcelo Linardi, Dra. Elisabete Inácio Santiago e aos professores do $\mathrm{CCCH}$, pela infraestrutura, materiais e conhecimentos ofertados.

Agradeço a imensa ajuda dos técnicos dos laboratórios do IPEN.

Aos meus colegas de laboratório e da escola Paulo Freire, pelos momentos de entusiasmo partilhados em conjunto. 
A secretária da pós-gradução do IPEN/CNEN, Ana Claudia M. Feher e Magali B. Silva, pela paciência e pela imensa ajuda na parte burocrática do processo.

Agradeço a assistente social Carla M. Cucolo, por toda assistência prestada a mim junto ao COSEAS-USP .

Meu muitíssimo obrigado ao CNPq, pela bolsa de estudos no país e no exterior.

Agradeço também Fundação Lemann pelo auxílio financeiro durante o Doutorado Sanduiche.

Agradeço ao Programa de Pós-Graduação em Tecnologia Nuclear de Materiais e a todos os professores que fazem parte deste programa que lutam por uma educação digna e ensino de qualidade.

Enfim, Agradeço de coração a todos que de maneira indireta contribuíram para eu chegasse até aqui: Márcio Paiva, Zezito R. Gonçaves, Haroldo G. Oliveira, Nelson V. Navarrete, Osmar Tonon e Milton J. Rubio. 


\title{
ESTUDO DA PREPARAÇÃO DE ELETROCATALISADORES Pt-Sn/C POR MEIO DA DEPOSIÇÃO SUPERFICIAL DE Pt SOBRE Sn/C UTILIZANDO DIFERENTES METODOLOGIAS PARA APLICAÇÃO NA OXIDAÇÃO ELETROQUÍMICA DO ETANOL
}

\author{
Vilmaria Aparecido Ribeiro
}

\begin{abstract}
RESUMO
Foram preparados eletrocatalisadores $\mathrm{Pt}-\mathrm{Sn} / \mathrm{C}$ a partir da deposição de $\mathrm{Pt}$ sobre $\mathrm{Sn} / \mathrm{C}$ por diferentes metodologias. Os suportes $\mathrm{Sn} / \mathrm{C}$ foram preparados pela redução com boroidreto de sódio $(\mathrm{BH})$ e pelo método da redução por álcool (MRA). A deposição da Pt foi efetuada pelo processo de troca galvânica e utilizando agentes redutores pelos métodos $\mathrm{BH}$ e MRA. Os materiais obtidos foram caracterizados por energia dispersiva de raios $X$ (EDX), difração de raios $X(D R X)$, microscopia eletrônica de transmissão (TEM), energia dispersiva de raios $X$ de varredura linear (EDX- line scan), voltametria cíclica (VC) e stripping de $\mathrm{CO}$ e testados na oxidação eletroquímica do etanol. $O$ difratograma de raios $X$ do $\mathrm{Sn} / \mathrm{C}$ preparado pelo método $\mathrm{BH}$ mostrou a presença da fase $\mathrm{Sn}$ metálico, enquanto que, o $\mathrm{Sn} / \mathrm{C}$ preparado pelo método MRA levou a formação da fase $\mathrm{SnO}_{2}$. Apesar de o material obtido por deposição espontânea apresentar-se mais ativo que o suporte $\mathrm{Sn}(\mathrm{BH}) / \mathrm{C}$, sua atividade foi inferior ao do catalisador comercial PtSn/C BASF. Os materiais obtidos apresentaram-se mais ativos que o catalisador comercial. A deposição da Pt pelo método $\mathrm{BH}$ sobre o suporte $\mathrm{Sn}(\mathrm{BH}) / \mathrm{C}$ levaram a catalisadores com desempenhos inferiores ao catalisador comercial, isto devido a deposição da Pt ocorrer preferencialmente sobre as nanopartículas de Sn metálico, tornando a superfície do catalisador rica em Pt. Os estudos realizados por microscopia eletrônica de transmissão - EDX scan-line mostraram que este material apresentou a distribuição mais homogênea dos sítios de Pt e Sn na superfície do catalisador. Assim, nas condições estudadas, a deposição de Pt na superfície do Sn/C, apesar de alguns casos, os materiais obtidos apresentarem melhor atividade que 0
\end{abstract}


catalisador PtSn/C comercial, estes apresentaram-se menos ativos que os materiais preparados em uma única etapa por co-redução. 


\title{
STUDY OF THE PREPARATION OF Pt-Sn//C ELECTROCATALYSTS THROUGH DEPOSITION OF Pt ON THE SURFACE OF Sn/C FOR ETHANOL ELECTROOXIDATION
}

\section{Vilmaria Aparecido Ribeiro}

\begin{abstract}
We present a study of the achievement of $\mathrm{Pt}-\mathrm{Sn} / \mathrm{C}$ electrocatalysts from the deposition of Pt on Sn/C surface using different methodologies. The $\mathrm{Sn} / \mathrm{C}$ support were obtained by reduction method with sodium borohydride $(\mathrm{BH})$ and by the alcohol reduction method (MRA). Pt deposition was carried out by the galvanic exchange process and by using reducing $\mathrm{BH}$ and MRA methods. The materials were characterized using energy dispersive X-ray (EDX), X-ray diffraction (XRD), transmission electron microscopy (TEM), energy dispersive X-ray linear scan (EDXline scan), cyclic voltammetry (VC) and CO stripping and tested by electrochemical oxidation of ethanol. A comparison between MRA and BH method showed the presence of $\mathrm{Sn}$ metal phase in the X-ray diffractogram $\mathrm{Sn} / \mathrm{C}$ using the first method while the second lead to the formation of the $\mathrm{SnO}_{2}$ phase. The obtained material resulted by deposition process more active than the $\mathrm{Sn}$ holder $(\mathrm{BH}) / \mathrm{C}$ but less active than commercial catalyst PtSn/C BASF. The materials result to be more active than the commercial catalyst. The Pt deposition process using $\mathrm{BH}$ method on $\mathrm{Sn}(\mathrm{BH}) / \mathrm{C}$ support led to catalysts with lower performance to the commercial catalyst because, in this case, the deposition occurs of Pt preferably on Sn metal nanoparticles, making the surface of the catalyst rich in Pt. Studies by transmission electron microscopy - EDX-line - scan showed that this material had the most even distribution of $\mathrm{Pt}$ and $\mathrm{Sn}$ sites on the catalyst surface. In this work, we obtained electrocatalyst by $\mathrm{Pt}$ deposition on $\mathrm{Sn} / \mathrm{C}$ 's surface, with higher activity than the Commercial $\mathrm{PtSn} / \mathrm{C}$ catalyst and verified that the materials obtained in a single step process by co-reduction are the ones with higher activity.
\end{abstract}




\section{SUMÁRIO}

Página

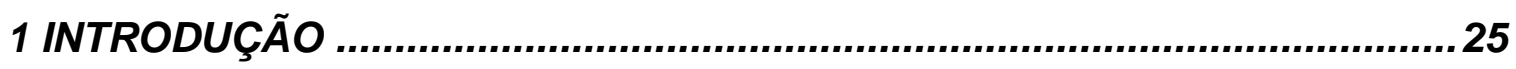

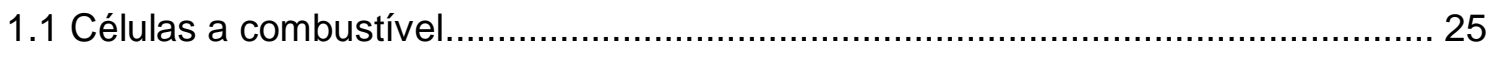

1.2 Células a combustível de eletrólito polimérico sólido (PEMFC) …………………...2

1.3 Célula a combustível utilizando alcoóis diretamente como combustíveis (Direct

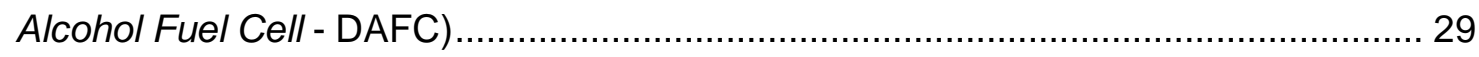

1.3.1 Mecanismo da Oxidação do Metanol sobre Platina ………………………………..... 30

1.4 Célula a combustível utilizando etanol diretamente como combustível (Direct

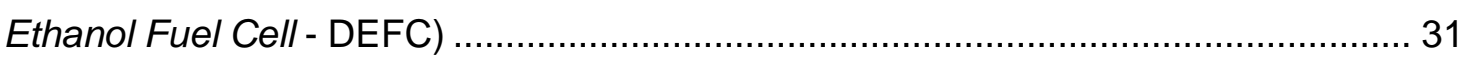

1.4.1 Eletrocatalisadores $\mathrm{PtSn} / \mathrm{C}$ para a oxidação eletroquímica do etanol nas células

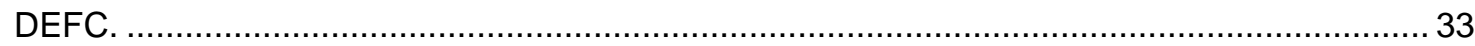

1.5 Preparação de eletrocatalisadores PtSn por meio da Deposição de Pt ou

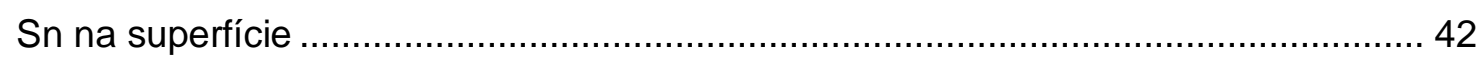

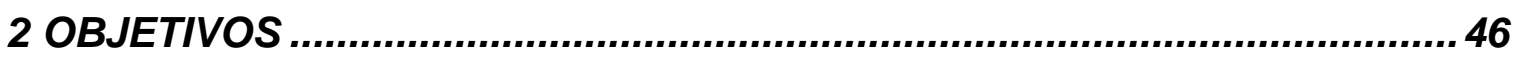

3 EXPERIMENTAL

3.1 Preparações dos eletrocatalisadores Pt-Sn/C ................................................... 47

3.1.1 Preparação dos eltrocatalisadores Pt-Sn/C por substituição galvânica ..................... 47

3.1.2 Preparação de eletrocatalisadores $\mathrm{Pt}-\mathrm{Sn} / \mathrm{C}$ por redução sucessiva por meio da deposição de Pt por diferentes metodologias sobre Sn/C preparado pelo método da redução

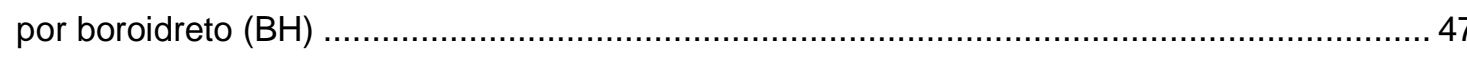

3.1.3 Preparação de eletrocatalisadores $\mathrm{Pt}-\mathrm{Sn} / \mathrm{C}$ por redução sucessiva por meio da deposição de Pt por diferentes metodologias sobre Sn/C preparado pelo método da redução por álcool (MRA)

3.1.4 Preparação dos Eletrocatalisadores $\mathrm{PtSn} / \mathrm{C}$ por co-redução pelos métodos MRA e BH

3.2 Caracterização Físico-Química dos Eletrocatalisadores ....................................... 50

3.2.1 Análise de raios $X$ por energia dispersiva ......................................................... 50

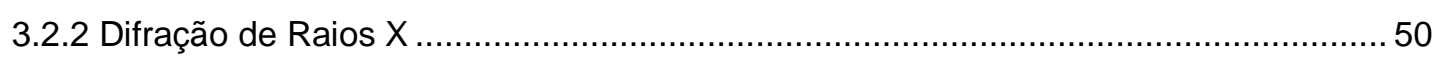

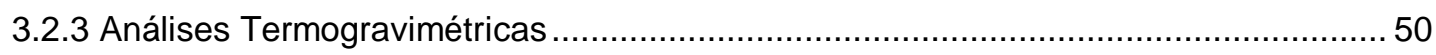

3.2.4 Microscopia Eletrônica de Transmissão............................................................ 51 
3.3 Estudos Eletroquímicos

3.4 Medidas de stripping por adsorção de monóxido de carbono (COads) ...... 53

4 RESULTADOS E DISCUSSÕES. 55

4.1 Preparação de eletrocatalisadores Pt-Sn/C por troca galvânica 55

4.2 Preparação de eletrocatalisadores Pt-Sn/C por redução sucessiva utilizando diferentes metodologias.

4.2.1 Preparação do Sn/C com diferentes \% em massa de Sn utilizando o método da redução por boroidreto $(\mathrm{BH})$.

4.2.2 Preparação de Sn/C com diferentes \% em massa de Sn utilizando o método da redução por álcool (MRA)

4.3 Comparação PtSn/C preparados por co-redução (única etapa de síntese) e redução sucessiva (deposição Pt na segunda etapa de síntese) pelos métodos MRA e $\mathrm{BH}$ em diferentes condições. 96

4.3.1 Análise da superfície dos eletrocatalisadores pela técnica TEM-EDX line- scan........98

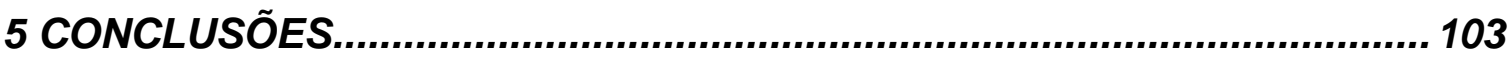

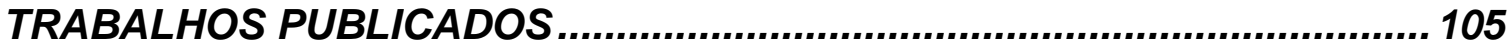




\section{LISTA DE FIGURAS}

Página

FIGURA 1- Desenho esquemático de uma célula a combustível unitária [6] 26

FIGURA 2 - Esquema simplificado de uma célula a combustível .29

FIGURA 3 - Esquema do método da redução por álcool (MRA) .48

FIGURA 4 - Diagrama esquemático do eletrodo de camada fina porosa..52

FIGURA 5 - Representação esquemática da célula eletroquímica usada para realização das medidas de voltametria e cronoamperometria e por eletrodo de camada fina porosa

FIGURA 6 - Difratogramas de raios $X$ do precursor $S n / C$ e do eletrocatalisador Pt-Sn/C obtido por deposição espotânea .58

FIGURA 7 - Espectro de EDX do eletrocatalisador Pt-Sn/C obtido por deposição espotânea. 59

FIGURA 8 - Voltametria cíclica do suporte $\mathrm{Sn} / \mathrm{C}$ e do eletrocatalisador Pt$\mathrm{Sn} / \mathrm{C}$ em solução de $\mathrm{H}_{2} \mathrm{SO}_{4} 0,5 \mathrm{~mol} \mathrm{~L}^{-1}$ a $10 \mathrm{mVs}^{-1}$ 60

FIGURA 9 - Curvas cronoamperometricas obtidas a $0,5 \mathrm{~V}$ em solução de $0,5 \mathrm{~mol} \mathrm{~L}^{-1}$ de $\mathrm{H}_{2} \mathrm{SO}_{4}$ contendo $1 \mathrm{~mol} \mathrm{~L}^{-1}$ de etanol

FIGURA 10 - Curvas cronoamperometricas obtidas a $0.5 \mathrm{~V}$ em solução de $0.5 \mathrm{~mol} \mathrm{~L}^{-1}$ de $\mathrm{H}_{2} \mathrm{SO}_{4}$ contendo $1 \mathrm{~mol} \mathrm{~L}^{-1}$ de etanol normalizadas por grama de $\mathrm{Pt}$, para o catalisador obtido por deposição espontânea

FIGURA 11 - Curvas cronoamperometricas obtidas a $0.5 \mathrm{~V}$ em solução de $0.5 \mathrm{~mol} \mathrm{~L}^{-1}$ de $\mathrm{H}_{2} \mathrm{SO}_{4}$ contendo $1 \mathrm{~mol} \mathrm{~L}^{-1}$ de etanol normalizadas por grama de catalisador, obtido por deposição espontânea

FIGURA 12 - Difratogramas de raios X dos eletrocatalisadores $\mathrm{Sn} / \mathrm{C}$ preparado pelo método $\mathrm{BH}$ com 10, 20, 40,60 \% em massa de Sn .65

FIGURA 13 - Micrografias eletrônicas de transmissão do suporte Sn/C preparado pelo método $\mathrm{BH}$ com $10 \%$ em massa de $\mathrm{Sn}$ .66

FIGURA 14 - Micrografias eletrônicas de transmissão do suporte Sn/C preparado pelo método $\mathrm{BH}$ com $20 \%$ em massa de $\mathrm{Sn}$ .66 
FIGURA 15 - Termogramas dos eletrocatalisadores $\mathrm{Pt}(\mathrm{MRA})-\mathrm{Sn}(\mathrm{BH}) / \mathrm{C}$ preparados a partir do suporte com $20 \%$ em massa de $\mathrm{Sn}$

FIGURA 16 - Difratogramas de raios $X$ dos eletrocatalisadores $\mathrm{PtSn} / \mathrm{C}$ BASF, Pt(MRA)-Sn(BH)/C e o $\mathrm{Sn}(\mathrm{BH}) / \mathrm{C}$ com $10 \%$ em massa de $\mathrm{Sn}$ .71

FIGURA 17 - Micrografia eletrônica de Transmissão do eletrocatalisador $\mathrm{Pt}(\mathrm{MRA})-\mathrm{Sn}(\mathrm{BH}) / \mathrm{C}$ (10\% em massa Sn e 12,4\% em massa de Pt) 72

FIGURA 18 - Voltamogramas cíclicos obtidos em solução $0,5 \mathrm{~mol} \mathrm{~L}^{-1}$ de $\mathrm{H}_{2} \mathrm{SO}_{4}$ para os eletrocatalisadores $\mathrm{Pt}(\mathrm{MRA})-\mathrm{Sn}(\mathrm{BH}) / \mathrm{C}$ (10\% em massa de $\mathrm{Sn}$ ), $\mathrm{PtSn} / \mathrm{C}$ BASF .73

FIGURA 19 - Comparação das curvas cronoamperométricas, para os eletrocatalisadores PtSn/C BASF, Pt(MRA)-Sn(BH)/C e o suporte $\mathrm{Sn}(\mathrm{BH}) / \mathrm{C}$ com $10 \%$ em massa de Sn em etanol $1.0 \mathrm{~mol} \mathrm{~L}^{-1}$ e potencial fixo de $500 \mathrm{mV}$ por 30 $\min$

FIGURA 20 - Difratogramas de raios $X$ dos eletrocatalisadores $\mathrm{PtSn} / \mathrm{C}$ BASF, Pt(MRA)-Sn(BH)/C e o suporte $\mathrm{Sn}(\mathrm{BH}) / \mathrm{C}(20 \%$ massa de $\mathrm{Sn})$ .75

FIGURA 21 - Micrografia eletrônica de Transmissão do eletrocatalisador Pt$\mathrm{Sn} / \mathrm{C}$ (20\% em massa Sn e $12,4 \%$ em massa de Pt) .76

FIGURA 22 - Voltamogramas cíclicos obtidos em solução $0,5 \mathrm{~mol} \mathrm{~L}^{-1} \mathrm{de}$ $\mathrm{H}_{2} \mathrm{SO}_{4}$ para os eletrocatalisadores PtSn/C BASF e Pt(MRA)-Sn(BH)/C com 20\% em massa de $\mathrm{Sn}$ .77

FIGURA 23 - Comparação das curvas cronoamperométricas para os eletrocatalisadores PtSn/C BASF e Pt(MRA)-Sn(BH)/C com 20\% em massa de Sn em etanol $1,0 \mathrm{~mol} \mathrm{~L}^{-1}$ e potencial fixo de $500 \mathrm{mV}$ por $30 \mathrm{~min}$ .78

FIGURA 24 - Comparação das curvas cronoamperométricas dos eletrocatalisadores $\mathrm{Pt}-\mathrm{Sn} / \mathrm{C}$ preparados com diferentes \% em massa de $\mathrm{Sn}$ em etanol $1,0 \mathrm{~mol} \mathrm{~L}^{-1}$ e potencial fixo de $500 \mathrm{mV}$ por $30 \mathrm{~min}$ .79

FIGURA 25 - Oxidação eletroquímica do $\mathrm{CO}$ (CO stripping) nos eletrocatalisadores $\mathrm{Pt}(\mathrm{MRA})-\mathrm{Sn}(\mathrm{BH}) / \mathrm{C}$ preparados no suporte $\mathrm{Sn} / \mathrm{C}$ com $10 \%$ em massa de Sn

FIGURA 26 - Difratogramas de raios $X$ dos eletrocatalisadores $\mathrm{Pt}(\mathrm{BH})$ $\mathrm{Sn}(\mathrm{BH}) / \mathrm{C}$ preparados com suporte $\mathrm{Sn} / \mathrm{C}$ com $10 \%$ em massa 
FIGURA 27 - Difratogramas de raios $X$ dos eletrocatalisadores $\mathrm{Pt}(\mathrm{BH})$ $\mathrm{Sn}(\mathrm{BH}) / \mathrm{C}$ preparados com suporte $\mathrm{Sn} / \mathrm{C}$ com $20 \%$ em massa

FIGURA 28 - Micrografias eletrônica de Transmissão do eletrocatalisador $\mathrm{Pt}(\mathrm{BH})-\mathrm{Sn}(\mathrm{BH}) / \mathrm{C}(10 \%$ em massa Sn e 12,4\% em massa de $\mathrm{Pt})$

FIGURA 29 - Voltamogramas cíclicos obtidos em solução $0,5 \mathrm{~mol} \mathrm{~L}^{-1}$ de $\mathrm{H}_{2} \mathrm{SO}_{4}$ para os eletrocatalisadores $\mathrm{PtSn} / \mathrm{C}$ BASF e Pt(BH)-Sn(BH)/C com $20 \%$ em massa de $\mathrm{Sn}$

FIGURA 30 - Comparação das curvas cronoamperométricas dos eletrocatalisadores $\mathrm{Pt}(\mathrm{BH})-\mathrm{Sn}(\mathrm{BH}) / \mathrm{C}$ preparados com diferentes \% em massa de Sn em etanol $1,0 \mathrm{~mol} \mathrm{~L}^{-1}$ e potencial fixo de $500 \mathrm{mV}$ por $30 \mathrm{~min}$, a) $\mathrm{Sn} / \mathrm{C} 10 \% \mathrm{em}$ massa e b) $\mathrm{Sn} / \mathrm{C} 20 \%$ em massa .86

FIGURA 31 - Oxidação eletroquímica do $\mathrm{CO}$ (CO stripping) nos eletrocatalisadores $\mathrm{Pt}(\mathrm{BH})-\mathrm{Sn}(\mathrm{BH}) / \mathrm{C}$ preparados utilizando suporte $\mathrm{Sn}(\mathrm{BH}) / \mathrm{C}$ com 10 e $20 \%$ em massa de Sn 90

FIGURA 32 - Comparação das curvas cronoamperométricas dos eletrocatalisadores $\mathrm{Pt}(\mathrm{BH})-\mathrm{Sn}(\mathrm{BH}) / \mathrm{C}$ e $\mathrm{Pt}(\mathrm{MRA})-\mathrm{Sn}(\mathrm{BH}) / \mathrm{C}$ preparados com diferentes $12,5 \%$ em massa de Pt em etanol $1,0 \mathrm{~mol} \mathrm{~L}^{-1}$ e potencial fixo de 500 $\mathrm{mV}$ por $30 \mathrm{~min}$

FIGURA 33 - Difratogramas de raios $X$ para os catalisadores $S n / C$ pelo método MRA com 10 e $20 \%$ em massa de $\mathrm{Sn}$ 92

FIGURA 34 - Difratogramas de raios $X$ dos eletrocatalisadores preparados pela deposição de Pt pelos métodos MRA e BH sobre o Sn(MRA)/C com 10 (A) e $20 \%$ (B) em massa de $\mathrm{Sn}$

FIGURA 35 - Comparação das curvas cronoamperométricas dos eletrocatalisadores $\mathrm{Pt}(\mathrm{MRA})-\mathrm{Sn}(\mathrm{MRA}) / \mathrm{C}$ e $\mathrm{Pt}(\mathrm{BH})-\mathrm{Sn}(\mathrm{MRA}) / \mathrm{C}$ preparados com $10 \%$ (A) e $20 \%$ (B) em massa de Sn em etanol 1,0 $\mathrm{mol} \mathrm{L}^{-1}$ e potencial fixo de 500 $\mathrm{mV}$ por $30 \mathrm{~min}$ 96

FIGURA 36 - Comparação das curvas cronoamperométricas dos diferentes eletrocatalisadores PtSn/C (12,4\% em massa de Pt e 20\% massa Sn) preparados por co-redução e redução sucessiva em etanol $1,0 \mathrm{~mol} \mathrm{~L}^{-1}$ e potencial fixo de 500 $\mathrm{mV}$ por $30 \mathrm{~min}$ 
FIGURA 37 - Micrografias eletrônicas de transmissão com o correspondente localização do line-scan e os gráficos mostrando as intensidades dos elementos com a posição da linha para o eletrocatalisador $\mathrm{Pt}(\mathrm{BH})-\mathrm{Sn}(\mathrm{BH}) / \mathrm{C}$ 100

FIGURA 38 - Micrografias eletrônicas de transmissão com o correspondente localização do line-scan e os gráficos mostrando as intensidades dos elementos com a posição da linha para o eletrocatalisador Pt(MRA)-Sn(MRA)/C 101

FIGURA 39 - Micrografias eletrônicas de transmissão com o correspondente localização do line-scan e os gráficos mostrando as intensidades dos elementos com a posição da linha para o eletrocatalisador $\mathrm{PtSn} / \mathrm{C}$ preparado por co-redução pelo método MRA 102 


\section{LISTA DE TABELAS}

Página

TABELA 1 - Razão atômica nominal e a obtida por EDX dos eletrocatalisadores $\mathrm{Pt}(\mathrm{MRA})-\mathrm{Sn}(\mathrm{BH}) / \mathrm{C}$, com 10, 20, 40 e 60\% em massa de $\mathrm{Sn}$ e com diferentes razões atômicas de $\mathrm{Pt}$.

TABELA 2 - Porcentagem em massa dos metais presentes nos eletrocatalisadores $\mathrm{Pt}(\mathrm{MRA})-\mathrm{Sn}(\mathrm{BH}) / \mathrm{C}$ preparados a partir do suporte $20 \%$ em massa de Sn determinadas por TGA .70

TABELA 3 - Razão atômica Pt:Sn nominal e a determinada por EDX dos eletrocatalisadores $\mathrm{Pt}(\mathrm{BH})-\mathrm{Sn}(\mathrm{BH}) / \mathrm{C}$, com 10 e $20 \%$ em massa de $\mathrm{Sn}$ e com diferentes razões atômicas de $\mathrm{Pt}$

TABELA 4 - Razão atômica Pt:Sn nomimal e a obtida por EDX para os eletrocatalisadores preparados pela deposição de Pt pelos métodos MRA e BH nos suportes $\mathrm{Sn} / \mathrm{C}$ preparados pelo método MRA .93 


\section{INTRODUÇÃo}

\subsection{Células a combustível}

O avanço industrial sempre foi instrumento de medição para o progresso, pois é o fator primordial no desenvolvimento econômico e social de uma nação. Durante muitos anos esse avanço garantiu o retorno financeiro esperado e pouco se falava sobre os efeitos prejudiciais ao meio ambiente e à saúde da população. Esse assunto tornou pauta de reunião em Kyoto [1, 2], onde líderes de países se reuniram com o objetivo de discutir e implantar medidas de redução da emissão de gases prejudiciais à camada de ozônio, desde então há um interesse mundial no desenvolvimento de novas tecnologias capazes de tornar sistemas mais eficientes e menos poluentes no processo de geração de energia, entre esses sistemas destacam-se as células a combustível [3].

As células a combustível FIGURA 1 são dispositivos que convertem energia química diretamente em energia elétrica, da mesma forma que as pilhas e as baterias em geral. Porém, uma diferença fundamental entre as baterias convencionais e as células a combustível é que nestas últimas os componentes da reação de oxido-redução (combustível e o oxidante) não se encontram confinados em seu interior, mas são alimentados externamente. Nas células, o combustível oxida-se continuamente em um dos eletrodos (ânodo), enquanto reduz-se oxigênio no outro eletrodo (cátodo). A reação completa-se com a circulação dos elétrons, através do circuito externo, que realiza o trabalho elétrico [4]. Atualmente, o combustível que apresenta o maior interesse prático é o hidrogênio. Desta forma, ao se dispor de combustíveis como o gás natural, metanol, etanol, biogás etc., o procedimento usual consiste em submetê-los a um processo de reforma a vapor e a finalidade é obter hidrogênio para introduzi-lo posteriormente na célula. Atualmente o processo de reforma a vapor do gás natural é amplamente utilizado para a produção de hidrogênio, o qual é principalmente usado na fabricação de fertilizantes [5]. 


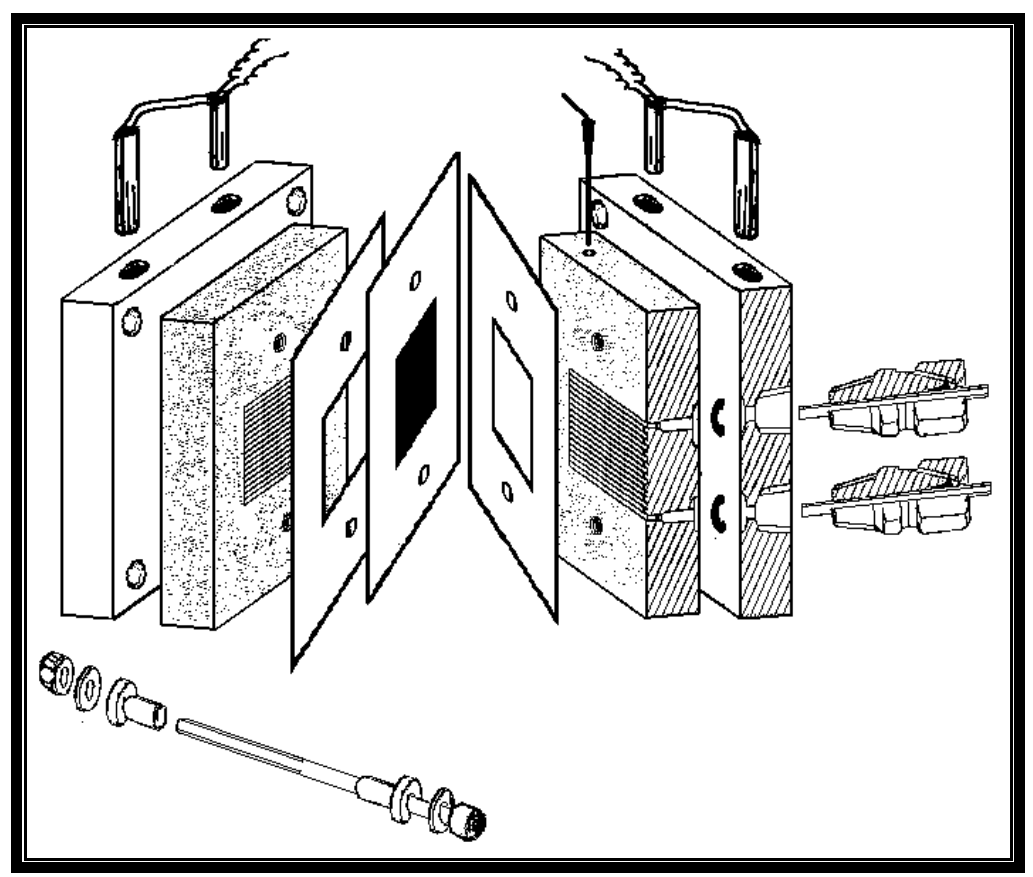

FIGURA 1- Desenho esquemático de uma célula a combustível unitária [6]

Embora os estudos iniciais sobre células a combustível tenham sido feitos há mais de cem anos, as suas aplicações práticas começaram a ser consideradas há pouco mais de quarenta anos. Desde 1960, as células a combustível são utilizadas com sucesso no programa espacial norte-americano, incluindo os projetos Gemini, Apollo e Space Shuttle. Nos veículos espaciais as células trabalham com hidrogênio puro como combustível e têm sido preferidas comparadas à outras fontes de energia pela sua elevada densidade de potência e por terem como produto de reação água potável, a qual é aproveitada pelos astronautas. A partir de 1973, principalmente por causa da crise do petróleo, surgiu um enorme interesse nas aplicações terrestres destes sistemas devido, principalmente, à sua alta eficiência energética (conversão de energia química diretamente em elétrica) quando comparado às máquinas térmicas. Pode-se dizer que nas décadas dos anos 70 e 80 do século passado, a busca pelo aumento da eficiência energética foi um fator determinante do progresso alcançado no campo das células a combustível [7,8].

Apesar das perspectivas pessimistas em relação ao petróleo não se concretizarem em curto prazo, surgiu a consciência de que o petróleo deveria ser utilizado para fins mais nobres e não ser, simplesmente, queimado. Atualmente, 
a necessidade de medidas urgentes para proteger o meio ambiente tem crescido sem precedentes, o qual aumentou ainda mais o interesse nas células a combustível, pois, em contraste com as máquinas térmicas, são conversores de energia essencialmente limpos. Isto significa que, por um lado, as células a combustível podem ser instaladas sem prejuízos ambientais em zonas com alta densidade populacional e ainda evitam o alto custo de instalação de linhas de transmissão de eletricidade em grandes distâncias para o abastecimento de núcleos isolados. É importante destacar também que as células a combustível empregam poucos dispositivos com partes móveis. Isto significa não somente um baixo nível de ruído em operação (baixa poluição sonora), como também uma baixa necessidade de manutenção [3]. Neste sentido as células a combustível também superam as máquinas térmicas.

Por estas razões, atualmente, existe um enorme interesse em promover a aplicação das células a combustível como sistemas autônomos de produção de energia elétrica, no entanto as células a combustível apresentam ainda um custo bastante elevado. No caso das células a combustível de eletrólito polimérico sólido (Proton Exchange Membrane Fuel Cell-PEMFC) a platina, utilizada nos eletrocatalisadores, e a membrana (eletrólito) representam uma porcentagem significativa deste custo [3].

\subsection{Células a combustível de eletrólito polimérico sólido (PEMFC)}

Nas células de tipo PEMFC FIGURA 2, o eletrólito consiste em uma membrana polimérica trocadora de prótons (geralmente Nafion, produzida pela Du Pont), o qual é um polímero perfluorado com grupamentos sulfônicos. A principal função da membrana é permitir a condução dos íons $\mathrm{H}^{+}$do ânodo para o cátodo. Para que a condução protônica ocorra, a membrana deve estar hidratada e, portanto, as células tipo PEMFC apresentam temperatura de operação de até 100 ${ }^{\circ} \mathrm{C}$ considerando pressão de $1 \mathrm{~atm}$. Como ânodo e cátodo são utilizados os eletrodos de difusão de gás (EDG), os quais são constituídos por uma camada catalítica formada por nanopartículas de platina suportadas em carbono, além de uma camada difusora constituída por uma mistura de politetrafluoretileno (PTFE) e carbono finamente dividido. 
A PEMFC é alimentada com hidrogênio no ânodo o qual é oxidado a prótons e elétrons EQ. 1, os elétrons percorrem um circuito externo, enquanto que, os prótons atravessam a membrana até o compartimento catódico, onde o oxigênio do ar atmosférico é reduzido EQ. 2 [9]. Dessa forma, uma corrente elétrica é gerada e $\mathrm{H}_{2} \mathrm{O}$ é formada como produto EQ. 3. Nesta célula ocorrem as seguintes reações:

Ânodo:

$$
\mathrm{H}_{2}+2 \mathrm{H}_{2} \mathrm{O} \quad \leftrightarrow \quad 2 \mathrm{H}_{3} \mathrm{O}^{+}+2 \mathrm{e}^{-}
$$

Cátodo:

$$
2 \mathrm{e}^{-}+2 \mathrm{H}_{3} \mathrm{O}^{+}+1 / 2 \mathrm{O}_{2} \quad \leftrightarrow \quad 3 \mathrm{H}_{2} \mathrm{O}
$$

Reação global: $\quad \mathrm{H}_{2}+1 / 2 \mathrm{O}_{2} \quad \leftrightarrow \quad \mathrm{H}_{2} \mathrm{O}$

O oxigênio pode ser obtido diretamente do ar atmosférico, enquanto que a forma mais barata de obter o hidrogênio é através do processo de reforma catalítica de um combustível primário rico em hidrogênio (renovável ou não). Neste processo, certa quantidade de monóxido de carbono é formada como subproduto da reação. A presença de monóxido de carbono (CO) no hidrogênio leva ao envenenamento da platina, pois este se adsorve fortemente nos sítios ativos para a reação (adsorção química). Desse modo, alguns ppm de CO (> 10 ppm) na alimentação de hidrogênio levam a uma queda no desempenho da célula em mais de $80 \%$. Uma alternativa para contornar este problema é adicionar um segundo metal à platina (co-catalisador), por exemplo, o rutênio, o qual leva à formação de espécies oxigenadas em potenciais inferiores a $0,25 \mathrm{~V}$, facilitando a oxidação do $\mathrm{CO}$ a $\mathrm{CO}_{2}$. Quando se utiliza somente platina, as espécies oxigenadas são formadas em potenciais acima de $0,8 \mathrm{~V}$, diminuindo a eficiência do processo $[7,8,10]$. $O$ hidrogênio apresenta ainda alguns inconvenientes operacionais e de infra-estrutura. A compressão, o armazenamento e a distribuição do hidrogênio requerem tecnologias relativamente sofisticadas e de custo elevado, o que dificulta o uso deste combustível, particularmente em certas aplicações que seriam de grande impacto, como na utilização em veículos e em equipamentos portáteis. Devido a esta constatação, têm surgido esforços significativos para desenvolver células a combustível que possam operar diretamente com combustíveis líquidos [7, 8, 10]. 


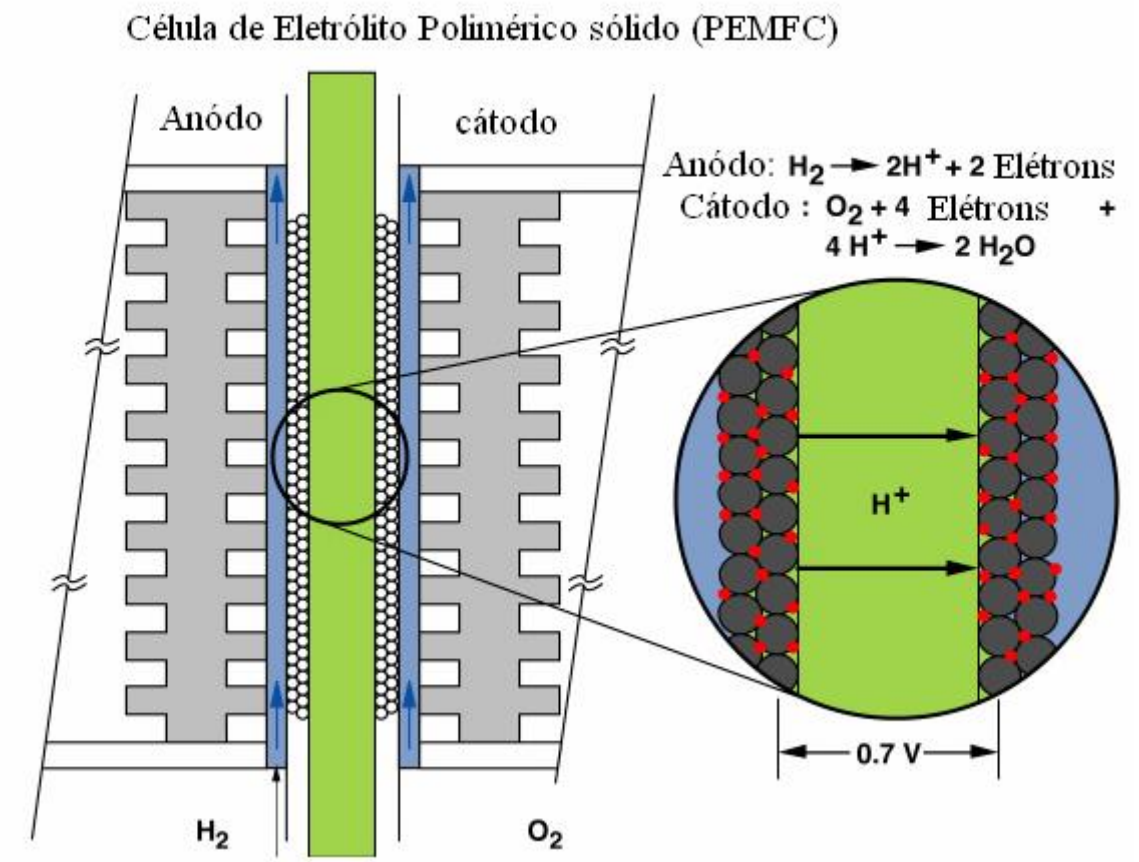

FIGURA 2 - Esquema simplificado de uma célula a combustível.

\subsection{Célula a combustível utilizando alcoóis diretamente como combustíveis (Direct Alcohol Fuel Cell - DAFC)}

O metanol tem sido o principal álcool utilizado diretamente como combustível em células de eletrólito polimérico sólido, sendo estas células denominadas de Direct Methanol Fuel Cell (DMFC) [11]. Esta célula é alimentada com metanol, na forma de vapor ou líquido e opera a temperaturas menores que $100{ }^{\circ} \mathrm{C}$. Idealmente, as reações que ocorrem em células a metanol direto são apresentadas nas EQ. 4-6:

ânodo: $\mathrm{CH}_{3} \mathrm{OH}+\mathrm{H}_{2} \mathrm{O} \rightarrow \mathrm{CO}_{2}+\mathrm{H}^{+}+6 \mathrm{e}^{-}$

cátodo: $3 / 2 \mathrm{O}_{2}+6 \mathrm{e}^{-}+6 \mathrm{H}^{+} \rightarrow 3 \mathrm{H}_{2} \mathrm{O}$

Reação global: $\mathrm{CH}_{3} \mathrm{OH}+3 / 2 \mathrm{O}_{2} \rightarrow \mathrm{CO}_{2}+2 \mathrm{H}_{2} \mathrm{O}$

A reação de eletro-oxidação completa do metanol produz 6 elétrons e o potencial padrão da DMFC $(1,20 \mathrm{~V})$ não é muito diferente do potencial da PEMFC 
$(1,23$ V). Entretanto, a reação é bastante lenta, devido à formação de intermediários fortemente adsorvidos, tais como o monóxido de carbono ( $\mathrm{CO}_{\mathrm{ads}}$ ), resultando em potenciais operacionais bem menores. A oxidação desses intermediários a $\mathrm{CO}_{2}$ requer a participação de espécies que contém oxigênio $(\mathrm{OH}$, $\mathrm{H}_{2} \mathrm{O}$ ), que devem ser adsorvidas também nos sítios ativos do catalisador. Como mencionado anteriormente, no caso da presença de $\mathrm{CO}$ no hidrogênio, a platina sozinha não é suficientemente ativa para a oxidação do $\mathrm{CO}_{\text {ads }}$ a $\mathrm{CO}_{2}$, necessitando de um co-catalisador para fornecer espécies oxigenadas em baixos valores de potencial [12].

\subsubsection{Mecanismo da Oxidação do Metanol sobre Platina}

A reação da oxidação do metanol foi objetos de vários estudos no passado $[12,13]$. Foram propostos vários mecanismos para a oxidação anódica do metanol, envolvendo várias etapas, nas quais ocorre a formação de intermediários como, por exemplo, formaldeído, ácido fórmico e monóxido de carbono (CO). A existência destes intermediários é comprovada por várias técnicas, mas o que não se sabe com detalhes é a rota pela qual a reação acontece. Um possível mecanismo para a reação de oxidação do metanol [14] é mostrado a seguir EQ 714:

$\mathrm{CH}_{3} \mathrm{OH}+\mathrm{Pt}(\mathrm{s}) \rightarrow \mathrm{Pt}-\mathrm{CH}_{2} \mathrm{OH}_{\mathrm{ads}}+\mathrm{H}^{+}+\mathrm{e}^{-}$

$\mathrm{Pt}-\mathrm{CH}_{2} \mathrm{OH}_{\text {ads }}+\mathrm{Pt}_{(\mathrm{s})} \rightarrow \mathrm{Pt}_{2}-\mathrm{CHOH}_{\text {ads }}+\mathrm{H}^{+}+\mathrm{e}^{-}$

$\mathrm{Pt}_{2}-\mathrm{CHOH}_{\text {ads }}+\mathrm{Pt}(\mathrm{s}) \rightarrow \mathrm{Pt}_{3}-\mathrm{COH}_{\mathrm{ads}}+\mathrm{H}^{+}+\mathrm{e}^{-}$

$\mathrm{Pt}_{3}-\mathrm{COH}_{\text {ads }} \rightarrow \mathrm{Pt}-\mathrm{CO}_{\text {ads }}+2 \mathrm{Pt}(\mathrm{s})+\mathrm{H}^{+}+\mathrm{e}^{-}$

$\mathrm{Pt}(\mathrm{s})+\mathrm{H}_{2} \mathrm{O} \rightarrow \mathrm{Pt}_{-} \mathrm{OH}_{\mathrm{ads}}+\mathrm{H}^{+}+\mathrm{e}^{-}$

Pt-COads $+\mathrm{H}_{2} \mathrm{O} \rightarrow \mathrm{Pt}-\mathrm{COOH}_{\text {ads }}+\mathrm{H}^{+}+\mathrm{e}^{-}$

ou

$\mathrm{Pt}-\mathrm{OH}_{\mathrm{ads}}+\mathrm{Pt}-\mathrm{CO}_{\text {ads }} \rightarrow \mathrm{Pt}-\mathrm{COOH}_{\text {ads }}$

$\mathrm{Pt}-\mathrm{COOH}_{\mathrm{ads}} \rightarrow \mathrm{Pt}(\mathrm{s})+\mathrm{CO}_{2}+\mathrm{H}^{+}+\mathrm{e}^{-}$ 
Observa-se que as reações mostradas nas EQ. 7-10 são processos de eletrossorção, enquanto que, as reações seguintes EQ. 11-14 envolvem transferência de oxigênio para a oxidação dos intermediários ligados à superfície da platina [12-14].

Devido ao envenenamento que ocorre pela adsorção do $\mathrm{CO}$, a platina não é suficientemente ativa para ser usada de forma eficiente na eletro-oxidação do metanol. Para resolver este problema, uma alternativa para favorecer a oxidação dos intermediários, como o $\mathrm{CO}$, é a incorporação de um segundo metal, formando catalisadores que sejam capazes de formar espécies oxigenadas a potenciais menores do que o da platina, facilitando assim a oxidação do $\mathrm{CO}_{\text {ads }}$ [15]. Este mecanismo é chamado de mecanismo bifuncional e foi proposto por Watanabe et al. [13]. O catalisador bimetálico que têm apresentado melhores resultados para o uso em células a combustível de metanol direto (DMFC) utiliza platina e rutênio como metais [16].

\subsection{Célula a combustível utilizando etanol diretamente como combustível (Direct Ethanol Fuel Cell - DEFC)}

No Brasil o etanol é produzido em larga escala, portanto, estudos quanto à utilização deste combustível diretamente em células a combustível é de extrema importância para o País. Além disso, o etanol apresenta vantagens por ser um combustível proveniente de fontes renováveis e menos tóxico que o metanol [16]. Por outro lado, a oxidação completa do etanol a $\mathrm{CO}_{2}$ em uma DEFC (EQ. 15-17) é mais difícil que a do metanol devido à dificuldade da quebra da ligação $\mathrm{C}-\mathrm{C}$ e a formação de intermediários (monóxido de carbono, acetaldeido e ácido acético) que bloqueiam os sítios ativos do eletrocatalisador. As reações que ocorrem são: Ânodo: $\mathrm{CH}_{3} \mathrm{CH}_{2} \mathrm{OH}+15 \mathrm{H}_{2} \mathrm{O} \rightarrow 2 \mathrm{CO}_{2}+15 \mathrm{H}_{3} \mathrm{O}^{+}+12 \mathrm{e}^{-}$

Cátodo: $12 \mathrm{e}^{-}+12 \mathrm{H}_{3} \mathrm{O}^{+}+3 \mathrm{O}_{2} \rightarrow 18 \mathrm{H}_{2} \mathrm{O}$

Reação global: $\mathrm{CH}_{3} \mathrm{CH}_{2} \mathrm{OH}+3 \mathrm{O}_{2} \rightarrow 2 \mathrm{CO}_{2}+3 \mathrm{H}_{2} \mathrm{O}$

Neste caso, quando se utiliza catalisadores à base de $\mathrm{Pt}$, a oxidação do etanol ocorre apenas parcialmente resultando principalmente na formação de 
acetaldeído (AAL) e ácido acético (AA). Rousseau et al [17] verificaram que a adição de $\mathrm{Sn}$ à $\mathrm{Pt}$ favoreceu a formação de $\mathrm{AA}$ comparativamente ao $\mathrm{AAL}$. Isto foi atribuído ao mecanismo bifuncional onde o etanol é adsorvido dissociativamente nos sítios de Pt, seja através da adsorção pelo átomo de oxigênio EQ. 18 ou, pelo átomo de carbono EQ. 19 da molécula do etanol levando à formação de espécies AAL EQ. 20,21:

$\mathrm{Pt}+\mathrm{CH}_{3}-\mathrm{CH}_{2} \mathrm{OH} \rightarrow \mathrm{Pt}-\left(\mathrm{OCH}_{2}-\mathrm{CH}_{3}\right)_{\text {ads }}+\mathrm{H}^{+}+\mathrm{e}^{-}$

$\mathrm{Ou}$

$\mathrm{Pt}+\mathrm{CH}_{3}-\mathrm{CH}_{2} \mathrm{OH} \rightarrow \mathrm{Pt}-\left(\mathrm{CHOH}-\mathrm{CH}_{3}\right)_{\text {ads }}+\mathrm{H}^{+}+\mathrm{e}^{-}$
$\mathrm{Pt}-\left(\mathrm{OCH}_{2}-\mathrm{CH}_{3}\right)_{\text {ads }} \rightarrow \mathrm{Pt}+\mathrm{CHO}-\mathrm{CH}_{3}+\mathrm{H}^{+}+\mathrm{e}^{-}$

$\mathrm{Ou}$

$\mathrm{Pt}-\left(\mathrm{CHOH}-\mathrm{CH}_{3}\right)_{\mathrm{ads}} \rightarrow \mathrm{Pt}+\mathrm{CHO}-\mathrm{CH}_{3}+\mathrm{H}^{+}+\mathrm{e}^{-}$

Tão logo o acetaldeído é formado, ele pode ser adsorvido nos sítios de Pt levando à formação de espécies $\mathrm{Pt}-\mathrm{CH}_{3}-\mathrm{CO}$ conforme a EQ. 22,

$\mathrm{Pt}+\mathrm{CHO}-\mathrm{CH}_{3} \rightarrow \mathrm{Pt}-\left(\mathrm{CO}-\mathrm{CH}_{3}\right)_{\mathrm{ads}}+\mathrm{H}^{+}+\mathrm{e}^{-}$

Como o Sn é conhecido por ativar moléculas de $\mathrm{H}_{2} \mathrm{O}$ a potenciais mais baixos que a $\mathrm{Pt}$, algumas espécies $\mathrm{OH}$ podem ser formadas em baixos potenciais nos sítios de Sn EQ. 23:

$\mathrm{Sn}+\mathrm{H}_{2} \mathrm{O} \rightarrow \mathrm{Sn}-(\mathrm{OH})_{\text {ads }}+\mathrm{H}^{+}+\mathrm{e}^{-}$

As espécies de acetaldeído adsorvidas podem reagir com as espécies $\mathrm{OH}$ adsorvidas, para produzir ácido acético conforme a EQ. 24:

$\mathrm{Pt}-\left(\mathrm{CO}-\mathrm{CH}_{3}\right)_{\text {ads }}+\mathrm{Sn}-(\mathrm{OH})_{\mathrm{ads}} \rightarrow \mathrm{Pt}+\mathrm{Sn}+\mathrm{CH}_{3}-\mathrm{COOH}$

Por outro lado, o rendimento em $\mathrm{CO}_{2}$ é duas vezes mais elevado para o catalisador $\mathrm{Pt} / \mathrm{C}$ do que para o catalisador de $\mathrm{Pt}-\mathrm{Sn} / \mathrm{C}$. Os autores atribuíram isto a necessidade da existência de vários sítios de Pt adjacentes, os quais seriam necessários para adsorver a molécula de etanol e facilitar a quebra da ligação C- 
C. No entanto, quando alguns átomos de Sn são introduzidos entre os átomos de $\mathrm{Pt}$, a reação de formação de $\mathrm{CO}_{2}$ é favorecida.

Dessa forma, a busca por catalisadores, mais eficientes para a oxidação completa do etanol a $\mathrm{CO}_{2}$ é um dos desafios desta área, no entanto, os catalisadores a base de PtSn tem se mostrado ainda como os mais ativos [18-40].

\subsubsection{Eletrocatalisadores $\mathrm{PtSn} / \mathrm{C}$ para a oxidação eletroquímica do etanol nas células DEFC.}

Vigier et al [19] foram os primeiros pesquisadores a descreverem o uso de eletrocatalisadores $\mathrm{PtSn} / \mathrm{C}$ como ânodos na oxidação eletroquímica do etanol. Os eletrocatalisadores foram preparados com carga metálica de 30\% em massa de metais usando o método da co-impregnação e redução em atmosfera de hidrogênio. As composições atômicas Pt:Sn foram variadas e os melhores resultados foram obtidos com a razão atômica Pt:Sn próxima de 100:20. Os autores compararam também a atividade eletrocatalítica com catalisadores $\mathrm{Pt} / \mathrm{C}$ e PtRe/C, sendo o catalisador PtSn/C o mais ativo. Durante experimentos de eletrólise do etanol, este foi oxidado a acetaldeído, ácido acético e $\mathrm{CO}_{2}$, sendo o catalisador $\mathrm{PtSn} / \mathrm{C}$ o mais seletivo para a produção de $\mathrm{CO}_{2}$, apesar de este ser o produto minoritariamente formado em todos os casos. Os experimentos em células a combustível também mostraram uma maior atividade para o catalisador $\mathrm{PtSn} / \mathrm{C}$ comparado aos catalisadores Pt/C e PtRe/C. Dessa forma, os resultados mostraram claramente o efeito positivo da adição de Sn à Pt para a oxidação eletroquímica do etanol.

Lamy et al. [20] dando sequência ao estudo de eletrocatalisadores PtSn/C prepararam estes materiais a partir de precursores coloidais os quais foram dispersos em carbono Vulcan XC-72. Este método de preparação é conhecido como método de Bönneman. Neste método, o precursor coloidal é inicialmente sintetizado sob atmosfera inerte a partir de sais metálicos anidros em um solvente orgânico (tetraidrofurano) na presença de um surfactante (sal de amônio quaternário). O papel do surfactante é essencial para prevenir a aglomeração das partículas metálicas formadas durante a etapa de redução. Por esta metodologia foi encontrado uma composição ótima de Sn na faixa 10-20 \% proporção atômica, 
sendo mostrado que o envenenamento dos sítios de Pt por espécies adsorvidas de CO (provenientes da quimissorção dissociativa do etanol) foi fortemente reduzida levando a um aumento significativo a atividade eletrocatalítica. No entanto, apesar desta melhora significativa da atividade dos eletrocatalisadores $\mathrm{PtSn} / \mathrm{C}$ quando comparados a Pt/C, a oxidação eletroquímica completa do etanol a $\mathrm{CO}_{2}$ é ainda minoritária e, dessa forma, sua oxidação não é completa, levando, principalmente, à formação de acetaldeído e ácido acético. Os testes em células a combustível com os catalisadores $\mathrm{PtSn} / \mathrm{C}$ mostraram que os valores de densidade de potência $\left(\mathrm{mW} \mathrm{cm}^{-2}\right)$ foram três vezes maiores que os observados para o catalisador $\mathrm{Pt} / \mathrm{C}$.

Zhou et al. [21] prepararam eletrocatalisadores PtSn/C com 20\% em massa de metais e diferentes razôes atômicas $\mathrm{Pt}$ Sn (1:1, 3:2, 2:1, 3:1 e 4:1) por meio da dissolução dos precursores metálicos de Pt e Sn em etilenoglicol. A esta solução foi adicionado o suporte de carbono, o pH foi ajustado a 13 e a mistura resultante foi mantida a $120^{\circ} \mathrm{C}$ por $1 \mathrm{~h}$. Os materiais obtidos apresentaram nanopartículas com uma faixa de distribuição bem estreita e a análise por XPS mostrou que a maior parte da Pt encontrava-se no estado metálico, enquanto que, a maior parte do Sn estava no estado oxidado. Os desempenhos em células a combustível DEFC apresentaram variações para os diferentes eletrocatalisadores e temperaturas de operação. À $90{ }^{\circ} \mathrm{C}$, o eletrocatalisador $\mathrm{Pt}_{2} \mathrm{Sn}_{1} / \mathrm{C}$ apresentou $\mathrm{o}$ melhor desempenho em termos de densidade de potência. Os autores também observaram que altos conteúdos de Sn levam a uma diminuição da condutividade eletrônica do ânodo devido à baixa condutividade eletrônica do $\mathrm{SnO}_{2}$. Além disso, os sítios ativos de Pt do catalisador com alto conteúdo de Sn podem também se encontram parcialmente bloqueados (recobertos) pelo $\mathrm{Sn}$ ou seus óxidos, os quais acabam inibindo a adsorção do etanol. Dessa forma, concluíram que deve existir um ótimo conteúdo de Sn para um melhor desempenho da célula a diferentes temperaturas.

Jiang et al [22] prepararam o eletrocatalisador $\mathrm{Pt}_{3} \mathrm{Sn} / \mathrm{C}$ pelo processo do poliol modificado (uso de etilenoglicol como agente redutor) e os materiais obtidos foram tratados em diferentes atmosferas (ar, $\mathrm{H}_{2}$ e argônio) visando esclarecer quais seriam as fases mais ativas para a oxidação eletroquímica do etanol. As 
análises por difração de raios-X mostraram que os materiais obtidos apresentavam estrutura cúbica de face centrada (fcc) e análises por redução à temperatura programada mostraram que mais Sn existe no estado de valência $(0)$ quando tratado em argônio que em outras atmosferas. A avaliação eletrocatalítica destes materiais mostrou que o desempenho na oxidação eletroquímica do etanol é bastante afetado pelo estado químico do Sn nestes materiais. O material PtSn/C como preparado apresentou a maior densidade de potência nos testes em células, enquanto que o PtSn/C tratado em argônio apresentou o mais baixo desempenho. Os autores propuseram que o melhor desempenho estava associado à existência de Sn em estados multivalentes.

Jiang et al. [23] sintetizaram nanopartículas de $\mathrm{SnO}_{2}$ por meio do aquecimento de uma solução aquosa de etilenoglicol contendo $\mathrm{SnCl}_{2}$ à pressão atmosférica. O material obtido apresentou nanopartículas esféricas e o tamanho e distribuição de partículas mostrou-se dependente das condições experimentais como $\mathrm{pH}$, tempo de reação, concentração de água e concentração do precursor de $\mathrm{Sn}$. A análise por difração de raios- $\mathrm{X}$ mostrou que o $\mathrm{SnO}_{2}$ obtido apresentava estrutura cristalina tetragonal o qual foi formado por meio da hidrólise do $\mathrm{SnCl}_{2}$. As nanopartículas de $\mathrm{SnO}_{2}$ foram utilizadas na preparação do eletrocatalisador $\mathrm{PtSnO}_{2} / \mathrm{C}$, o qual exibiu uma atividade surpreendentemente alta para a oxidação eletroquímica do etanol.

Jiang et al. [24] também estudaram a preparação de eletrocatalisadores $\mathrm{PtSn} / \mathrm{C}$, na forma PtSn liga e na $\mathrm{PtSnO}_{x}$, por meio do método do poliol modificado e com razão atômica Pt:Sn de 3:1. Os resultados de difração de raios-X mostraram que o parâmetro de rede da $\mathrm{Pt}$ na liga $\mathrm{PtSn}$ foi deslocado devido aos átomos de Sn estarem inseridos na rede cristalina da mesma. Por outro lado, para as nanopartículas de $\mathrm{PtSnO}_{2}$, a variação no parâmetro de rede foi negligenciável. Os estudos por voltametria cíclica em meio ácido mostraram que a região de adsorção/desorção de hidrogênio foi inibida na superfície da liga PtSn quando comparada àquela da superfície do catalisador $\mathrm{PtSnO}_{x}$, o qual mostrou uma maior atividade catalítica para a oxidação eletroquímica do etanol que a liga PtSn. Os autores consideraram que a pequena variação na rede cristalina da $\mathrm{Pt}$ no catalisador $\mathrm{PtSnO}_{x}$ foi favorável para a adsorção do etanol e que o $\mathrm{SnO}_{x}$ nas 
vizinhanças da Pt poderia fornecer espécies oxigenadas adequadas para remover as espécies tipo $\mathrm{CO}_{a d s}$ resultantes da reação das moléculas de etanol adsorvidas nos sítios de Pt.

Mann et al. [25] também relatam a preparação de eletrocatalisadores $\mathrm{PtSnO}_{x}$ por meio do método do poliol modificado e consideraram a quantidade de Sn para intensificar as propriedades catalíticas da Pt como sendo da ordem de 5 a $25 \%$. Os autores concluíram também que o desempenho do catalisador $\mathrm{PtSnO}_{x}$ na oxidação eletroquímica do etanol apresentava-se semelhante ou até superior à de compostos intermetálicos do tipo $\mathrm{Pt}_{3} \mathrm{Sn}$.

Oliveira Neto et al [26] prepararam eletrocatalisadores PtSn/C, PtRu/C e PtRuSn/C por um processo de redução por álcool, utilizando etilenoglicol. A maior parte do $\mathrm{Sn}$ nos materiais obtidos apresentava-se na forma de $\mathrm{SnO}_{2}$. O eletrocatalisador PtSn/C obtido apresentou bom desempenho tanto na oxidação eletroquímica do metanol quanto do etanol. $\mathrm{O}$ bom desempenho foi atribuído a habilidade dos sítios de Pt adsorverem o etanol e facilitar a quebra das ligações $\mathrm{C}-\mathrm{H}$, enquanto que as espécies $\mathrm{SnO}_{2}$ facilitariam a oxidação do $\mathrm{CO}_{\text {ads }}$ nos sítios de Pt através do mecanismo bifuncional.

Colmati et al [27] prepararam eletrocatalisadores $\mathrm{PtSn} / \mathrm{C}$ na forma de liga PtSn com diferentes razões atômicas Pt:Sn por meio da redução dos precursores de $\mathrm{Pt}$ e $\mathrm{Sn}$ com ácido fórmico. A atividade desses materiais foram comparadas aos catalisadores comerciais $\mathrm{Pt} / \mathrm{C}$ e $\mathrm{Pt}_{3} \mathrm{Sn} / \mathrm{C}$ e discutido em termos das propriedades intrínsecas desses materiais. Os autores relataram que a atividade dos catalisadores para a oxidação eletroquímica do etanol parece depender da quantidade de Sn na forma de liga. Dessa forma, se propuseram que a atividade destes materiais para a oxidação eletroquímica do etanol deveria não somente ser relacionada à quantidade total de $\mathrm{Sn}$ no catalisador, mas também ao grau de liga formado entre a Pt e o Sn.

Jiang et al. [28] prepararam eletrocatalisadores $\mathrm{PtSnO}_{\sqrt{ }} / \mathrm{C}$ com razões atômicas Pt:Sn de 5:5, 6:4, 7:3 e 8:2 pelo método do poliol modificado, onde o $\mathrm{SnCl}_{2} .2 \mathrm{H}_{2} \mathrm{O}$ foi dissolvido em etilenoglicol e submetido a refluxo em $190{ }^{\circ} \mathrm{C}$. A solução, inicialmente clara, tornou-se levemente azul indicando a formação de 
hidróxido de Sn coloidal. O coloide resultante e ácido cloroplatínico foram misturados na proporção desejada e o pH da solução foi ajustado em 12. A mistura foi aquecida a $130^{\circ} \mathrm{C}$ por $2 \mathrm{~h}$ para a redução dos íons $\mathrm{Pt}(\mathrm{IV})$. Após isso, o suporte de carbono foi disperso nesta solução para a deposição das nanopartículas. As análises dos materiais obtidos mostraram que este era composto por nanopartículas de Pt metálica e $\mathrm{SnO}_{2}$. Os estudos da oxidação eletroquímica do etanol mostraram que para todos os catalisadores, o ácido acético e o acetaldeído foram os produtos dominantes, enquanto que a formação de $\mathrm{CO}_{2}$ contribuiu com apenas $1-3 \%$ dos produtos formados. Observou-se também um leve aumento na seletividade para $\mathrm{CO}_{2}$ quando comparado ao catalisador PtSn na forma de liga. Os autores atribuíram o melhor desempenho destes catalisadores à boa sinergia entre as espécies de óxido de Sn (formação $\mathrm{OH}$ ) e o sítios ativos de Pt (que atuam na desidrogenação do etanol e na quebra da ligação C-C).

Colmati et al. [29] prepararam o catalisador $\mathrm{PtSn/C}$ com razâo atômica 75:25 por meio da redução dos precursores com ácido formico e submeteu o material obtido a tratamentos térmicos em temperaturas de 200 e $500{ }^{\circ} \mathrm{C}$, observando a formação predominante de uma fase cúbica $\mathrm{Pt}_{3} \mathrm{Sn}$ e de uma fase hexagonal PtSn em menor extensão. Foi observado também que o tamanho de partículas e da porção de fase hexagonal aumentava com o aumento da temperatura. A atividade catalítica para a oxidação eletroquímica do etanol e na DEFC foi melhor para o catalisador tratado a $200^{\circ} \mathrm{C}$ comparado ao material comopreparado e ao catalisador comercial PtSn/C E-TEK. O melhor desempenho do catalisador tratado a $200^{\circ} \mathrm{C}$ foi atribuído à presença da fase $\mathrm{Pt}_{3} \mathrm{Sn}$ e à limpeza do material devido ao tratamento térmico.

Zhu et al [30] preparam eletrocatalisadores PtSn/C com diferentes graus de liga entre a $\mathrm{Pt}$ e o $\mathrm{Sn}$, utilizando diferentes procedimentos. O catalisador $\mathrm{PtSn}$ liga/C apresentava o maior grau de liga e o catalisador $\mathrm{PtSnO}_{2} / \mathrm{C}$ o mais baixo grau entre os materiais preparados. Os estudos da oxidação eletroquímica do etanol mostraram que o catalisador $\mathrm{PtSnO}_{2} / \mathrm{C}$ levava a um aumento no rendimento de ácido acético e o catalisador $\mathrm{PtSn}$ liga/C promovia a desidrogenação do etanol a acetaldeído. Foi proposto para o catalisador $\mathrm{PtSnO}_{2} / \mathrm{C}$ que as espécies $\mathrm{SnO}_{2}$ facilitariam a oxidação dos intermediários adsorvidos nos sítios de Pt, por meio do 
fornecimento de espécies $\mathrm{OH}$, através do mecanismo bifuncional. Segundo os autores, a formação de acetaldeído pelo catalisador PtSnliga/C deve-se ao efeito eletrônico existente na liga PtSn.

Purgato et al [31] preparam catalisadores $\mathrm{PtSn} / \mathrm{C}$ com diferentes composições usando o método de Pechini-Adams. Neste método, precursores poliméricos de Pt e $\mathrm{Sn}$ foram preparados separadamente e misturados com ácido cítrico em etilenoglicol, adiciona-se o suporte de carbono e depois a mistura resultante foi calcinada em diferentes temperaturas aberta ao ar. Os autores concluíram que os catalisadores obtidos por esta metodologia apresentavam propriedades físico-químicas e eletroquímicas diferentes quando comparados aos catalisadores $\mathrm{PtSn} / \mathrm{C}$ preparados por outros métodos. As medidas por FTIR e análises cromatográficas também mostraram que a adição de Sn à Pt favoreceu a oxidação do etanol a acetaldeido levando a uma maior eficiência elétrica quando comparado a $\mathrm{Pt} / \mathrm{C}$.

Antolini et al [32] a fim de avaliar o efeito da formação de ligas na atividade dos catalisadores para a oxidação eletroquímica do etanol, prepararam os catalisadores $(\mathrm{PtSnPd})$ liga $_{\mathrm{SnO}} / \mathrm{SnO}_{2}$ e $(\mathrm{PtSn})_{\text {liga }} / \mathrm{SnO}_{2}$ suportados em carbono pelo método do ácido fórmico. $\mathrm{A}$ análise de difração de raios $\mathrm{X}$ mostrou a presença de picos da fase cúbica de $\mathrm{Pt}$ deslocados para baixos ângulos, indicando a formação de ligas, além da presença da fase $\mathrm{SnO}_{2}$. Os autores acreditam existir um papel fundamental da liga na oxidação eletroquímica do etanol para os catalisadores $(\mathrm{PtSnPd})_{\text {liga/ }} / \mathrm{SnO}_{2}$ e (PtSn $)_{\text {liga/SnO}}$. Também propuseram que a adição do terceiro metal na forma de óxido aumenta a atividade para a oxidação eletroquímica do etanol.

Godoi et al [33] estudaram a oxidação eletroquímica do etanol usando catalisadores $\mathrm{PtSn} / \mathrm{C}$ com tamanho de partículas e composições semelhantes, no entanto, com diferentes quantidades de fases óxido e liga. As quantidades de óxidos e liga foram promovidas por tratamento térmico. Nas condições estudadas os autores concluíram que, apesar dos catalisadores PtSn/C apresentarem boa atividade para a oxidação eletroquímica do etanol, a corrente de oxidação pode ser intensificada pelo aumento da formação da liga PtSn. 
Higuchi et al [41] prepararam o catalisador $\mathrm{PtSnO}_{2} / \mathrm{C}$ com diferentes razões $\mathrm{Pt}: \mathrm{SnO}_{2}$ pelo método de Bönnemann modificado, obtendo um material contendo $\mathrm{Pt} \mathrm{e} \mathrm{SnO}_{2}$ altamente dispersos no suporte de carbono. O catalisador $\mathrm{PtSnO}_{2} / \mathrm{C}$ (razão atômica Pt:Sn de 3:1) apresentou uma excelente atividade e estabilidade para a oxidação eletroquímica do etanol comparado ao Pt/C. O principal produto formado foi o ácido acético. A eficiência para a produção de ácido acético foi de cerca de $70 \%$ e para $\mathrm{CO}_{2}$ em torno de $30 \%$. Os autores supuseram que o contato da fase $\mathrm{SnO}_{2}$ com os sítios de $\mathrm{Pt}$ facilitam a oxidação dos intermediários adsorvidos por meio do mecanismo bifuncional.

Baranova et al [34] preparam catalisadores PtSn/C na forma de ligas PtSn desordenadas e na forma bifásica $\left(\mathrm{Pt}\right.$ e $\mathrm{SnO}_{\mathrm{x}}$ ). Os catalisadores foram sintetizados em etilenoglicol e o ajuste do $\mathrm{pH}$ com $\mathrm{NaOH}$ influenciou o tamanho de partículas e a estrutura das nanopartículas. Os materiais na forma de ligas foram formados, principalmente, com baixa concentração de $\mathrm{NaOH}$ e o material bifásico $\mathrm{Pt}$ e $\mathrm{SnO}_{x}$ em altas concentrações deste reagente. A mais alta atividade catalítica para a oxidação do etanol foi encontrada para o material bifásico contendo nanopartículas de $\mathrm{Pt}$ (com tamanho médio de 6,5 nm) e a fase $\mathrm{SnO}_{2}$.

De Souza et al [35] prepararam o catalisador $\mathrm{Pt}_{3} \mathrm{Sn} / \mathrm{C}$ pelo método do precursor polimérico e tratamento térmico a $400{ }^{\circ} \mathrm{C}$ por $2 \mathrm{~h}$ em atmosfera de nitrogênio. A análise do material obtido mostrou que a maior parte do Sn encontrava-se na forma de liga com a $\mathrm{Pt}$, formando uma fase dominante $\mathrm{Pt}_{3} \mathrm{Sn}$. Os testes em DEFC mostraram uma maior atividade do catalisador $\mathrm{Pt}_{3} \mathrm{Sn} / \mathrm{C}$ comparado ao catalisador comercial PtSn/C E-ETEK.

Li et al [36] prepararam eletrocatalisadores $\mathrm{Pt}_{x} \mathrm{Sn} / \mathrm{C}$ (onde $\mathrm{x}=1,0 ; 2,0 ; 2,5$; 3,0 e 4,0) pelo método da microemulsão. Inicialmente, os precursores metálicos foram dissolvidos em etilenoglicol sendo, posteriormente, adicionado água destilada, Triton X-100 e cicloexano, respectivamente. A solução resultante foi agitada formando uma microemulsão água em óleo. Os estudos eletroquímicos mostraram que o catalisador $\mathrm{Pt}_{3} \mathrm{Sn} / \mathrm{C}$ apresentou 0 melhor desempenho comparado aos demais materiais preparados e ao catalisador comercial $\mathrm{Pt} / \mathrm{C}$ (Johnson Mattehy). O método da microemulsão não resolveu somente o problema da hidrólise do $\mathrm{SnCl}_{2}$ em água, mas também contribuiu para a co-redução dos 
íons $\mathrm{Pt}(\mathrm{IV})$ e $\mathrm{Sn}(\mathrm{II})$ e a formação de liga PtSn. Ao dissolver os precursores metálicos em etilenoglicol preveniu-se a hidrólise dos mesmos. O etilenoglicol faz com que os metais precursores localizem-se na interface água/óleo das microemulsões, o que ajuda a promover suas co-reduções e a formação de liga.

Liu et al [37] desenvolveram um protocolo geral para a síntese de catalisadores $\mathrm{PtSn} / \mathrm{C}$ pelo método do poliol através de um estudo sistemático das variáveis de síntese. Nesta metodologia, quantidades calculadas de $\mathrm{H}_{2} \mathrm{PtCl}_{6} \cdot 6 \mathrm{H}_{2} \mathrm{O}$ e $\mathrm{SnCl}_{2} .2 \mathrm{H}_{2} \mathrm{O}$ foram dissolvidos em uma mistura de etilenoglicol e água. Uma quantidade apropriada de solução aquosa de $\mathrm{NaOH}$ foi introduzida, seguida pela adição do suporte de carbono. A mistura resultante foi aquecida a $160{ }^{\circ} \mathrm{C}$ e mantida a esta temperatura por $3 \mathrm{~h}$. Após foi resfriada e $\mathrm{HCl}$ foi introduzido para liberar as nanopartículas dos agentes estabilizantes formados in situ e permitir sua deposição no suporte de carbono. Segundo os autores isto permitiu a completa transferência de todos os elementos catalíticos para o suporte. Além disso, eles relataram também que água é necessário como um co-solvente para o etilenoglicol e que a adição de solução de $\mathrm{NaOH}$ para o ajuste do $\mathrm{pH}$ antes da etapa de redução é a chave para obter nanopartículas de tamanhos bem pequenos. O material preparado com razão atômica Pt:Sn de 3:1 foi o melhor catalisador para a oxidação eletroquímica do etanol.

Liu et al [38] também estudaram a preparação de catalisadores $\mathrm{PtSnO} / \mathrm{C}$ com razão atômica Pt:Sn de 3:1 pelo método do poliol usando diferentes misturas etilenoglicol-água e observaram que, quando o conteúdo de água na síntese é muito pequeno $(2 \% \mathrm{v} / \mathrm{v})$, somente uma quantidade limitada de $\mathrm{Sn}$ pode ser incorporada (Pt:Sn de 91:9) sendo que o aumento na quantidade de água leva a um aumento no conteúdo de $\mathrm{Sn}$ e, consequentemente, a um aumento da atividade do catalisador pra a oxidação eletroquímica do etanol. No entanto, conteúdos de água maiores que $50 \%(\mathrm{v} / \mathrm{v})$ levam a um aumento no tamanho de partícula e na redução da área eletroquimicamente ativa.

Zignani et al. [39] prepararam PtSn/C por meio da redução com ácido fórmico e caracterizaram os materiais obtidos em termos de estrutura, morfologia e propriedades superficiais. O conteúdo de $\mathrm{Sn}$ aumentou com o aumento da quantidade de precursor de Sn utilizada, no entanto, somente uma fração do Sn 
total encontrava-se na forma de liga PtSn. Os estudos físico-químicos e eletroquímicos indicaram que é necessário a existência de um balanço apropriado das espécies de $\mathrm{Pt}$ e $\mathrm{Sn}$ na superfície dos catalisadores para maximizar a velocidade da reação. O melhor desempenho na oxidação do etanol foi encontrado para o catalisador $\mathrm{Pt}_{3} \mathrm{Sn} / \mathrm{C}$. Ao utilizar este catalisador como ânodo na $D E F C$, os principais produtos formados foram o acetaldeído e o ácido acético, enquanto que, somente uma pequena quantidade de $\mathrm{CO}_{2}$ foi observada. Os autores especularam também que grandes quantidades de espécies $\mathrm{SnO}_{x}$ na superfície das amostras ricas em Sn poderiam favorecer oxidações posteriores dos adsorbatos etanólicos nos sítios de Pt levando a altos rendimentos de ácido acético e $\mathrm{CO}_{2}$.

Wang et al. [40] prepararam eletrocatalisadores PtSn suportados em óxido de grafeno (GO) partindo de uma razão atômica Pt:Sn de 2:1. Foi utilizado o método do poliol, onde uma mistura de $\mathrm{H}_{2} \mathrm{PtCl}_{6} \mathrm{H}_{2} \mathrm{O}$ e $\mathrm{SnCl}_{2}$ em etilenoglicol ou em uma mistura etilenoglicol-água foram adicionados a uma dispersão de $\mathrm{GO}$ em etilenoglicol-água. Após o ajuste do pH em 12 (usando solução de $\mathrm{NaOH}$ em etilenoglicol) submeteu-se a mistura a refluxo em $130{ }^{\circ} \mathrm{C}$ por $3 \mathrm{~h}$ sob fluxo de argônio. Após o resfriamento da mistura, o pH foi ajustado em 2 com solução de $\mathrm{HNO}_{3}$, promovendo a adsorção das nanopartículas suspensas no suporte. Observou-se que o aumento da quantidade de água leva a um aumento no conteúdo de Sn do catalisador. Entretanto, foi observado que um aumento no conteúdo de Sn pode levar a uma diminuição da área ativa (ESCA) do catalisador devido ao bloqueio pelo $\mathrm{SnO}_{x}$ formado e a uma gradual agregação das partículas do catalisador. O máximo de atividade do catalisador foi observado para um conteúdo de água de $5 \%(\mathrm{v} / \mathrm{v})$.

Como mostrado anteriormente, pode-se dizer que o estudo da preparação dos eletrocatalisadores PtSn/C é um dos temas mais estudados na oxidação eletroquímica do etanol. Trata-se de um tema bastante complexo, pois as propriedades dos catalisadores obtidos dependem fortemente do método de preparação. Como visto, os autores atribuem o aumento de atividade dos materiais obtidos a diversos fatores como: à composição do catalisador, ou seja, razão Pt:Sn, à formação de liga entre o Pt e o Sn, à formação de espécies isoladas 
como $\mathrm{Pt}(0)$ e $\mathrm{SnO}_{x}$, ou ainda à presença de $\mathrm{PtSn}$ liga e de espécies $\mathrm{SnO}_{\mathrm{x}}$. Um consenso a respeito disso parece ainda bastante difícil, pois as superfícies dos catalisadores heteregêneos são bastante complexas e as comparações nem sempre são feitas sob as mesmas condições. Apesar disso, os catalisadores a base de PtSn têm se mostrado os mais eficientes para as DEFC. No entanto, a Pt é ainda bastante cara [7]. Assim, nos últimos anos, uma tendência encontrada na literatura buscando diminuir a quantidade de Pt é colocá-la apenas na superfície do catalisador.

\subsection{Preparação de eletrocatalisadores PtSn por meio da Deposição de Pt ou Sn na superfície}

A deposição de Pt ou Sn na superfície de eletrocatalisadores para aplicação nas células a combustível tem sido efetuada de diferentes formas:

- por meio da deposição de camadas, ou sub-camadas, de Pt na superfície de outro metal suportado em carbono [22, 27, 31, 34, 42].

- por meio da troca galvânica (também chamada de deposição espontânea ou reação de transmetalação) envolvendo a troca de íons $\mathrm{Pt}(\mathrm{II})$ ou $\mathrm{Pt}(\mathrm{IV})$ por metais menos nobres suportados em carbono [43, 44].

- por meio da síntese de nanopartículas na forma núcleo-casca (core-shell), onde a Pt envolve outro metal localizado no núcleo $[45,46]$.

Diversos trabalhos têm mostrado que a deposição de Pt na superfície de uma nanopartícula suportada em carbono (seja na forma de camadas ou subcamadas de Pt ou na forma de estruturas tipo core-shell) visam a obtenção de catalisadores mais eficientes utilizando menores quantidades de Pt [22, 27, 31, $34,42,45,46]$. No entanto, ainda existem poucos trabalhos envolvendo a deposição de Pt na superfície de Sn ou de Sn na superfície da Pt e o uso dos catalisadores resultantes na oxidação eletroquímica do etanol.

El-Shafei e Eiswirth [47] efetuaram a deposição de Sn sobre eletrodos de trabalho contendo Pt monocristalina (111), (100) e (110) utilizando a técnica de deposição forçada, a qual consiste em mergulhar o eletrodo em uma solução de Sn e a subsequente redução das espécies de Sn em atmosfera de hidrogênio. 
Repetindo este procedimento, diferentes frações de cobertura puderam ser obtidas. Os materiais foram testados na oxidação eletroquímica do etanol usando as técnicas de voltametria cíclica e cronoamperometria. Os autores concluíram que, ao contrário da deposição espontânea, a deposição forçada facilitou a adsorção do Sn na superfície dos eletrodos de Pt. Para todos os eletrodos preparados a adsorção de $S n$ aumentou fortemente a corrente na oxidação do etanol, sendo o sistema $\mathrm{Sn} / \mathrm{Pt}(110)$ o que exibiu a maior atividade.

Silva et al [45] preparam o catalisador $\mathrm{SnO}_{2} @ \mathrm{Pt} / \mathrm{C}$ na forma core-shell e testaram na oxidação eletroquímica do etanol. O material foi preparado com razão atômica Pt:Sn de 1:1. Inicialmente, o $\mathrm{SnCl}_{2}$ foi adicionado a uma solução aquosa de citrato de sódio, subsequentemente, a solução foi aquecida a $90{ }^{\circ} \mathrm{C}$ e então boroidreto de sódio foi adicionado a esta solução. Dessa forma, foi preparado o core. A camada exterior da nanopartícula (shell) foi preparada a partir da adição de uma solução contendo $\mathrm{H}_{2} \mathrm{PtCl}_{6}$ e ácido ascórbico (em excesso) na solução contendo o core a $90{ }^{\circ} \mathrm{C}$. Após, o suporte de carbono foi adicionado resultando em uma carga metálica de $20 \%$ em massa. A mistura resultante permaneceu sob agitação por $24 \mathrm{~h}$ a temperatura ambiente. Finalmente, o material foi separado e tratado a $300{ }^{\circ} \mathrm{C}$ por $1 \mathrm{~h}$ sob fluxo de nitrogênio. Os estudos da oxidação eletroquímica do etanol utilizando experimentos de voltametria cíclica e cronoamperometria mostraram que o material $\mathrm{SnO}_{2} @ \mathrm{Pt} / \mathrm{C}$ obtido apresentou bom desempenho catalítico quando comparado aos catalisadores comerciais $\mathrm{Pt} / \mathrm{C} \mathrm{e}$ $\mathrm{PtSn} / \mathrm{C}$ E-TEK.

Zhang et al [46] prepararam como eletrocatalisadores Pt/(CNT@SnO 2$)$ e $\mathrm{Pt} / \mathrm{CNT}$ utilizando um procedimento em duas etapas. Primeiro, nanopartículas de Pt foram preparadas por meio da redução de precursores dissolvidos em etilenoglicol e aquecimento utilizando microondas. Após, as nanopartículas de $\mathrm{Pt}$ foram depositadas no suporte $\mathrm{CNT} @ \mathrm{SnO}_{2}$, ou seja, nanotubos de carbonos contendo uma fina camada de $\mathrm{SnO}_{2}$. Para promover a adsorção das nanopartículas de Pt neste suporte, ácido nítrico foi utilizado como um promotor de sedimentação. O sólido resultante foi filtrado, lavado e seco. Estudos eletroquímicos usando voltametria cíclica e cronoamperometria mostraram que o catalisador Pt/(CNT@SnO 2$)$ exibiu maior atividade catalítica que o material 
$\mathrm{Pt} / \mathrm{CNT}$, provavelmente, devido a interação sinergética entre a $\mathrm{Pt}$ e o $\mathrm{SnO}_{2}$. Os autores consideraram que este material poderia ser um bom candidato como catalisador para células DEFC, no entanto, comparações com catalisadores comerciais não foram efetuadas.

Zhou et al. [43] vaporizaram Sn metálico sobre a superfície $\mathrm{Pt}(111)$ por meio de um processo de deposição assistida. A análise do material resultante mostrou um crescimento tridimensional de ilhas de $\mathrm{SnO}_{x}$ sobre $\mathrm{Pt}(111)$. Após a exposição da superfície do material $\mathrm{SnO}_{\rtimes} / \mathrm{Pt}(111)$ à água ou a uma solução de eletrólito, foi verificada (por XPS) uma quantidade significante de espécies $\mathrm{H}_{2} \mathrm{O} / \mathrm{OH}$ adsorvidas na superfície do $\mathrm{SnO}_{x}$. Os testes eletroquímicos para a oxidação eletroquímica do etanol revelaram que o desempenho catalítico da $\mathrm{Pt}(111)$ é significantemente intensificado com as ilhas de $\mathrm{SnO}_{x}$ em sua superfície. Segundo os autores, as evidências experimentais mostram a importância da interface $\mathrm{Pt}_{-} \mathrm{SnO}_{\mathrm{x}}$ na oxidação eletroquímica do etanol.

Li et al. [42] com o objetivo de melhorar a atividade e a estabilidade de catalisadores de Pt para a oxidação eletroquímica do etanol depositaram seletivamente Pt na superfície de nanotubos de carbono suportados com $\mathrm{SnO}_{2}$. A deposição de $\mathrm{Pt}$ foi efetuada em duas etapas: inicialmente $\mathrm{Na}_{2} \mathrm{PtCl}_{6}$ foi adicionada sob agitação ao suporte $\mathrm{SnO}_{2} / \mathrm{CNT}$ levando à formação de $[\mathrm{Pt}]-\mathrm{Sn}(\mathrm{OH})_{2} / \mathrm{CNT}$, o qual foi filtrado, lavado, seco e reduzido a $100^{\circ} \mathrm{C}$ por $1 \mathrm{~h}$ sob fluxo hidrogênio. $\mathrm{O}$ conteúdo de Pt nesta etapa foi de 1,3\% em massa. Numa segunda etapa, o material obtido [Pt]-SnO $\mathrm{Sn}_{2} \mathrm{CNT}$ foi disperso em um solução aquosa contendo $\mathrm{HCOONa}$, na qual $\mathrm{Na}_{2} \mathrm{PtCl}_{6}$ foi adicionada. Após a mistura permaneceu sob agitação por 30 min e o sólido foi filtrado e seco. O conteúdo de Pt após esta etapa foi de $8 \%$ em massa. Pt suportada em CNT também foi preparada pelo método da impregnação para ser usada como referência. Os resultados mostraram que a degradação da área eletroquimicamente ativa do [Pt]- $\mathrm{SnO}_{2} / \mathrm{CNT}$ foi menor que do Pt/CNT, sendo sua atividade também maior, indicando que as interfaces Pt e $\mathrm{SnO}_{2}$ contribuíram para isso.

Velazquez-Palenzuela et al [44] descreveram a deposição espontânea de $\mathrm{Sn}$ em $\mathrm{Pt} / \mathrm{C}$ depositada na superfície de eletrodo de carbono. As espécies de Sn foram depositadas sobre $\mathrm{Pt} / \mathrm{C}$ pela imersão deste em uma solução de $\mathrm{SnCl}_{2} \mathrm{em}$ 
$\mathrm{HClO}_{4}$ por diferentes tempos. Os testes catalíticos na oxidação eletroquímica do etanol mostraram que o catalisador Sn-Pt/C apresentou um melhor desempenho que o material $\mathrm{Pt} / \mathrm{C}$, o que foi atribuído à deposição de espécies $\mathrm{SnO}_{x}$ na superfície das nanopartículas de Pt.

Magee et al [48] prepararam nanopartículas de $\mathrm{SnO}_{2}$ em etilenoglicol e depositaram em eletrodos de Pt policristalina. Os autores concluíram que a adição de nanopartículas de $\mathrm{SnO}_{2}$ contribuem para a oxidação eletroquímica do etanol por meio do fornecimento de espécies oxigenadas $(\mathrm{OH})$ que promovem a remoção das espécies adsorvidas nos sítios de $\mathrm{Pt}$, como o $\mathrm{CO}_{a d s}$. Por outro lado, estas espécies não participam da quebra da ligação $\mathrm{C}-\mathrm{C}$ da molécula do etanol, a qual ocorre nos sítios de Pt. Assim, a melhora no desempenho destes catalisadores foi atribuída ao aumento da produção de produtos parcialmente oxidados, como o acetaldeído e o ácido acético.

Como pode ser visto, ainda são poucos os estudos relatados na literatura em relação à preparação de eletrocatalisadores suportados $\mathrm{PtSn} / \mathrm{C}$ envolvendo a deposição superficial de Pt. Além disso, a comparação da atividade catalítica desses materiais com catalisadores PtSn comerciais nem sempre é efetuada para se avaliar o real ganho de atividade.

Dessa forma, neste estudo buscou-se fornecer mais contribuições sobre a preparação de eletrocatalisadores $\mathrm{PtSn} / \mathrm{C}$, dando enfoque à deposição de $\mathrm{Pt}$ na superfície de $\mathrm{Sn}$ suportado em carbono, utilizando como suporte $\mathrm{Sn}(0) / \mathrm{C}$ ou $\mathrm{SnO}_{2} / \mathrm{C}$. Além disso, buscou-se também utilizar métodos de síntese simples que possam ser realizados em poucas etapas e que não necessitem de condições complexas de operação como, por exemplo, o uso de atmosfera inerte, solventes orgânicos especiais e/ou uso de agentes estabilizantes. 


\section{OBJETIVOS}

Este trabalho teve como objetivo estudar a preparação de eletrocatalisadores $\mathrm{PtSn} / \mathrm{C}$ por meio da deposição superficial de Pt, utilizando diferentes metodologias.

Objetivos especificos:

Sintetizar eletrocatalisadores pela deposição de Pt na superfície de Sn/C utilizando o processo de deposição espontânea e por meio do uso de agentes redutores como o boroidreto de sódio e o etilenoglicol.

Preparar o suporte $\mathrm{Sn} / \mathrm{C}$ na forma de $\mathrm{Sn}$ metálico e $\mathrm{SnO}_{2}$. Os eletrocatalisadores $\mathrm{PtSn} / \mathrm{C}$ obtidos foram caracterizados fisico-quimicamente e testados na oxidação eletroquímica do etanol. A atividade catalítica dos materiais obtidos foi comparada aos materiais preparados por co-redução (deposição de Pt e Sn juntos na mesma etapa) e também ao catalisador comercial PtSn/C BASF, considerado referência na área. 


\section{EXPERIMENTAL}

\subsection{Preparações dos eletrocatalisadores Pt-Sn/C}

\subsubsection{Preparação dos eletrocatalisadores $\mathrm{Pt-Sn/C}$ por substituição galvânica}

Inicialmente, Sn suportado em carbono ( $\mathrm{Sn} / \mathrm{C}$ ) foi preparado, com $20 \% \mathrm{em}$ massa de Sn pelo método de redução com boroidreto de sódio (Aldrich) utlizando como precusor metálico o $\mathrm{SnCl}_{2} .2 \mathrm{H}_{2} \mathrm{O}$ (Aldrich) e como suporte o Carbono Vulcan $\mathrm{XC}-72$ (Cabot). $\mathrm{O} \mathrm{SnCl}_{2} .2 \mathrm{H}_{2} \mathrm{O}$ foi dissolvido em etanol e o suporte de carbono foi adicionado. A mistura resultante permaneceu no ultrassom por 5 min e, após isso, uma solução de boroidreto de sódio (razão molar $\mathrm{BH}_{4}{ }^{-}$:Sn igual a 5:1), o $\mathrm{NaBH}_{4}$ foi dissolvido em $10 \mathrm{~mL}$ de uma solução $\mathrm{KOH} 0,01 \mathrm{~mol} \mathrm{~L}^{-1}$ (Merck) foi adicionada de uma só vez à mistura, a qual permaneceu sob agitação por 30 min. $O$ sólido obtido foi filtrado, lavado e seco a $70^{\circ} \mathrm{C}$ por $2 \mathrm{~h}$.

Numa segunda etapa, foi realizada a reação de substituição galvânica, onde $200 \mathrm{mg}$ do suporte $\mathrm{Sn} / \mathrm{C}$ foi disperso em $50 \mathrm{~mL}$ de água e uma solução aquosa de $\mathrm{H}_{2} \mathrm{PtCl}_{6} 6 \mathrm{H}_{2} \mathrm{O}$ (contendo $30 \mathrm{mg}$ de $\mathrm{Pt}$ em $1,6 \mathrm{~mL}$ água) foi adicionada à temperatura ambiente e atmosfera aberta ao ar. A mistura resultante permeneceu sob agitação por $1 \mathrm{~h}$. A quantidade de $\mathrm{H}_{2} \mathrm{PtCl}_{6} 6 \mathrm{H}_{2} \mathrm{O}$ utilizada foi suficiente para obter um eletrocatalisador $\mathrm{Pt}-\mathrm{Sn} / \mathrm{C}$ com cerca de $15 \%$ em massa de $\mathrm{Pt}$, caso todos os íons $\mathrm{Pt}(\mathrm{IV})$ efetuassem a troca galvânica com o $\mathrm{Sn}(0)$ presente no suporte $\mathrm{Sn} / \mathrm{C}$. Finalmente, o sólido foi filtrado, lavado com excesso de água e seco a 70 ${ }^{\circ} \mathrm{C}$ por 2 h. A razão atômica Pt:Sn foi determinada por EDX e o conteúdo de Pt (\% em massa) foi determinada utilizando curva de calibração.

\subsubsection{Preparação de eletrocatalisadores $\mathrm{Pt}-\mathrm{Sn} / \mathrm{C}$ por redução sucessiva por meio da deposição de Pt por diferentes metodologias sobre Sn/C preparado pelo método da redução por boroidreto de sódio $(\mathrm{BH})$}

\subsubsection{Preparação do $\mathrm{Sn} / \mathrm{C}$ com diferentes \% em massa de Sn utilizando o método da redução por boroidreto de sódio $(\mathrm{BH})$}

Os suportes $\mathrm{Sn} / \mathrm{C}$ com 10, 20, 40 e 60\% em massa de $\mathrm{Sn}$ foram preparados a partir da dissolução de $\mathrm{SnCl}_{2} .2 \mathrm{H}_{2} \mathrm{O}$ (Aldrich) em etanol (Merck) e adição de carbono Vulcan XC-72 (Cabot) a esta solução. A mistura resultante foi submetida 
ao ultrassom por 5 min e, em seguida, foi efetuada de uma só vez a adição de uma solução de boroidreto de sódio $\left(\mathrm{NaBH}_{4}\right.$ - Aldrich) utilizando uma razão molar $\mathrm{BH}_{4}:$ :Sn igual a 5:1. O NaBH 4 foi dissolvido em $10 \mathrm{~mL}$ de uma solução $\mathrm{KOH} \mathrm{0,01}$ mol L-1 (Merck). A solução de $\mathrm{KOH}$ tem a função de evitar a decomposição do boroidreto de sódio $[49,50]$. A mistura resultante permaneceu sob agitação por 30 min. Na etapa seguinte, o sólido foi filtrado, lavado com $4 \mathrm{~L}$ de água e seco a $70{ }^{\circ} \mathrm{C}$ por $2 \mathrm{~h}[51,52]$.

\subsubsection{Deposição de Pt pelo método da redução por álcool (MRA)}

Para a deposição da Pt pelo MRA $[51,52]$ sobre o Sn/C preparado pelo método BH FIG. 3, $200 \mathrm{mg}$ do $\mathrm{Sn} / \mathrm{C}$ foi adicionado a uma solução de etilenoglicol/água (3/1, v/v) e diferentes quantidades de $\mathrm{H}_{2} \mathrm{PtCl}_{6} .6 \mathrm{H}_{2} \mathrm{O}$ (Aldrich) foram adicionados a esta mistura (dependendo da quantidade de Pt desejada no eletrocatalisador). A mistura resultante foi tratada no ultrassom por 5 min e, então, foi submetida a refluxo por $2 \mathrm{~h}$. Finalmente, o sólido foi filtrado, lavado com água e seco a $70^{\circ} \mathrm{C}$ durante $2 \mathrm{~h}$.
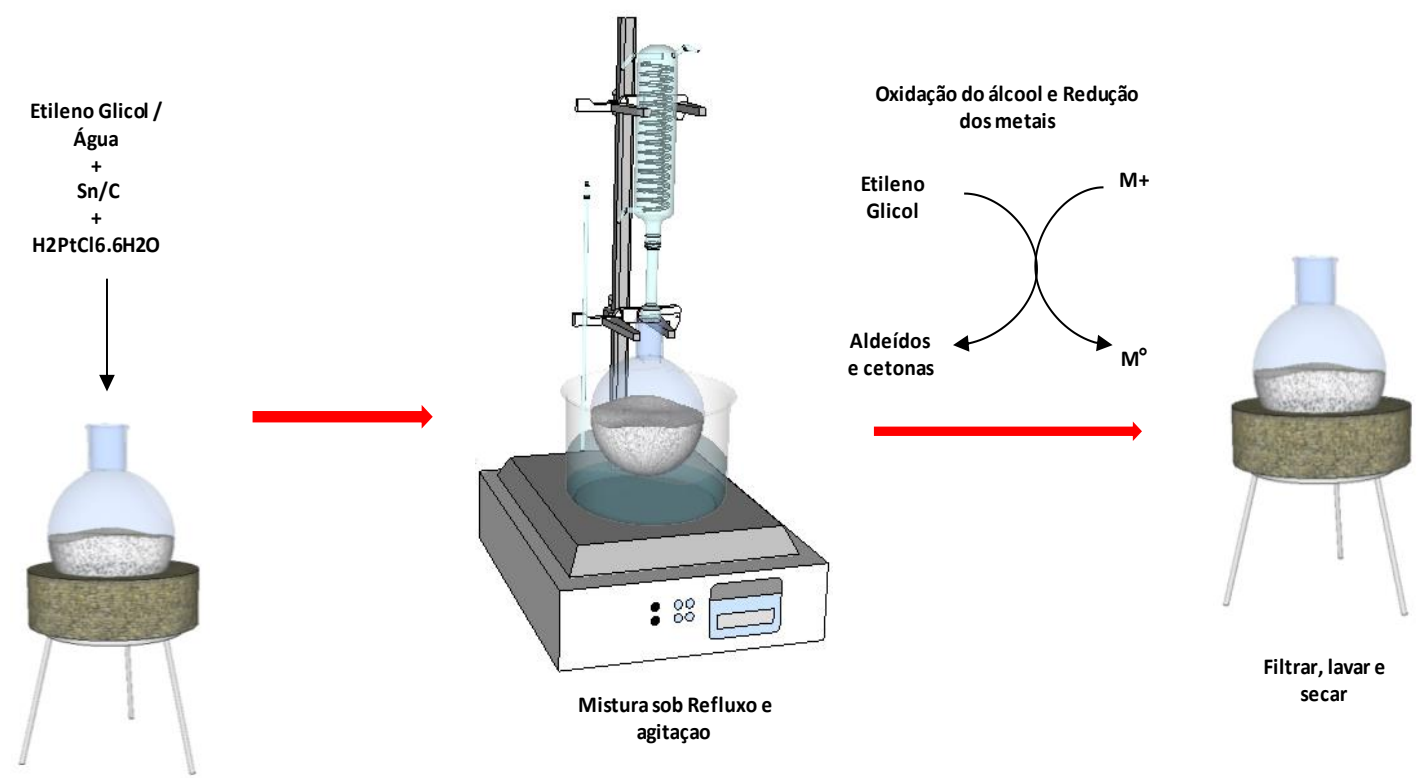

FIGURA 3 - Esquema do método da redução por álcool (MRA)

\subsubsection{Deposição de Pt pelo método BH}

Para a deposição da $\mathrm{Pt}$ pelo método $\mathrm{BH}$ sobre o $\mathrm{Sn} / \mathrm{C}$ preparado pelo método $\mathrm{BH}, 200 \mathrm{mg}$ do $\mathrm{Sn} / \mathrm{C}$ foi disperso em etanol e diferentes quantidades de 
$\mathrm{H}_{2} \mathrm{PtCl}_{6} .6 \mathrm{H}_{2} \mathrm{O}$ (Aldrich) foram adicionadas a esta mistura (dependendo da quantidade de $\mathrm{Pt}$ desejada no eletrocatalisador). A mistura resultante foi submetida ao ultrassom por 5 min e, após isso, uma solução de boroidreto de sódio (razão molar $\mathrm{BH}_{4}:$ :Sn igual a 5) em $10 \mathrm{~mL}$ de uma solução $\mathrm{KOH} 0,01 \mathrm{~mol} \mathrm{~L}$ ${ }^{1}$ (Merck) foi então adicionada de uma só vez à mistura, a qual permaneceu sob agitação por 30 min à temperatura ambiente. Finalmente, o sólido foi filtrado, lavado com água deionizada e seco $70^{\circ} \mathrm{C}$ durante $2 \mathrm{~h}$.

\subsubsection{Preparação de eletrocatalisadores $\mathrm{Pt}-\mathrm{Sn} / \mathrm{C}$ por redução sucessiva por meio da deposição de Pt por diferentes metodologias sobre $\mathrm{Sn} / \mathrm{C}$ preparado pelo método da redução por álcool (MRA)}

\subsubsection{Preparação Sn/C pelo MRA}

O Sn/C (com carga metálica de $20 \%$ em massa) foi preparado pelo método da redução por álcool $[51,52]$ como é apresentado na FIG. 3, usando $\mathrm{SnCl}_{2} \cdot 2 \mathrm{H}_{2} \mathrm{O}$ (Aldrich) como fonte de metal e o carbono Vulcan XC-72 como suporte. O $\mathrm{SnCl}_{2} .2 \mathrm{H}_{2} \mathrm{O}$ foi dissolvido em uma solução etilenoglicol/água (3/1, v/v) e o suporte de carbono Vulcan XC 72 foi adicionado. A mistura resultante foi submetida ao ultrassom por 5 min e, após isso, foi submetida a refluxo por $3 \mathrm{~h}$. Finalmente, o sólido foi filtrado, lavado com água em excesso e seco em estufa a $70^{\circ} \mathrm{C}$ por $2 \mathrm{~h}$.

\subsubsection{Deposição de Pt pelo MRA}

O procedimento foi realizado conforme descrito em 3.1.2.2, substituindo o suporte $\mathrm{Sn} / \mathrm{C}$ preparado pelo método BH pelo suporte $\mathrm{Sn} / \mathrm{C}$ preparado pelo MRA.

\subsubsection{Deposição de Pt pelo método BH}

O procedimento foi realizado conforme descrito em 3.1.2.3, substituindo o suporte $\mathrm{Sn} / \mathrm{C}$ preparado pelo método BH pelo suporte $\mathrm{Sn} / \mathrm{C}$ preparado pelo MRA.

\subsubsection{Preparação dos Eletrocatalisadores $\mathrm{PtSn} / \mathrm{C}$ por co-redução pelos métodos MRA e BH}

Para efeito de comparação os eletrocatalisadores $\mathrm{PtSn} / \mathrm{C}$ foram também preparados em uma única etapa por meio da co-redução dos sais precursores $\mathrm{SnCl}_{2} .2 \mathrm{H}_{2} \mathrm{O}$ (Aldrich) e $\mathrm{H}_{2} \mathrm{PtCl}_{6} .6 \mathrm{H}_{2} \mathrm{O}$ (Aldrich). O carbono Vulcan XC-72 (Cabot) foi utilizado como suporte. No método da redução por álcool $[51,53]$ foi utilizado 
como solvente etilenoglicol/água ( $3 / 1, v / v)$ e no método do boroidreto de sódio [ 49 , 50] foi utilizado como solvente etanol e uma razão molar $\mathrm{BH}_{4}^{-*}$ :metais igual a 5 , de maneira semelhante ao descrito nos ítens 3.1.2.2 e 3.1.2.3, respectivamente.

\subsection{Caracterização Físico-Química dos Eletrocatalisadores}

\subsubsection{Análise de raios $X$ por energia dispersiva}

As razões atômicas $\mathrm{Pt}: \mathrm{Sn}$ foram determinadas por análise de raios $\mathrm{X}$ por energia dispersiva (EDX) [54] usando um microscópio eletrônico de varredura Phillips XL30 com um feixe de elétrons de $20 \mathrm{keV}$ e equipado com um microanalisador EDAX DX-4.

\subsubsection{Difração de Raios X}

As análises por difração de raios $X(X R D)$ foram realizadas em um difratômetro Rigaku modelo Miniflex usando uma fonte radiação CuKa $(\lambda=$ $1,540556 \AA$ ), com varredura de $2 \theta$ de 20 a $90^{\circ} \mathrm{com}$ velocidade de varredura de $2^{\circ}$ $\mathrm{min}^{-1}$. Nestes experimentos foi utilizado uma pequena quantidade de catalisador compactado ao suporte de carbono.

O tamanho médio de cristalito foi calculado utilizando-se a equação de Scherrer (EQ. 25) [55]:

$$
a=\frac{K \cdot \lambda}{\beta \cdot \cos \theta}
$$

onde $d$ é o diâmetro médio dos cristalitos em Angstrons, $K$ é uma constante que depende da forma dos cristalitos, sendo utilizado o valor de 0,9 admitindo-se cristalitos esféricos, $\lambda$ é o comprimento de onda da radiação usada, no caso do Cu $\lambda=1,54056 \AA$, $\beta$ é a largura a meia altura do pico (110) em radianos e $\theta$ é o ângulo de Bragg em graus para o ponto máximo do pico analisado.

\subsubsection{Análises Termogravimétricas}

As análises termogravimétricas (TGA) $[56,57]$ foram realizadas em um equipamento Shimadzu D-50. As amostras foram aquecidas em um cadinho de platina, da temperatura ambiente até $1000^{\circ} \mathrm{C}$, com uma taxa de aquecimento 
igual a $5^{\circ} \mathrm{C} \mathrm{min}^{-1}$ em atmosfera de oxigênio seco $\left(30 \mathrm{~mL} \mathrm{~min}{ }^{-1}\right)$. A análise termogravimétrica possibilita verificar a carga metálica presente no catalisador. Este dado é necessário para o cálculo da porcentagem de Pt contida no catalisador para, futuramente, ser utilizada na normalização dos resultados eletroquímicos $[55,57]$.

\subsubsection{Microscopia Eletrônica de Transmissão}

As análises por microscopia eletrônica de transmissão (TEM) foram realizadas em um microscópio eletrônico JEOL modelo JEM 2100 operando a 200 $\mathrm{kV}$. As amostras de eletrocatalisadores foram dispersas em álcool isopropílico em banho de ultrasom e gotas desta suspensão foram depositadas em um suporte de cobre com collodion $2 \%$ recoberto com carbono. Com a microscopia eletrônica de transmissão foi possível avaliar a homogeneidade, distribuição e tamanho das nanopartículas.

\subsubsection{Microscopia Eletrônica de Transmissão - Line Scan EDX}

A análise de uma seção transversal de diferentes amostras foi realizada usando um microscópio eletrônico JEOL modelo JEM 2100 operando a $200 \mathrm{kV}$ e equipado com um sistema de análise por energia dispersiva de raios- $\mathrm{X}$ (line-scan) onde o perfil da linha (profundidade) pôde ser medido.

\subsection{Estudos Eletroquímicos}

Os estudos eletroquímicos foram realizados em uma célula eletroquímica de três eletrodos, sendo o eletrodo de trabalho preparado pelo método do eletrodo de camada fina porosa [58]. O eletrodo de camada fina porosa foi preparado pela adição de $20 \mathrm{mg}$ do catalisador e 3 gotas de dipersão de Teflon em $50 \mathrm{~mL}$ de água. A mistura resultante foi colocada em um sistema de ultrassom por 10 min sob agitação. Após este período, a mistura foi filtrada em um filtro Millipore HAWP04700. A mistura, ainda úmida, foi então retirada do filtro com auxílio de uma espátula e colocada sobre a cavidade do eletrodo $(0,30 \mathrm{~mm}$ de profundidade e 0,36 $\mathrm{cm}^{2}$ de área), sob leve pressão, procurando deixar a superfície o mais homogênea possível. A quantidade de eletrocatalisador no eletrodo de trabalho FIG. 4 foi determinada com precisão de $0,0001 \mathrm{~g}$. 
As medidas eletroquímicas foram realizadas em um potenciostato/galvanostato Microquímica modelo MQP01 acoplado a um computador. Os perfis voltamétricos dos diferentes eletrocatalisadores foram obtidos em uma célula eletroquímica de um compartimento FIG. 5, contendo um eletrodo de referência de hidrogênio e um contra-eletrodo de platina platinizado. Os experimentos foram realizados em solução de $\mathrm{H}_{2} \mathrm{SO}_{4} 0,5 \mathrm{~mol} \mathrm{~L}^{-1}$ com uma velocidade de varredura de $10 \mathrm{mV} \mathrm{s}^{-1}$.

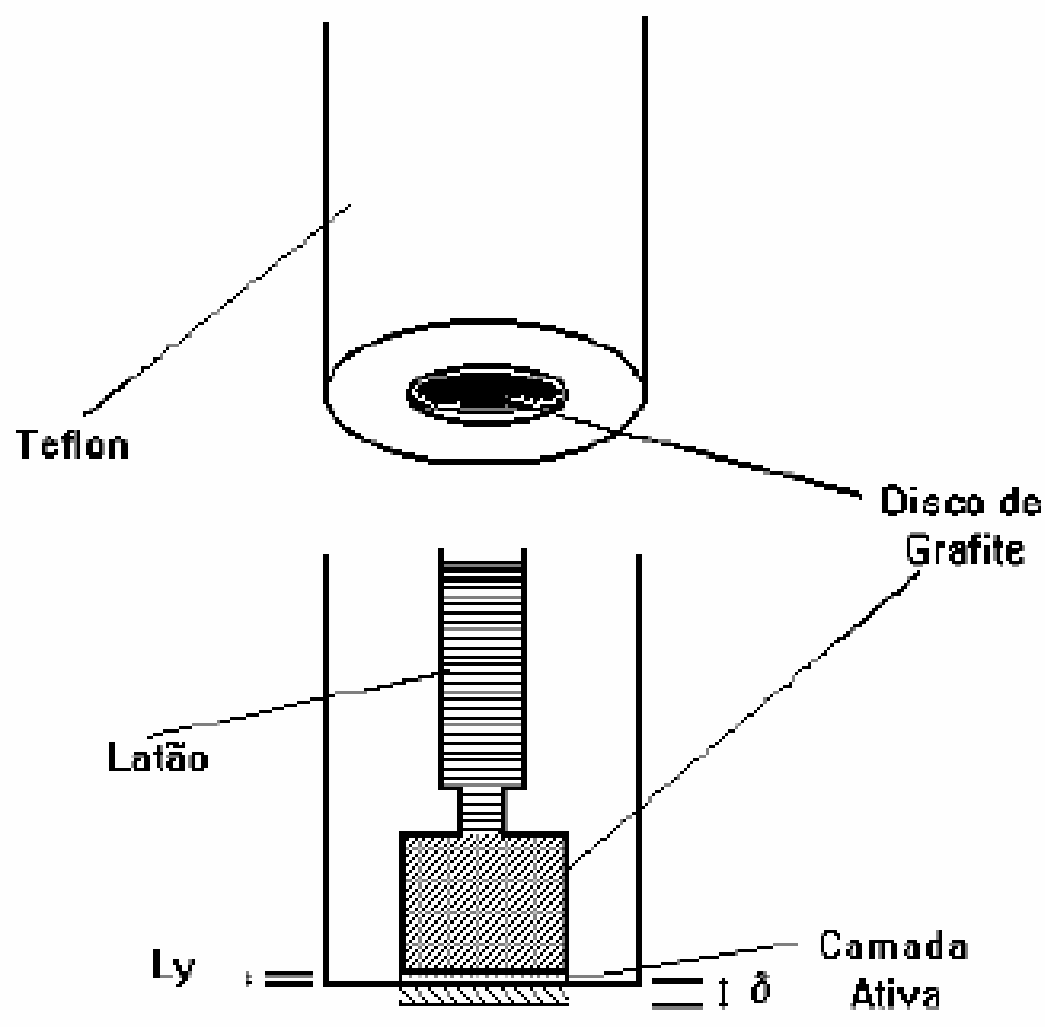

FIGURA 4 - Diagrama esquemático do eletrodo de camada fina porosa

A eletro-oxidação de etanol foi estudada por voltametria cíclica e cronoamperometria. Os estudos da eletro-oxidação de etanol foram realizados à temperatura ambiente utilizando solução $1,0 \mathrm{~mol} \mathrm{~L}^{-1}$ de etanol em 0,5 mol L-1 de $\mathrm{H}_{2} \mathrm{SO}_{4}$. Nestes experimentos, os valores de corrente (I) são expressos em Amperes e normalizados por grama de platina $\left(\mathrm{A} \mathrm{gPt}^{-1}\right)$. A quantidade de platina foi calculada considerando a massa de eletrocatalisador presente no eletrodo de 
trabalho multiplicada por seu conteúdo de platina. Os estudos de cronoamperometria foram realizados em solução $1 \mathrm{~mol} \mathrm{~L}^{-1}$ de etanol em $0,5 \mathrm{~mol}$ $\mathrm{L}^{-1}$ de $\mathrm{H}_{2} \mathrm{SO}_{4}$. $\mathrm{Na}$ análise por cronoamperometria um potencial $(\mathrm{V})$ é fixado e a corrente é medida ao longo do tempo. Dessa forma, pode-se avaliar, além do desempenho, a estabilidade do catalisador. O eletrocatalisador comercial PtSn/C BASF (20\% massa, razão atômica Pt:Sn de 3:1 e na forma liga segundo informações do fabricante) foi utilizado para comparação por ser considerado como referência em termos de desempenho na oxidação eletroquímica do etanol [59].

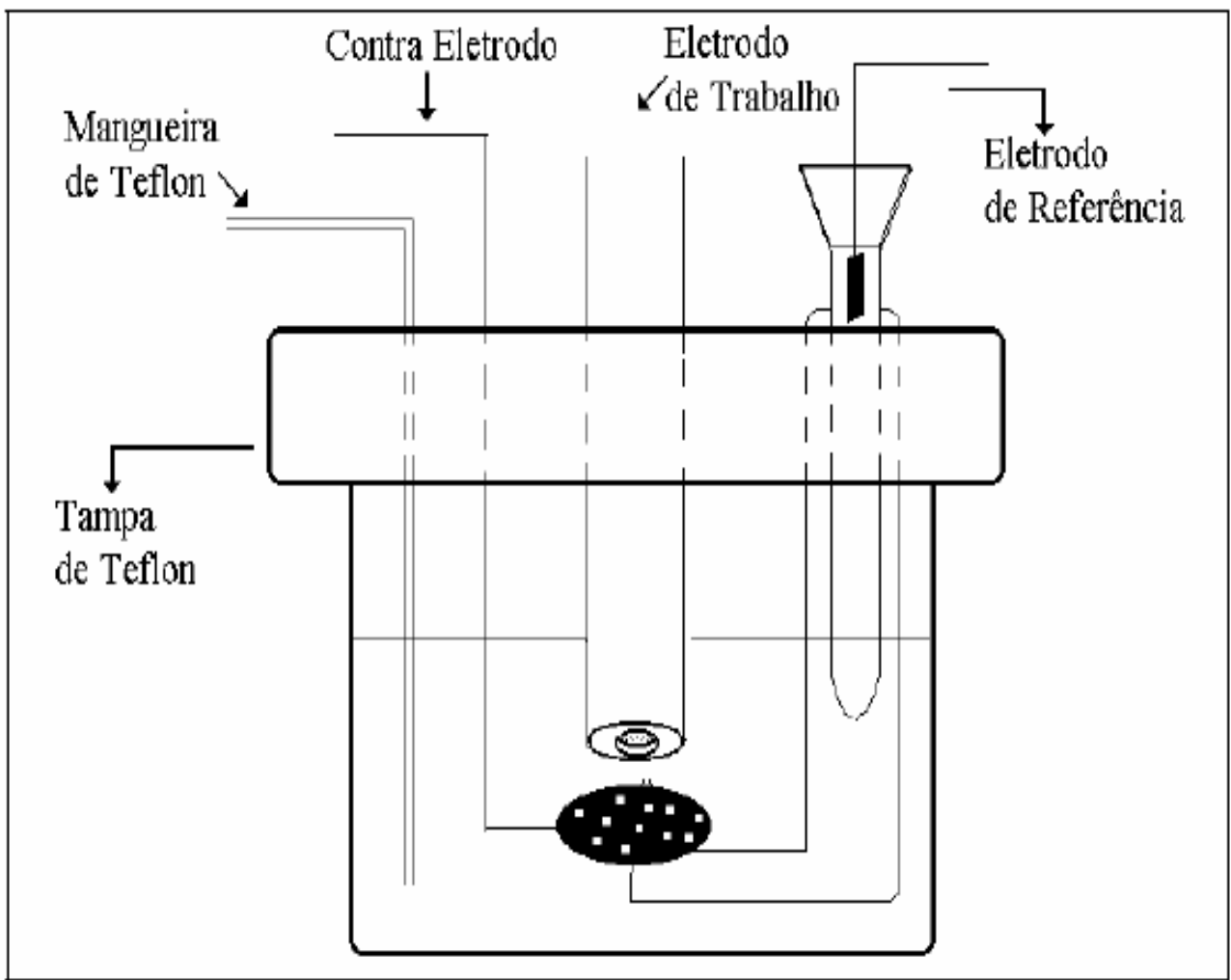

FIGURA 5 - Representação esquemática da célula eletroquímica usada para realização das medidas de voltametria e cronoamperometria e por eletrodo de camada fina porosa

\subsection{Medidas de stripping por adsorção de monóxido de carbono ( $\left.\mathrm{CO}_{\mathrm{ads}}\right)$}

As medidas de stripping por adsorção de $\mathrm{CO}$ foram realizadas utilizando a técnica do eletrodo de camada ultrafina. Inicialmente, uma suspensão contendo 5 mg de eletrocatalisador, $0,2 \mathrm{~mL}$ de isopropanol e $30 \mu \mathrm{L}$ de Nafion foi preparada. 
Esta mistura foi depositada sobre a superfície de um eletrodo de carbono vítreo $\left(0,30 \mathrm{~mm}\right.$ de profundidade e $0,36 \mathrm{~cm}^{2}$ de área) e seca por 30 min à temperatura ambiente. Um eletrodo de $\mathrm{Ag} / \mathrm{AgCl}$ foi usado como referência e uma placa de platina como contra-eletrodo. O eletrólito utilizado foi uma solução de $\mathrm{H}_{2} \mathrm{SO}_{4} 0,5$ mol L-1. A solução contida na célula eletroquímica foi saturada com monóxido de carbono (CO) pelo borbulhamento do mesmo durante $30 \mathrm{~min}$, enquanto um potencial constante de 0,02 V (vs NHE) foi aplicado. Posteriormente, o excesso de CO dissolvido na solução foi removido por meio da purga do sistema com nitrogênio por 30 min. Foi realizado, então, um experimento de voltametria cíclica entre 0,05 a $1 \mathrm{~V}$ (vs. NHE) a $0,01 \mathrm{mV} \mathrm{s}^{-1}$ registrando-se três ciclos consecutivos. Nas Figuras e no texto, os potenciais foram referenciados ao eletrodo normal de hidrogênio (NHE). 


\section{RESULTADOS E DISCUSSÃO}

\subsection{Preparação de eletrocatalisadores Pt-Sn/C por troca galvânica}

A reação de troca galvânica, também descrita como transmetalação ou deposição espontânea ocorre quando um metal (M1) com estado de oxidação positivo se aproxima de uma superfície metálica (M2) e, dessa forma, o íon metálico M1 é reduzido enquanto os átomos M2 da superfície são oxidados levando à deposição de M1 na superfície metálica M2. Para que a troca galvânica ocorra, o metal M1 deve possuir um potencial de redução menor que o metal M2, desse modo, a diferença de potencial eletroquímico entre os dois metais é usado para direcionar a reação [60-63]. Assim, a reação de troca galvânica ou transmetalação normalmente envolve a substituição espontânea de camadas de metais de transição menos nobres, como $\mathrm{Cu}, \mathrm{Fe}, \mathrm{Ni}$, etc, por um metal mais nobre como Pt, Pd, Au, Ir, etc, após a imersão do metal menos nobre em uma solução de íons do metal mais nobre. Este processo é bastante simples e vem sendo bastante utilizado na preparação de nanoestruturas metálicas [64].

Mintsouli et al [65] prepararam eletrocatalisadores $\mathrm{PtCu}$ para a oxidação eletroquímica do metanol por meio da troca galvânica parcial de $\mathrm{Cu}$ em um precursor contendo nanopartículas de $\mathrm{Cu}$ suportadas em carbono $(\mathrm{Cu} / \mathrm{C})$, o qual foi preparado pela redução de $\mathrm{CuSO}_{4} .5 \mathrm{H}_{2} \mathrm{O}$ com boroidreto de sódio em solução aquosa de $\mathrm{NaOH} 1 \mathrm{~mol} \mathrm{~L}^{-1}$ na presença do suporte de carbono. $\mathrm{O}$ sólido obtido $(\mathrm{Cu} / \mathrm{C})$ foi filtrado e seco ao ar. Após, o sólido foi o sólido foi adicionado a uma solução de $\mathrm{K}_{2} \mathrm{PtCl}_{6}$ em $\mathrm{HCl} 0,1 \mathrm{~mol} \mathrm{~L}^{-1}$ sob agitação em atmosfera aberta ao ar, onde ocorreu a seguinte reação EQ. 26:

$2 \mathrm{Cu}(0)+\mathrm{PtCl}_{6}^{2-} \leftrightarrow \mathrm{Pt}(0)+2 \mathrm{Cu}^{2+}+6 \mathrm{Cl}^{-}$

Como a preparação do precursor $\mathrm{Cu} / \mathrm{C}$ foi realizada ao ar, foi observado no difratograma de raios $\mathrm{X}$ a presença de picos referentes a fases de óxido de $\mathrm{Cu}$ ( $\mathrm{Cu}_{2} \mathrm{O}$ ou $\mathrm{CuO}$ ), os quais desapareceram após a troca com íons $\mathrm{Pt}(\mathrm{IV})$ em meio ácido. A presença de picos de óxido de cobre no precursor $\mathrm{Cu} / \mathrm{C}$ era esperado devido sua exposição ao ar durante a filtragem e secagem ao ar. $O$ desaparecimento dos picos referentes às fases de óxido de cobre no material 
$\mathrm{PtCu} / \mathrm{C}$, junto ao fato que a deposição da Pt ocorreu apesar da formação de $\mathrm{Cu}_{2} \mathrm{O}$ no precursor, foi atribuída ao fato de que estas fases encontram-se restritas às camadas superficiais e foram lixiviadas pela solução ácida contendo os íons $\mathrm{PtCl}_{6}{ }^{2-}$, revelando áreas de Cu metálico que prontamente reagiram com os íons $\mathrm{PtCl}_{6}{ }^{2-}[64,65]$. Resultados similares também foram observados por Bersani et al [62] os quais realizaram um experimento análogo e observaram que a reação de troca galvânica também ocorreu após a exposição de nanopartículas de Cu ao ar, as quais prontamente reagiram com um complexo $\mathrm{Pd}$ (II) formando nanopartículas PdCu.

Nesta primeira etapa do trabalho decidiu-se avaliar a preparação de um catalisador Pt-Sn/C por meio da troca galvânica entre os íons $\mathrm{Pt}(\mathrm{IV})$ e as nanopartículas de $\mathrm{Sn}(0)$ suportadas em carbono $(\mathrm{Sn} / \mathrm{C})$. No entanto, um dos objetivos do trabalho é também utilizar métodos simples de síntese, ou seja, realização das etapas de síntese em atmosfera de ar, pois normalmente, os procedimentos por troca galvânica descritos na literatura são realizados em atmosfera controlada (nitrogênio ou argônio) o que as torna mais complexas em termos de equipamentos e de operação. Dessa forma, o precursor Sn/C foi preparado pela redução de $\mathrm{SnCl}_{2} .2 \mathrm{H}_{2} \mathrm{O}$ utilizando boroidreto como agente redutor e, após obtenção de $\mathrm{Sn} / \mathrm{C}$, foi adicionado ao mesmo uma solução de $\mathrm{H}_{2} \mathrm{PtCl}_{6} .6 \mathrm{H}_{2} \mathrm{O}$ para deposição de Pt. Neste caso, similarmente ao trabalho de Mintsouli et al [65] para a preparação de $\mathrm{PtCu} / \mathrm{C}$, a reação de troca galvânica é representada pela EQ. 27,

$2 \mathrm{Sn}(0)+\mathrm{PtCl}_{6}^{2-} \leftrightarrow \mathrm{Pt}(0)+2 \mathrm{Sn}^{2+}+6 \mathrm{Cl}^{-}$

sendo esta favorecida pelo potenciais de redução como mostrado nas EQ. 28,29:

$$
\begin{array}{ll}
\mathrm{PtCl}_{6}^{2-}+4 \mathrm{e}^{-} \rightarrow \mathrm{Pt}+4 \mathrm{Cl}^{-} & \mathrm{E}^{\circ}=0.755 \mathrm{~V} \\
\mathrm{Sn}(0) \leftrightarrow \mathrm{Sn}^{2+}+2 \mathrm{e}^{-} & \mathrm{E}^{\circ}=-0.1375 \mathrm{~V}
\end{array}
$$

A meia-reação representada pela EQ. 28 tem um potencial padrão maior em relação ao do $S n$ (EQ. 29) sendo favorecida termodinamicamente. Os difratogramas de raios $X$ do precursor $\mathrm{Sn} / \mathrm{C}$ e do material $\mathrm{Pt}$-Sn/C preparado são mostrados na FIGURA 6. 
Nos difratogramas do Sn/C e do Pt-Sn/C observa-se um pico largo em cerca de $2 \theta=25^{\circ}$, o qual é associado ao suporte de carbono Vulcan XC-72. O precursor $\mathrm{Sn} / \mathrm{C}$ apresenta picos de difração em cerca $2 \theta=30^{\circ}, 32^{\circ}, 43^{\circ}, 44^{\circ}, 55^{\circ}, 62^{\circ}, 63^{\circ}$, $64^{\circ}, 72^{\circ}, 73^{\circ}, 79^{\circ}$ e $89^{\circ}$, que foram atribuídos aos planos ( 200), (101), ( 220), (211 ), (301 ), ( 112), (400), (321 ), (420), (411), ( 312) e ( 431), respectivamente, da fase Sn metálico [66]. A novel co-precipitation method for preparation of $\mathrm{Pt}-\mathrm{CeO} 2$ composites on multi-walled carbon nanotubes for direct methanol fuel cells, Journal of Power Sources 195, No. 12, 3802-3805. A presença de outras fases de Sn não é claramente observada nos difratogramas. Após a preparação do Pt-Sn/C não se observa no difratograma a presença de fases cristalinas de Pt, no entanto, a presença deste metal não pode ser destarcada, pois a Pt pode existir como uma fase amorfa ou as partículas formadas são muito pequenas para serem detectadas por difração de raios X [67]. Por outro lado, as análises por EDX FIG. 7 revelaram a presença de $\mathrm{Pt}$ no eletrocatalisador $\mathrm{Pt}-\mathrm{Sn} / \mathrm{C}$ e o teor de $\mathrm{Pt}$ determinado foi de $2,2 \%$ em massa. 


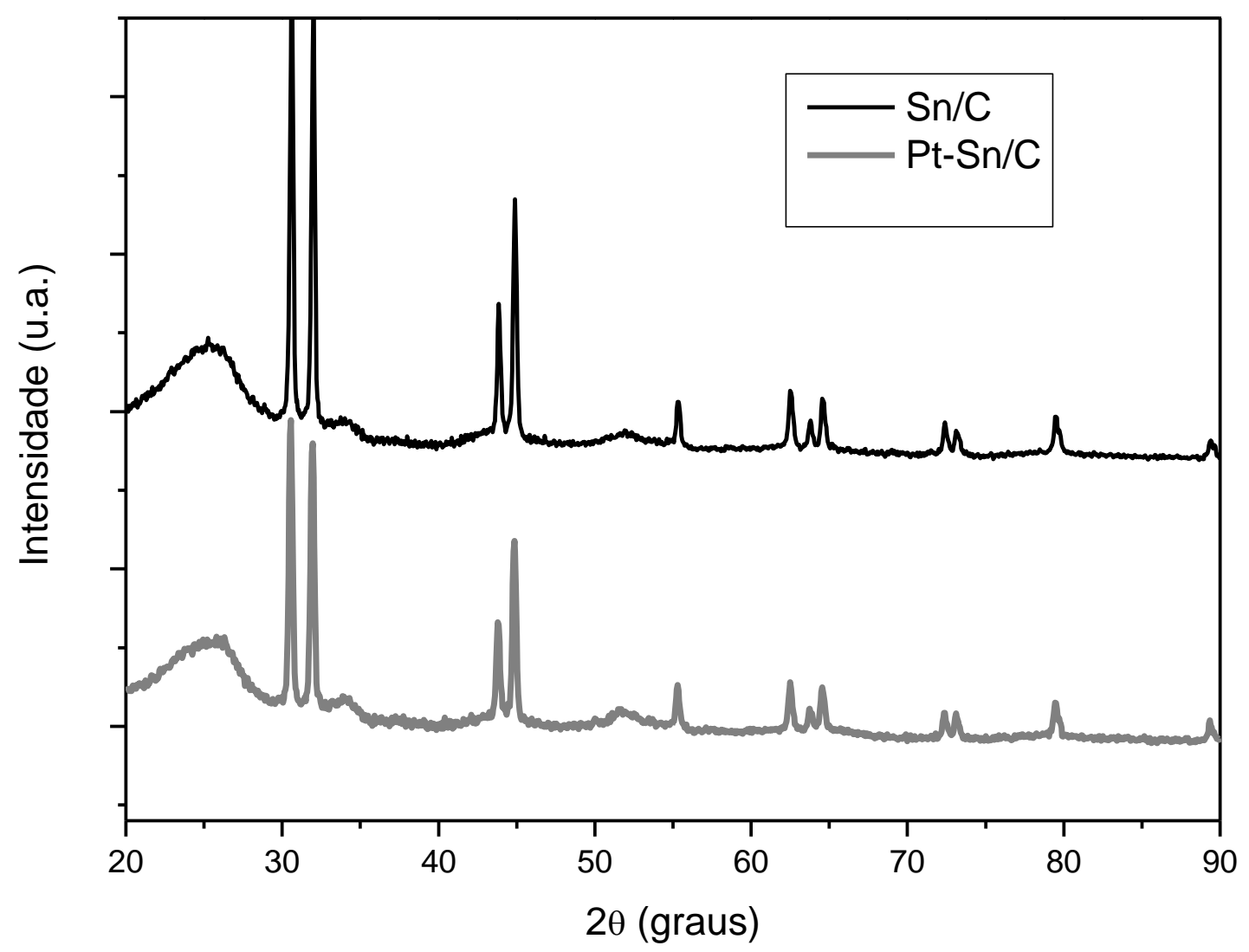

FIGURA 6 - Difratogramas de raios $X$ do precursor $S n / C$ e do eletrocatalisador PtSn/C obtido por deposição espotânea 


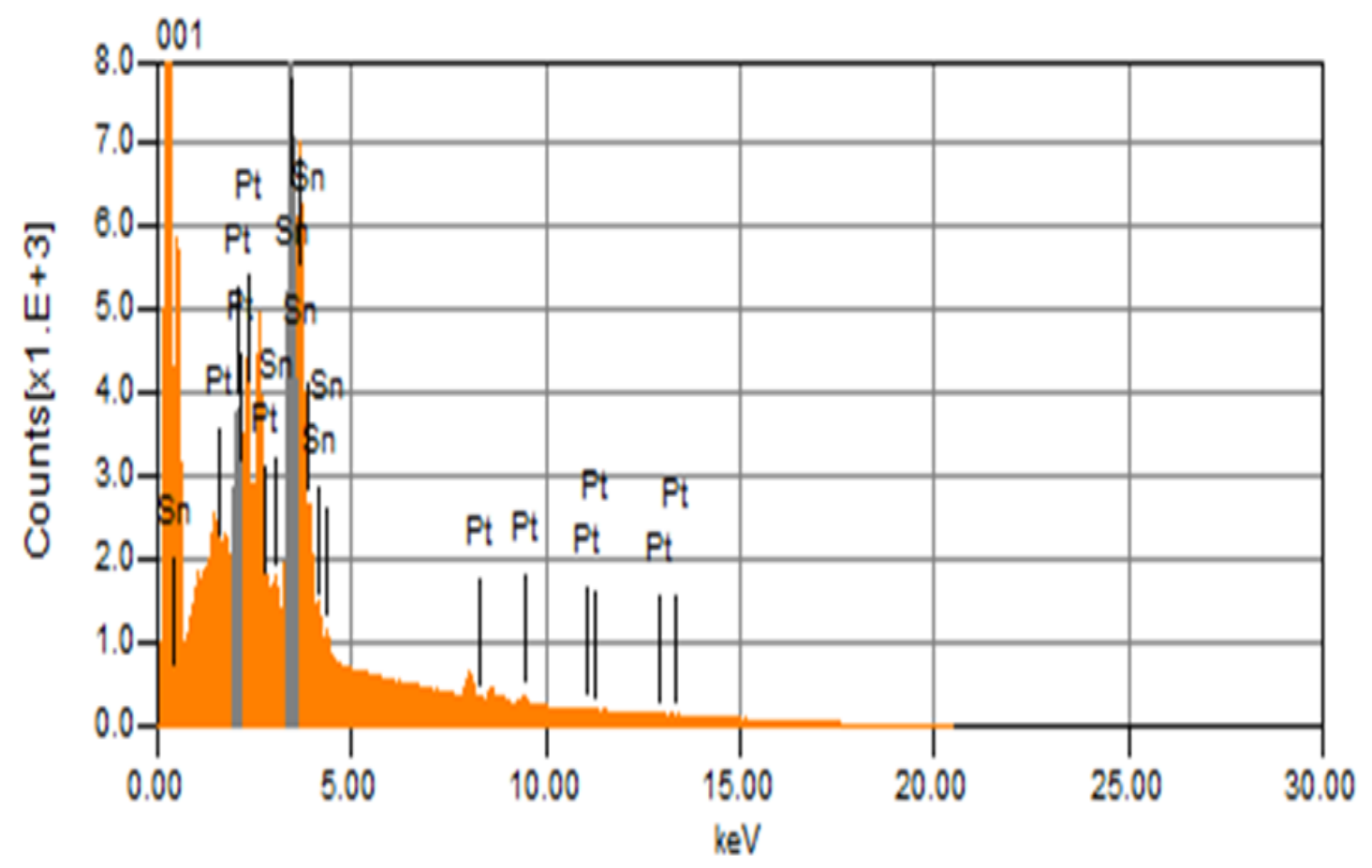

FIGURA 7 - Espectro de EDX do eletrocatalisador Pt-Sn/C obtido por deposição espotânea

Se toda a quantidade de íons Pt(IV) disponível para troca galvânica na preparação do eletrocatalisador Pt-Sn/C fosse depositada no suporte de Sn/C, seria obtido um material contendo cerca de $15 \%$ em massa de Pt. No entanto, a análise por EDX mostrou que apenas cerca de $15 \%$ em massa da quantidade total de Pt disponível, depositou-se sobre o suporte $\mathrm{Sn} / \mathrm{C}$ resultando em uma carga de 2,2\% em massa de Pt. A realização de um teste qualitativo para identificação de íons de Pt mostrou a presença destes no filtrado após a separação do sólido (eletrocatalisador Pt-Sn/C). Mintsouli et al [65] prepararam, inicialmente, o suporte $\mathrm{Cu} / \mathrm{C}$ com $27,7 \%$ em massa de $\mathrm{Cu}$ e, na etapa de troca galvânica, praticamente todos os íons Pt(IV) presentes na solução sofreram redução e depositaram no suporte $\mathrm{Cu} / \mathrm{C}$, sendo que a maior parte dos átomos de $\mathrm{Cu}(90 \%)$ foi oxidada indo para a solução. O material PtCu/C obtido apresentou 9,5\% em massa de Pt e uma razão atômica Pt:Cu de 0,89. A baixa deposição de $\mathrm{Pt}(2,2 \%$ em massa) observada em nosso caso para o Pt-Sn/C talvez seja explicada pela formação de óxidos de $\mathrm{Sn}$ na superfície do $\mathrm{Sn} / \mathrm{C}$, o qual foi preparado em atmosfera aberta ao 
ar. Estudos de materiais contendo Sn, pela técnica de XPS, mostraram que a maior parte do Sn na superfície encontra-se na forma de óxidos [21]. Como os óxidos de Sn são relativamente inertes a ataques químicos [68], isto provavelmente dificulta o acesso dos íons $\mathrm{Pt}(\mathrm{IV})$ aos átomos de Sn metálico, enquanto que, os materiais contendo óxidos de cobre são facilmente dissolvidos em meio ácido [65]. Dessa forma, a baixa quantidade de Pt depositada no suporte $\mathrm{Sn} / \mathrm{C}$ pode ser devido à formação de óxidos de Sn superficial, o qual dificultou o acesso dos íons $\mathrm{Pt}(\mathrm{IV})$ às espécies de Sn metálico.

Os voltamogramas cíclicos (VC) do suporte Sn/C e do eletrocatalisador PtSn/C, em meio ácido, são mostrados na FIG. 8.

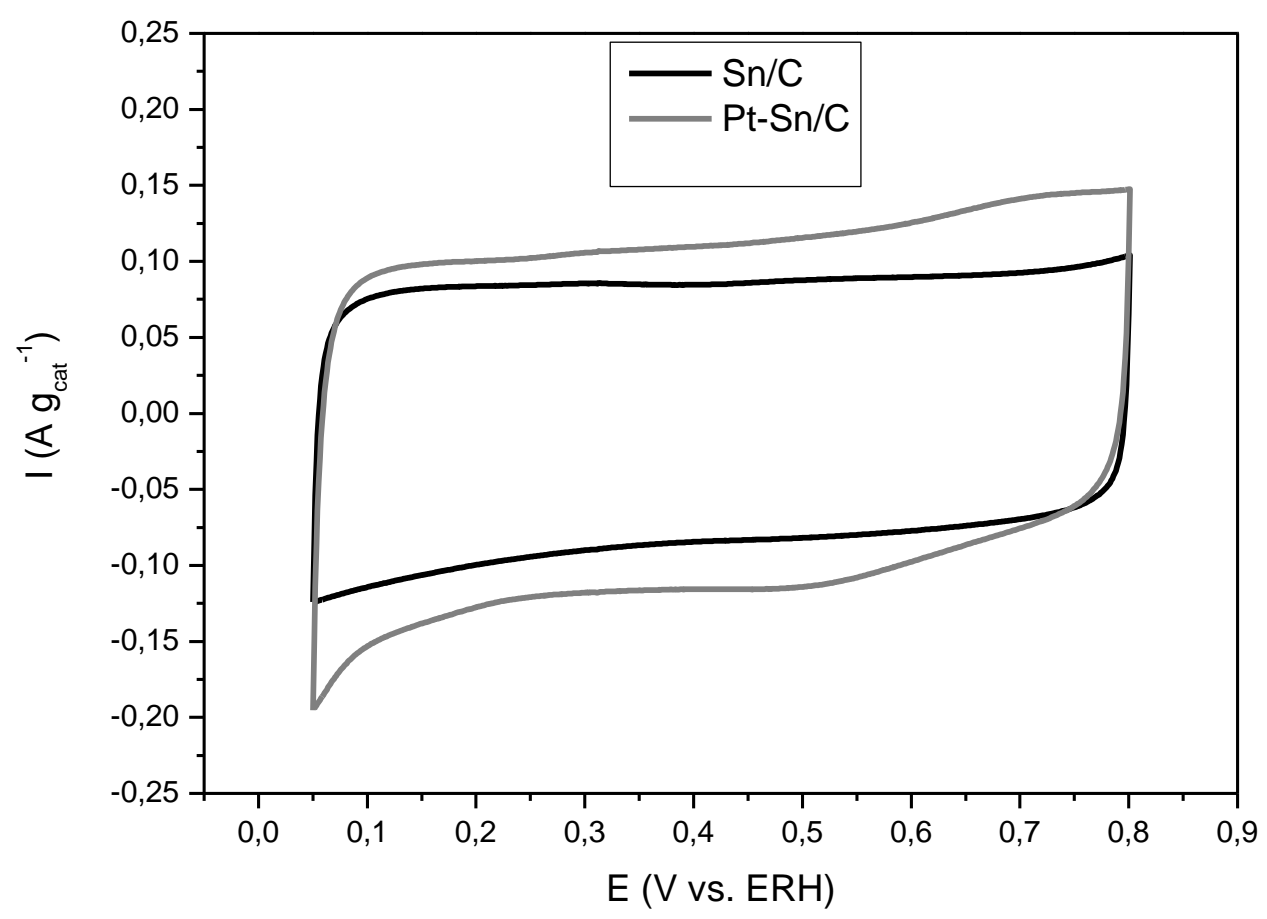

FIGURA 8 - Voltametria cíclica do suporte $\mathrm{Sn} / \mathrm{C}$ e do eletrocatalisador Pt-Sn/C em solução de $\mathrm{H}_{2} \mathrm{SO}_{4} 0,5 \mathrm{~mol} \mathrm{~L}^{-1}$ a $10 \mathrm{mVs}^{-1}$

Comparando os VCs do suporte $\mathrm{Sn} / \mathrm{C}$ e do eletrocatalisador $\mathrm{Pt}-\mathrm{Sn} / \mathrm{C}$ observa-se que o Pt-Sn/C apresenta uma mudança de perfil, similar aos observados na preparação de materiais contendo camadas de Pt depositadas em nanopartículas de Ir suportadas em carbono [67] e na deposição de Pt em ligas 
amorfas CoSn [69]. A fim de avaliar a atividade eletrocatalítica e a estabilidade do material obtido na oxidação eletroquímica do etanol foram realizados experimentos utilizando a técnica de cronoamperometria FIGURA 9.

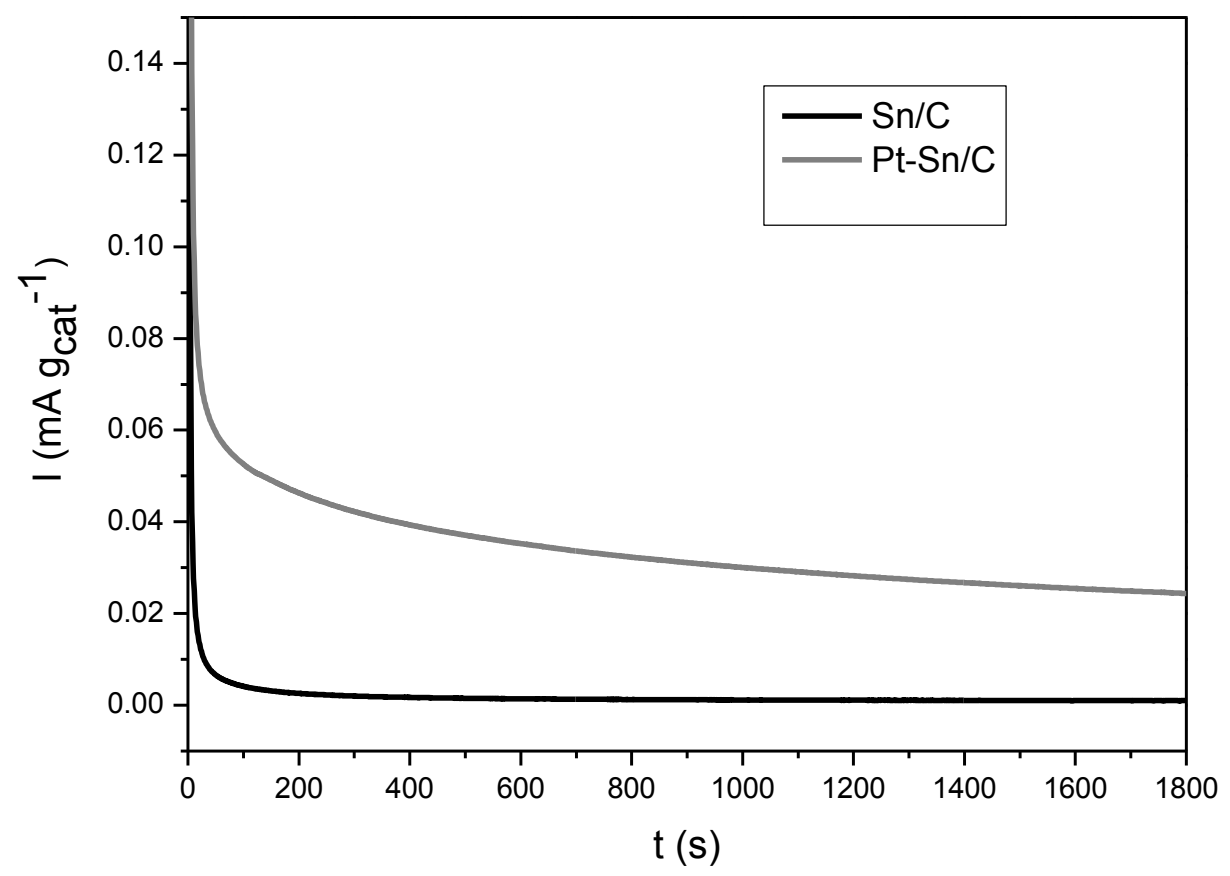

FIGURA 9 - Curvas cronoamperometricas obtidas a 0,5 V em solução de $0,5 \mathrm{~mol} \mathrm{~L}^{-1}$ de $\mathrm{H}_{2} \mathrm{SO}_{4}$ contendo $1 \mathrm{~mol} \mathrm{~L}^{-1}$ de etanol

Como esperado, após a deposição de Pt sobre o suporte Sn/C observa-se um aumento de atividade do material obtido devido a presença de espécies de $\mathrm{Pt}$ e de Sn no material Pt-Sn/C, as quais são fundamentais para a obtenção de materiais mais ativos para a oxidação eletroquímica do etanol. Resultados similares foram observados por outros autores $[69,70]$ para materiais preparados de maneira similar e testados na oxidação eletroquímica de alcoóis. No entanto, nestes estudos, os resultados obtidos são normalmente comparados ao material de partida (suporte) ou ao catalisador $\mathrm{Pt} / \mathrm{C}$, o qual também apresenta baixa atividade na oxidação eletroquímica do etanol. Assim, a comparação com um eletrocatalisador de composição similar, no caso PtSn, é necessária a fim de avaliar a real atividade do material obtido. Dessa forma efetuou-se a comparação do eletrocatalisador obtido com um eletrocatalisador comercial (catalisador 
PtSn/C BASF - 20\% em massa de metal e razão atômica Pt:Sn de 75:25) conforme mostrado na FIGURA 10.

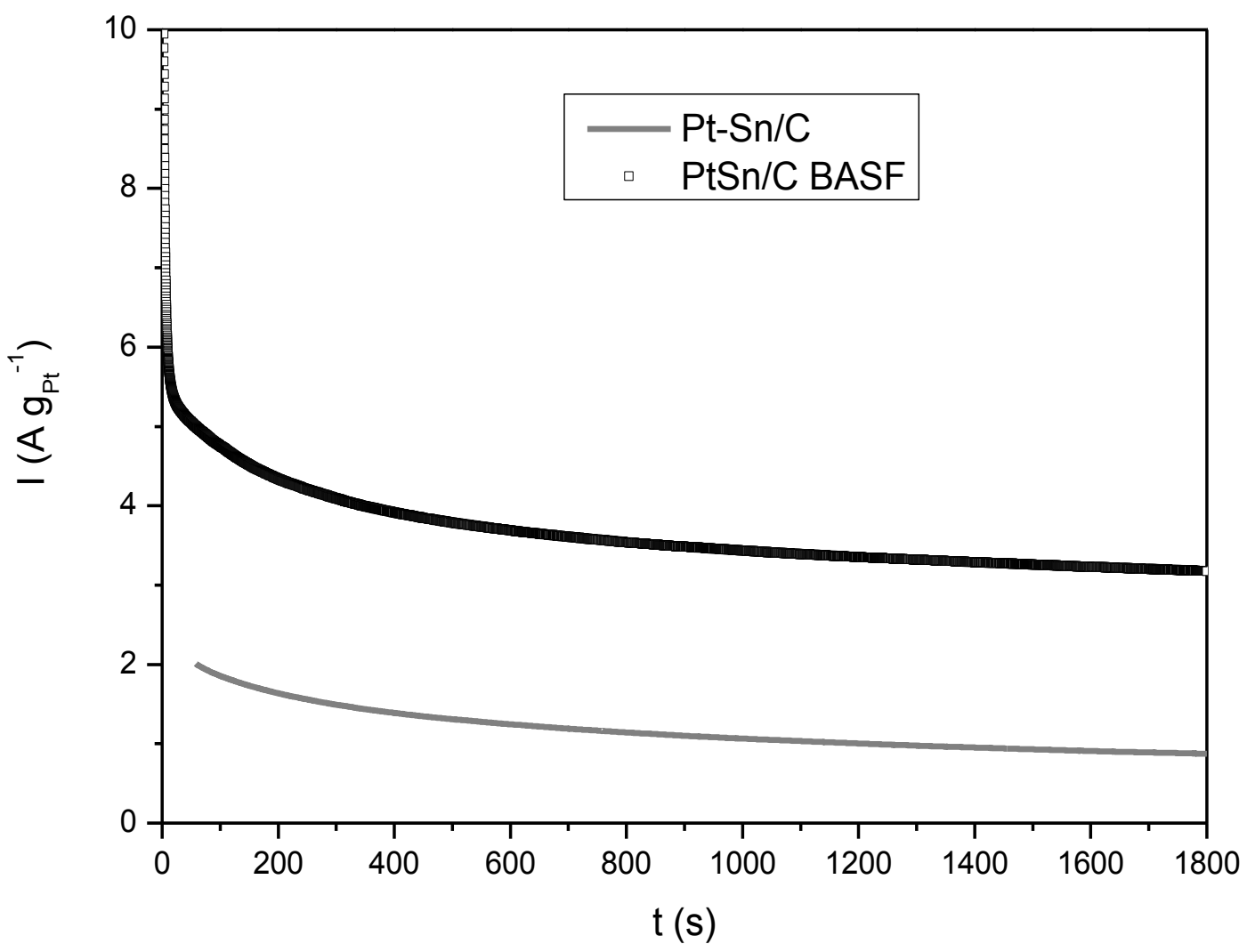

FIGURA 10 - Curvas cronoamperometricas obtidas a $0.5 \mathrm{~V}$ em solução de $0.5 \mathrm{~mol}$ $\mathrm{L}^{-1}$ de $\mathrm{H}_{2} \mathrm{SO}_{4}$ contendo $1 \mathrm{~mol} \mathrm{~L}^{-1}$ de etanol normalizadas por grama de $\mathrm{Pt}$, para o catalisador obtido por deposição espontânea

Observa-se que a atividade eletrocatalítica do material comercial PtSn/C BASF é maior que a do material obtido mesmo considerando-se a normalização da corrente obtida pela quantidade de Pt presente no catalisador. No caso de se normalizar a corrente obtida pela quantidade em massa de catalisador a diferença de atividade é ainda maior FIGURA 11. 


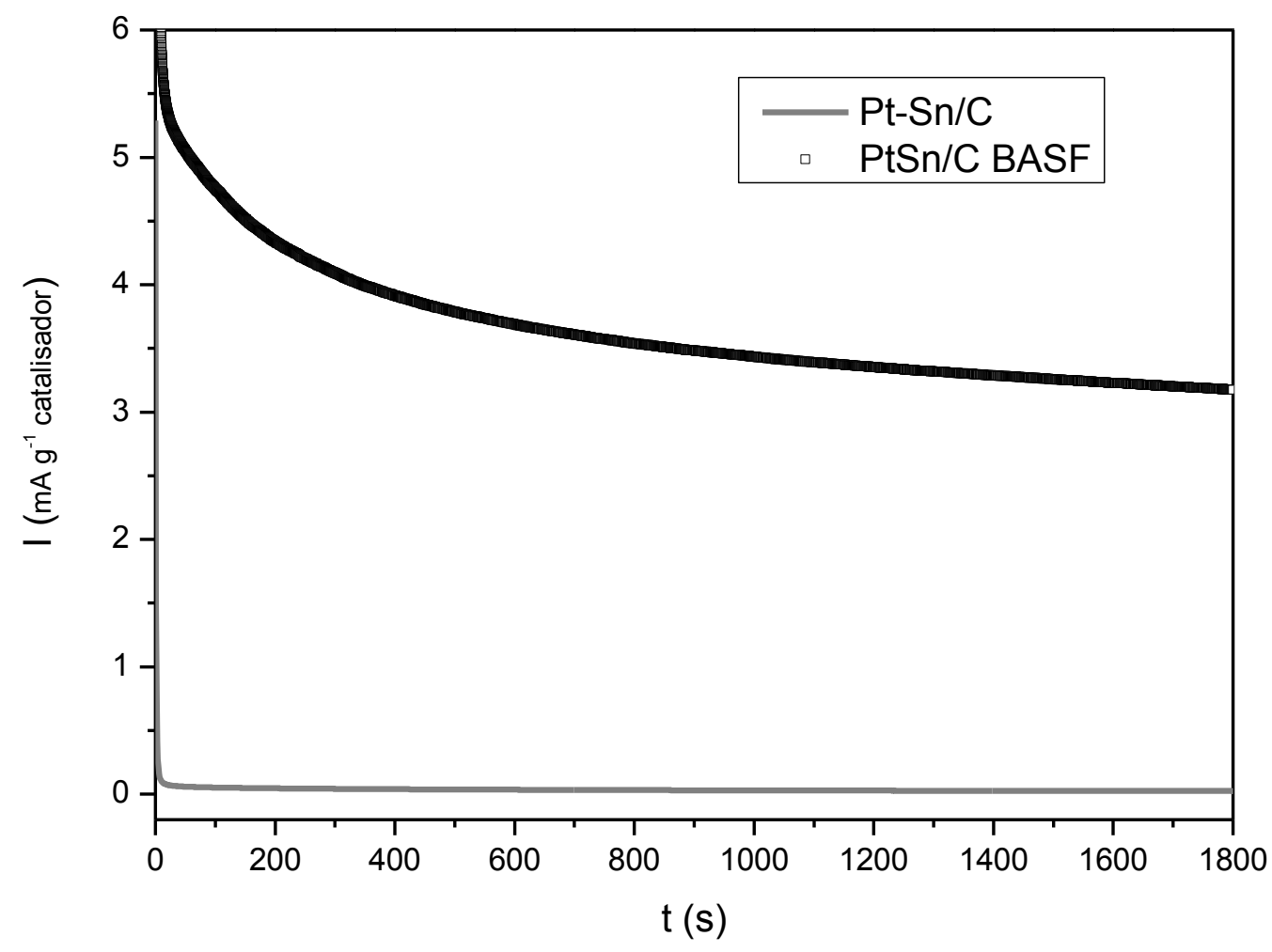

FIGURA 11 - Curvas cronoamperometricas obtidas a $0.5 \mathrm{~V}$ em solução de $0.5 \mathrm{~mol}$ $\mathrm{L}^{-1}$ de $\mathrm{H}_{2} \mathrm{SO}_{4}$ contendo $1 \mathrm{~mol} \mathrm{~L}^{-1}$ de etanol normalizadas por grama de catalisador, obtido por deposição espontânea

Isto pode ser devido à pequena quantidade de $\mathrm{Pt}$ que foi depositada no suporte $\mathrm{Sn} / \mathrm{C}$ e também a forma como a Pt encontra-se depositada na superfície do catalisador. Chen et al [71] relataram que tentativas de economizar Pt por meio da deposição de Pt em um suporte nem sempre são eficazes, pois os átomos de Pt nem sempre encontram-se nas posições "ideais" para determinadas reações e acabam não sendo eficientes para as mesmas. No entanto, eles obtiveram sucesso na deposição de $\mathrm{Pt}$ na forma de monocamadas ou sub-monocamadas atômicas por meio de deposição a vapor em uma superfície plana de monocarbeto de tungstênio (WC), sendo que este material apresentou bons resultados na reação de evolução de hidrogênio (HER). 
Assim, decidiu-se a preparar dos eletrocatalisadores Pt-Sn/C, utilizando agentes redutores para a deposição da Pt sobre os suportes Sn/C a fim de possibilitar a depositação de diferentes quantidades de Pt.

\subsection{Preparação de eletrocatalisadores $\mathrm{Pt}-\mathrm{Sn} / \mathrm{C}$ por redução sucessiva utilizando diferentes metodologias}

Nesta etapa do trabalho, preparou-se o suporte $\mathrm{Sn} / \mathrm{C}$ por duas diferentes metodologias, as quais têm se mostrado bastante efetivas e de fácil reprodução: o método de redução utilizando boroidreto de sódio $(\mathrm{BH})$ como agente redutor e o método da redução por álcool (MRA) desenvolvido no IPEN-CNEN/SP [52, 55, 72]. As deposições de Pt sobre os suportes de Sn/C preparados também foram realizadas utilizando estas mesmas metodologias.

\subsubsection{Preparação do $\mathrm{Sn} / \mathrm{C}$ com diferentes \% em massa de Sn utilizando o método da redução por boroidreto $(\mathrm{BH})$.}

Os difratogramas dos eletrocatalisadores $\mathrm{Sn}(\mathrm{BH}) / \mathrm{C}$ com diferentes porcentagens em massa Sn são mostrados na FIG. 12. Observa-se em todos os difratogramas um pico largo em, aproximadamente, $2 \theta=25^{\circ}$ associado ao suporte de carbono Vulcan XC-72. Para o material Sn/C (10\% em massa) o difratograma apresenta-se bastante similar ao do Vulcan XC-72. Assim, não foi possível avaliar a presença de fases de Sn neste material, no entanto, as análises por EDX confirmaram a presença de Sn neste material. Por outro lado, os difratogramas dos materiais preparados com concentrações maiores de Sn (20, 40 e 60\% em massa) apresentaram picos intensos de difração em, aproximadamente, $2 \theta=30^{\circ}$, $32^{\circ}, 43^{\circ}, 44^{\circ}, 55^{\circ}, 62^{\circ}, 63^{\circ}, 64^{\circ}, 72^{\circ}, 73^{\circ}, 79^{\circ}$ e $89^{\circ}$ que são atribuídos aos planos (200), (101), (220), (211), (301), (112), (400), (321), (420), (411), (312) e (431) e correspondem à fase $S n$ metálico [66]. A análise dos difratogramas não permite observar claramente a presença de outras fases de Sn entretanto, as mesmas podem estar presentes como fases amorfas. As reflexões do plano (312) da estrutura de $\mathrm{Sn}$ foram utilizadas para calcular o tamanho médio de cristalito através da equação de Scherrer e os valores encontrados encontram-se entre 7 e $8 \mathrm{~nm}$ para os materiais com \% em massa de Sn entre 20 e $60 \%$. 


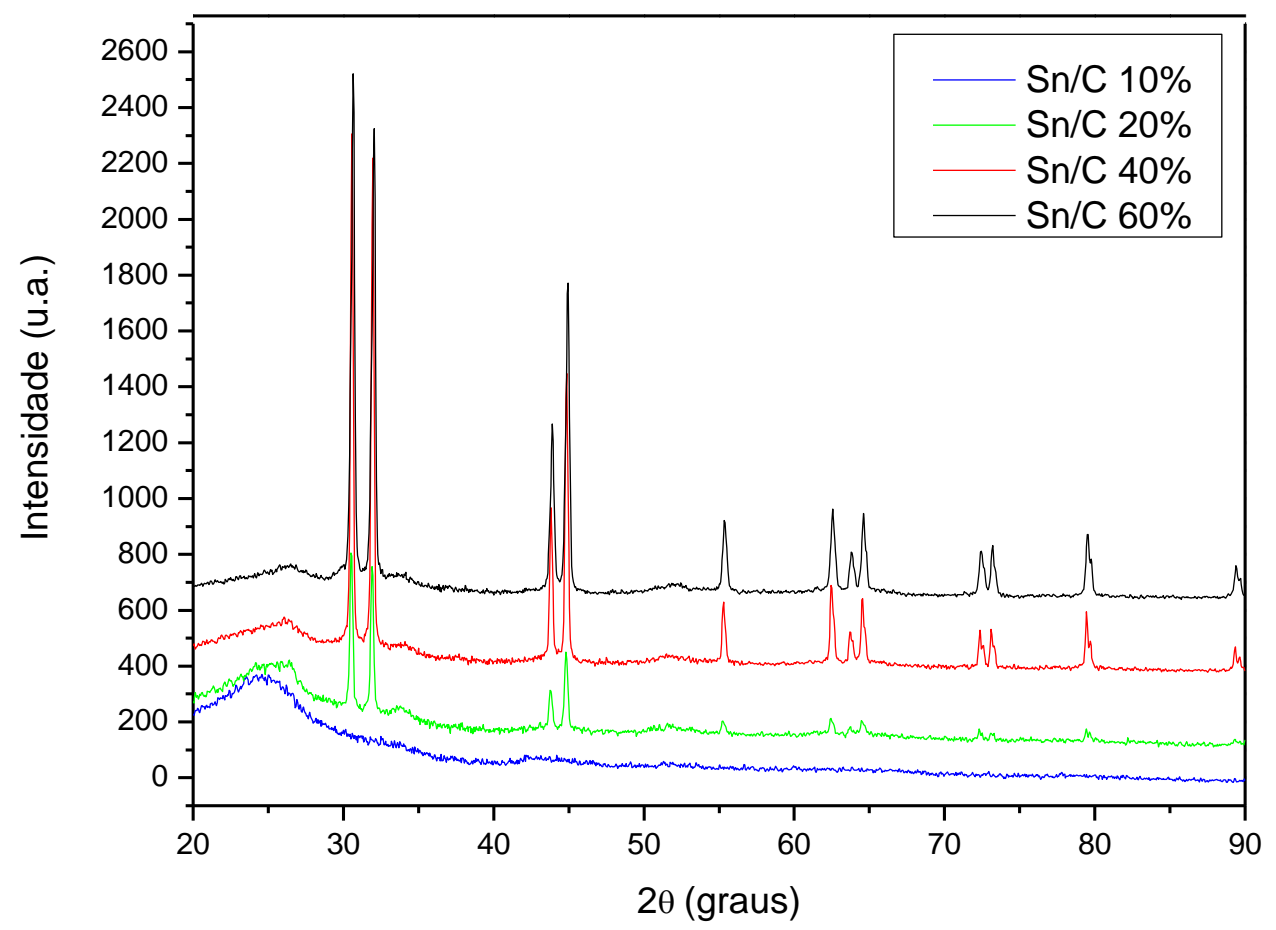

FIGURA 12 - Difratogramas de raios X dos eletrocatalisadores $\mathrm{Sn} / \mathrm{C}$ preparado pelo método $\mathrm{BH}$ com 10, 20, 40, 60 \% em massa de $\mathrm{Sn}$

Na FIGURA 13 ( $a$ e b) são mostradas as imagens obtida por microscopia eletrônica de transmissão (MET) dos suportes do eletrocatalisador $\mathrm{Sn}(\mathrm{BH}) / \mathrm{C}$ com $10 \%$ e $20 \%$ em massa de Sn. Observa-se que em ambos os casos, o Sn encontrase principalmente aglomerado no suporte de carbono.

A imagem obtida por microscopia eletrônica de transmissão para o eletrocatalisador Sn/C com 20\% em massa de Sn é mostrada na FIGURA 14. 

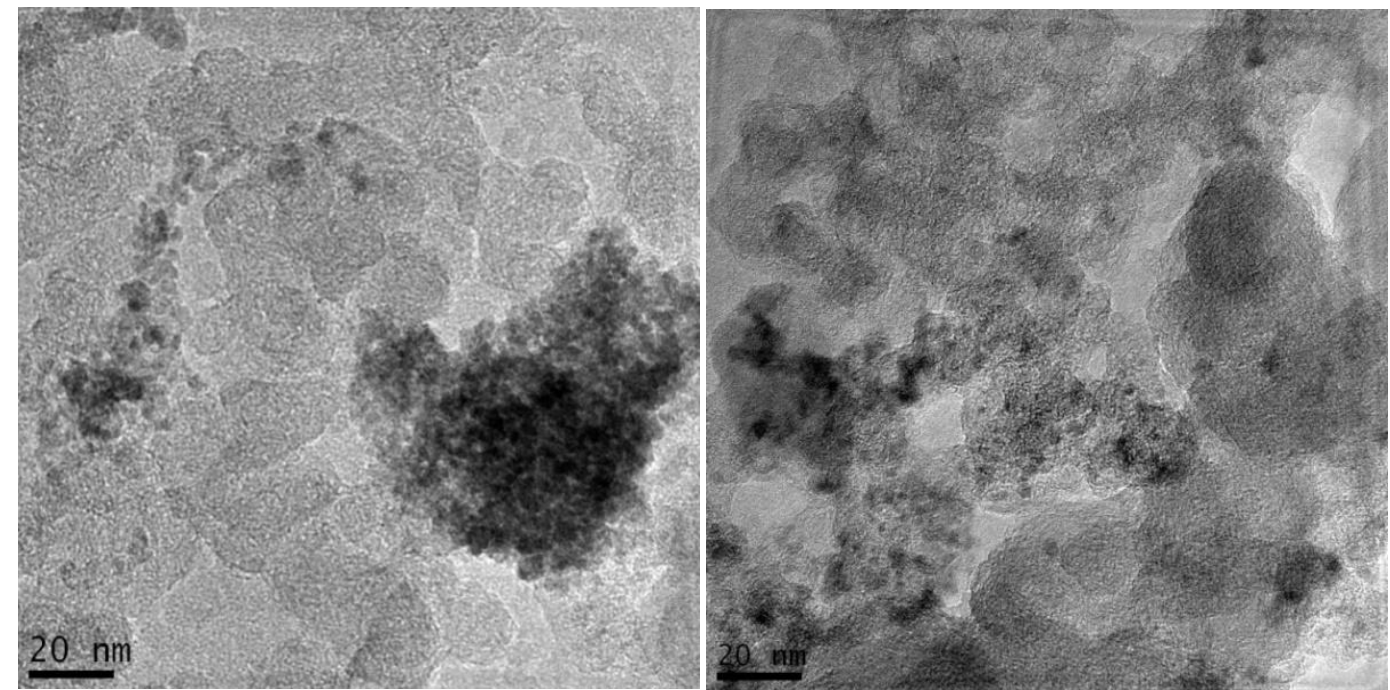

FIGURA 13 - Micrografias eletrônicas de transmissão do suporte Sn/C preparado pelo método $\mathrm{BH}$ com $10 \%$ em massa de $\mathrm{Sn}$

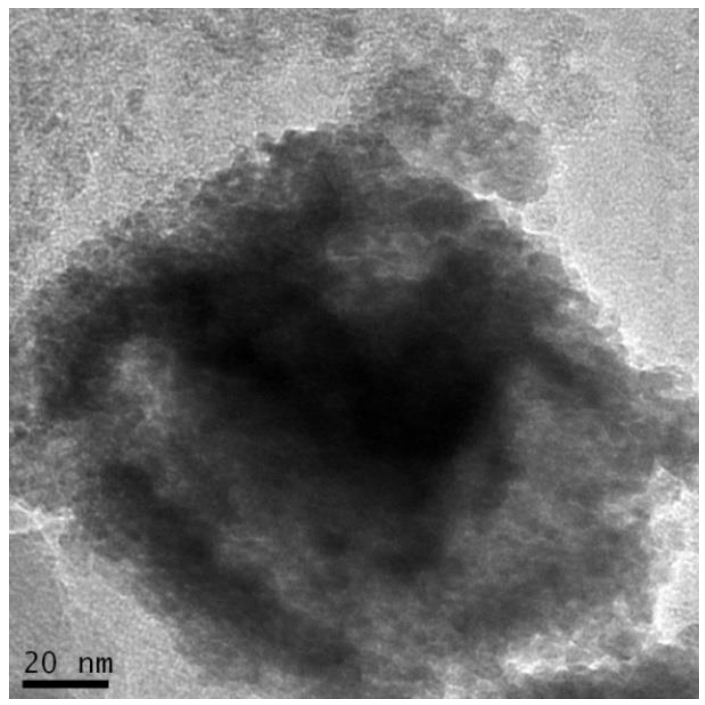

FIGURA 14 - Micrografia eletrônica de transmissão do suporte Sn/C preparado pelo método $\mathrm{BH}$ com $20 \%$ em massa de $\mathrm{Sn}$

Observa-se também neste caso que o Sn encontra-se principalmente aglomerado no suporte de carbono.

\subsubsection{Deposição de Pt pelo método da redução por álcool (MRA) nos suportes $\mathrm{Sn} / \mathrm{C}$ obtidos pelo método $\mathrm{BH}$.}

Os eletrocatalisadores obtidos pela deposição de $\mathrm{Pt}$ pelo método da redução por álcool (MRA) sobre suportes Sn/C obtidos pela redução por 
boroidreto (Pt(MRA)-Sn(BH)/C), com diferentes razões atômicas Pt:Sn, são mostrados na TABELA 1.

TABELA 1 - Razão atômica nominal e a obtida por EDX dos eletrocatalisadores $\mathrm{Pt}(\mathrm{MRA})-\mathrm{Sn}(\mathrm{BH}) / \mathrm{C}$, com 10, 20, 40 e $60 \%$ em massa de Sn e com diferentes razões atômicas de Pt.

\begin{tabular}{lllll}
$\begin{array}{r}\text { Sn (\% em } \\
\text { massa) }\end{array}$ & $\mathbf{1 0}$ & $\mathbf{2 0}$ & $\mathbf{4 0}$ & $\mathbf{6 0}$ \\
& & & & \\
\hline $\begin{array}{l}\text { Pt (\% em } \\
\text { massa) }\end{array}$ & nominal & $\begin{array}{l}\text { Razão } \\
\text { nominal }\end{array}$ & $\begin{array}{l}\text { Razão } \\
\text { nominal }\end{array}$ & $\begin{array}{l}\text { Razão } \\
\text { nominal }\end{array}$ \\
4,5 & $22: 78$ & $12: 88$ & $07: 93$ & $05: 95$ \\
8,6 & $36: 64$ & $22: 78$ & $12: 88$ & $08: 92$ \\
12,4 & $45: 55$ & $30: 70$ & $17: 83$ & $12: 88$ \\
\hline \multicolumn{4}{r}{ Razão determinada por EDX } & \\
\hline 4,5 & $48: 52$ & $26: 74$ & $16: 84$ & $09: 91$ \\
8,6 & $72: 28$ & $45: 55$ & $33: 67$ & $25: 75$ \\
12,4 & $80: 20$ & $56: 44$ & $43: 57$ & $29: 71$ \\
\hline
\end{tabular}

Para os eletrocatalisadores $\mathrm{Pt}(\mathrm{MRA})-\mathrm{Sn}(\mathrm{BH}) / \mathrm{C}$ preparados por redução sucessiva as análises por EDX mostraram que as razões atômicas Pt:Sn apresentam-se diferentes da razões atômicas nominais TABELA 1. Observa-se para todos os casos que as quantidades de Pt obtidas por EDX são sempre maiores e que as quantidades de Sn são menores que as razôes nomimais de partida. Estes resultados sugerem que parte do Sn presente nestas no suporte pode estar sofrendo algum processo que ocasiona sua perda durante a etapa de deposição da Pt. Neste caso, a etapa de deposição dos íons Pt(IV) pelo método MRA é realizado sob refluxo (temperatura na faixa $140-150^{\circ} \mathrm{C}$ ) e o sistema é 
aberto ao ar. Dessa forma, parte do Sn metálico suportado no carbono Vulcan XC72 pode estar sendo oxidado pelo oxigênio presente na atmosfera e acaba depositando na forma $\mathrm{SnO}_{2}$ (ver dados de DRX e TEM adiante - p. 66 e 67 ), bem como, parte do Sn pode estar formando espécies solúveis no meio reacional as quais são eliminadas na etapa de filtração e lavagem do eletrocatalisador. Desse modo, os valores obtidos para as razões atômicas Pt:Sn mostram que as quantidades de $\mathrm{Sn}$ são sempre menores que as nominais. Comparando as razões atômicas Pt:Sn nominais com as obtidas por EDX e calculando as quantidades relativas de Pt e Sn em cada eletrocatalisador, verifica-se que para os materiais preparados com o suporte $\mathrm{Sn} / \mathrm{C}$ contendo $10 \%$ em massa de $\mathrm{Sn}$ as perdas de $\mathrm{Sn}$ encontram-se na faixa $20-25 \%$, enquanto que, para os materiais preparados com o suporte $\mathrm{Sn} / \mathrm{C}$ contendo $20 \%$ em massa de $\mathrm{Sn}$ as perdas de Sn encontram-se ao redor de $30 \%$ para todos os casos. Dessa forma, a análise destes resultados mostra que as perdas de Sn parecem ser aproximadamente constantes para materiais contendo a mesma \% em massa de Sn. Assim, curiosamente, os valores da perda do $\mathrm{Sn}$ foram bastante semelhantes dentro de um mesmo grupo independente da quantidade de Pt utilizada na segunda etapa da preparação do eletrocatalisador.

Os eletrocatalisadores $\mathrm{Pt}(\mathrm{MRA})-\mathrm{Sn}(\mathrm{BH}) / \mathrm{C}$ preparados a partir do suporte $\mathrm{Sn} / \mathrm{C}$ com $20 \%$ em massa de $\mathrm{Sn}$ foram analisados por análise termogravimétrica [57] para determinar a massa final de metal nestes materiais. Os termogramas são mostrados na FIG.15. 


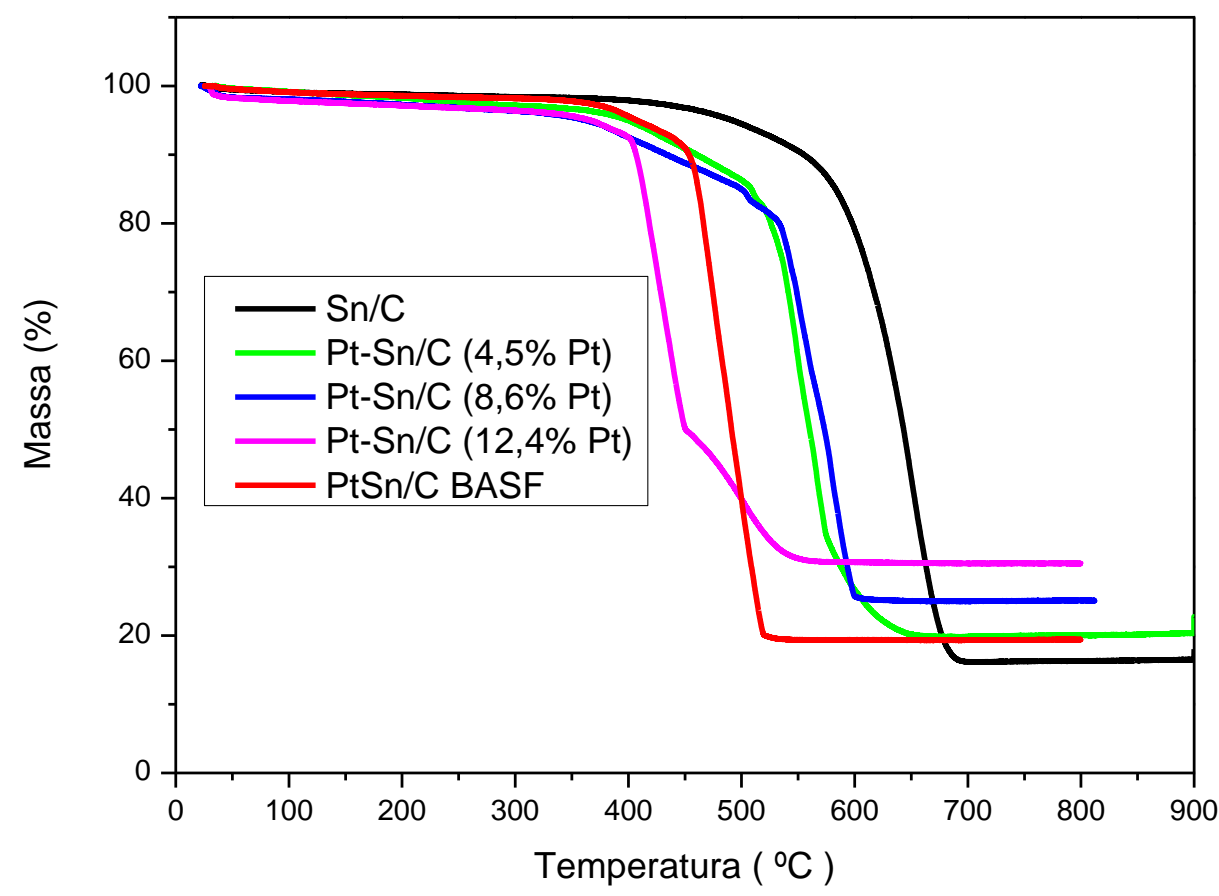

FIGURA 15 - Termogramas dos eletrocatalisadores Pt(MRA)-Sn(BH)/C preparados a partir do suporte com $20 \%$ em massa de $\mathrm{Sn}$

Nesta análise o suporte de carbono é oxidado em atmosfera de ar a $\mathrm{CO}_{2} \mathrm{e}$ $\mathrm{H}_{2} \mathrm{O}$ restando ao final da análise apenas a massa correspondente aos metais presentes na amostra. Como amostra "padrão" utilizamos o catalisador comercial da BASF PtSn/C com 20\% em massa de metais, sendo encontrado para este material um resíduo final de 19,4\% em massa o qual é bastante próximo do valor nominal. Os valores correspondentes à carga metálica para os eletrocatalisadores obtidos são mostrados na TAB. 2. 
TABELA 2 - Porcentagem em massa dos metais presentes nos eletrocatalisadores $\mathrm{Pt}(\mathrm{MRA})-\mathrm{Sn}(\mathrm{BH}) / \mathrm{C}$ preparados a partir do suporte $20 \% \mathrm{em}$ massa de Sn determinadas por TGA

\begin{tabular}{lccc}
\hline Eletrocatalisador & $\begin{array}{c}\text { \% Pt em massa } \\
\text { (nominal) }\end{array}$ & $\begin{array}{c}\text { \% em massa } \\
\text { metais (TGA) }\end{array}$ & $\begin{array}{c}\text { Diferença massa } \\
\text { entre } \\
\text { Pt-Sn/C e Sn/C }\end{array}$ \\
\hline Sn/C & - & 16,5 & - \\
Pt-Sn/C $(4,5)$ & 4,5 & 20,4 & 3,9 \\
Pt-Sn/C (8,6) & 8,6 & 25,1 & 8,6 \\
Pt-Sn/C (12,4) & 12,4 & 30,5 & 14,0 \\
\hline
\end{tabular}

Calculando as diferenças das massas de metais presentes nos eletrocatalisadores $\mathrm{Pt}(\mathrm{MRA})-\mathrm{Sn}(\mathrm{BH}) / \mathrm{C}$ e a massa de $\mathrm{Sn}$ presente no material suporte $(\mathrm{Sn} / \mathrm{C})$ verifica-se que os valores obtidos são bem próximos aos valores nominais de Pt. Dessa forma, como as perdas de Sn são semelhantes para os materiais de um mesmo grupo, pode-se supor que a maioria dos íons $\mathrm{Pt}(\mathrm{IV})$ foram reduzidos e depositados nos suportes de Sn/C, apesar de parte do Sn presente nos suportes $\mathrm{Sn}(\mathrm{RH}) / \mathrm{C}$ ser perdida durante a síntese destes materiais.

São mostrados, na FIG. 16, os difratogramas dos eletrocatalisadores $\operatorname{Pt}(\mathrm{MRA})-\mathrm{Sn}(\mathrm{BH}) / \mathrm{C}(10 \%$ em massa $\mathrm{Sn})$ preparados com diferentes razões atômicas Pt:Sn. Observa-se em todos os difratogramas um pico largo em aproximadamente $2 \theta=25^{\circ}$ o qual é associado ao suporte de carbono Vulcan XC72. Para o Sn/C (10\% em massa de Sn) sem adição da Pt o difratograma apresenta-se bastante similar ao do Vulcan XC-72 [73]. Para os materiais $\operatorname{Pt}(\mathrm{MRA})-\mathrm{Sn}(\mathrm{BH}) / \mathrm{C}$ observa-se quatro picos de difração em, aproximadamente, $2 \theta$ $=40^{\circ}, 47^{\circ}, 67^{\circ}$ e $82^{\circ}$ os quais são associados aos planos (111), (200), (220) e (311), respectivamente, da estrutura cúbica de face centrada (CFC) de platina e suas ligas [73]. Para o catalisador comercial PtSn/C BASF (Liga PtSn, razão atômica Pt:Sn 75:25) observa-se também os mesmos quatro picos, no entanto, estes encontram-se deslocados para ângulos menores mostrando a presença de liga PtSn neste material. As reflexões do plano (220) da estrutura cristalina da Pt 
(CFC) foram utilizadas para calcular o tamanho médio de cristalito através da equação de Scherrer e os valores foram de 2,5 nm para os eletrocatalisadores BASF e Pt-Sn/C com 8,6\% de Pt e de 2,0 nm para o eletrocatalisador Pt-Sn/C com $12,4 \%$ de Pt. Não foi possível calcular o tamanho médio de cristalito para o material Pt-Sn/C com 4,5\% de Pt, pois o pico usado no cálculo apresenta-se pouco definido, indicando um tamanho de cristalito menor que 2,0 nm [55].

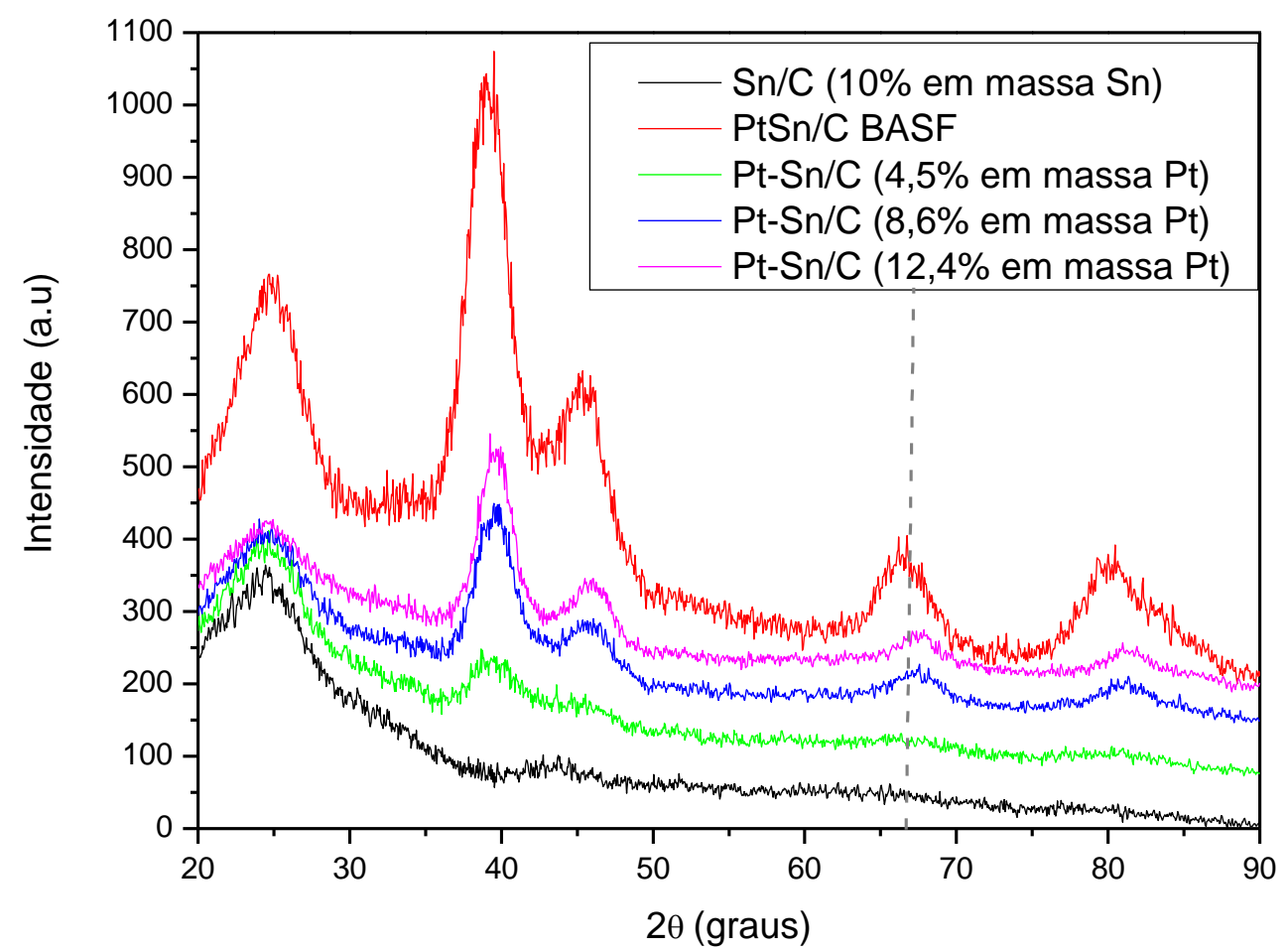

FIGURA 16 - Difratogramas de raios $X$ dos eletrocatalisadores PtSn/C BASF, $\mathrm{Pt}(\mathrm{MRA})-\mathrm{Sn}(\mathrm{BH}) / \mathrm{C}$ e o $\mathrm{Sn}(\mathrm{BH}) / \mathrm{C}$ com $10 \%$ em massa de $\mathrm{Sn}$

NA FIGURA 17 é mostrada a imagem obtida por microscopia eletrônica de transmissão do eletrocatalisador Pt(MRA)-Sn(BH)/C com 12,4\% de Pt preparado com suporte $\mathrm{Sn}(\mathrm{RH}) / \mathrm{C}$ com $10 \%$ em massa de Sn. Observa-se uma boa distribuição das nanopartículas sobre o suporte de carbono, pouquíssimos aglomerados e um tamanho médio de nanopartículas d,e aproximadamente, 3,4 $\pm 1,4 \mathrm{~nm}$. Vale ressaltar que os aglomerados de $\mathrm{Sn}$ não são mais vistos após a deposição da Pt no eletrocatalisador. 


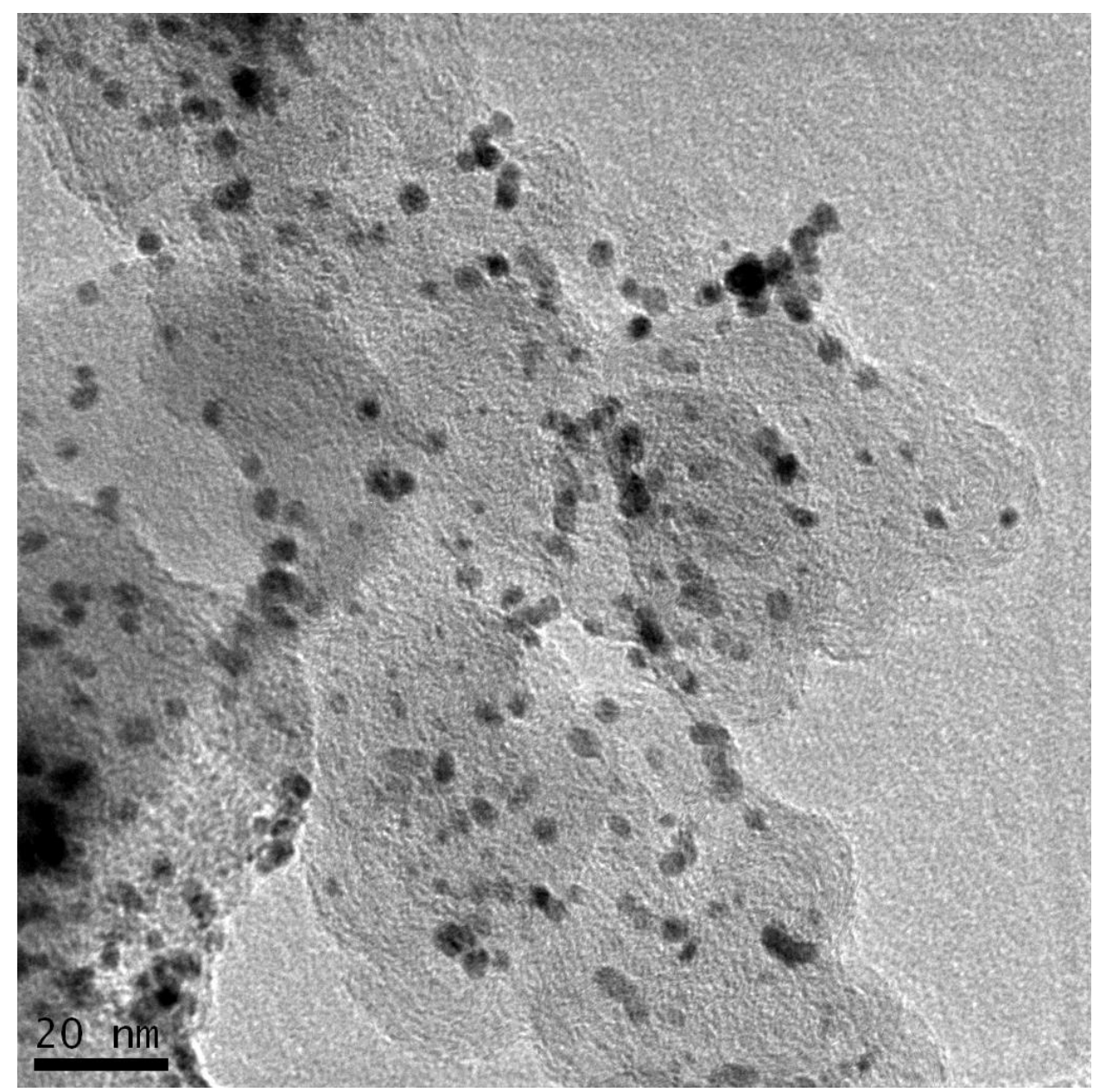

FIGURA 17 - Micrografia eletrônica de Transmissão do eletrocatalisador Pt(MRA)$\mathrm{Sn}(\mathrm{BH}) / \mathrm{C}(10 \%$ em massa Sn e $12,4 \%$ em massa de Pt)

$\mathrm{Na}$ FIGURA 18 são mostrados os voltamogramas cíclicos dos eletrocatalisadores em solução $0,5 \mathrm{~mol} \mathrm{~L}^{-1} \mathrm{de}_{2} \mathrm{SO}_{4}$. Observa-se para todos eletrocatalisadores a região de adsorção-dessorção de hidrogênio $(0,0-0,4 \mathrm{~V})$ pouco definida, a qual é característica de eletrocatalisadores bimetálicos contendo Pt [59]. Observa-se também um menor alargamento na região de dupla-camada $(0,4-0,8 \mathrm{~V})$ conforme a quantidade de Pt aumenta, ou seja, quanto menor a quantidade de $\mathrm{Sn}$, sendo este comportamento característico de catalisadores contendo menores quantidades de espécies oxigenadas na superfície do material [59]. 
FIGURA 18 - Voltamogramas cíclicos obtidos em solução $0,5 \mathrm{~mol}$ $\mathrm{L}^{-1}$ de $\mathrm{H}_{2} \mathrm{SO}_{4}$ para os eletrocatalisadores $\mathrm{Pt}(\mathrm{MRA})-\mathrm{Sn}(\mathrm{BH}) / \mathrm{C}$ (10\% em massa de $\mathrm{Sn}), \mathrm{PtSn} / \mathrm{C}$ BASF

Na FIG. 19 são apresentados os estudos de cronoamperometria em $50 \mathrm{mV}$ por $30 \mathrm{~min}$. Os resultados mostram que os eletrocatalisadores $\mathrm{Pt}(\mathrm{MRA})-\mathrm{Sn}(\mathrm{BH}) / \mathrm{C}$ preparados utilizando o suporte $\mathrm{Sn}(\mathrm{RH}) / \mathrm{C}$ com $10 \%$ de $\mathrm{Sn}$ e com 4,5 , 8,5 e 12,4\% em massa de Pt apresentaram um melhor desempenho (por grama de Pt) que o catalisador comercial PtSn/C BASF.

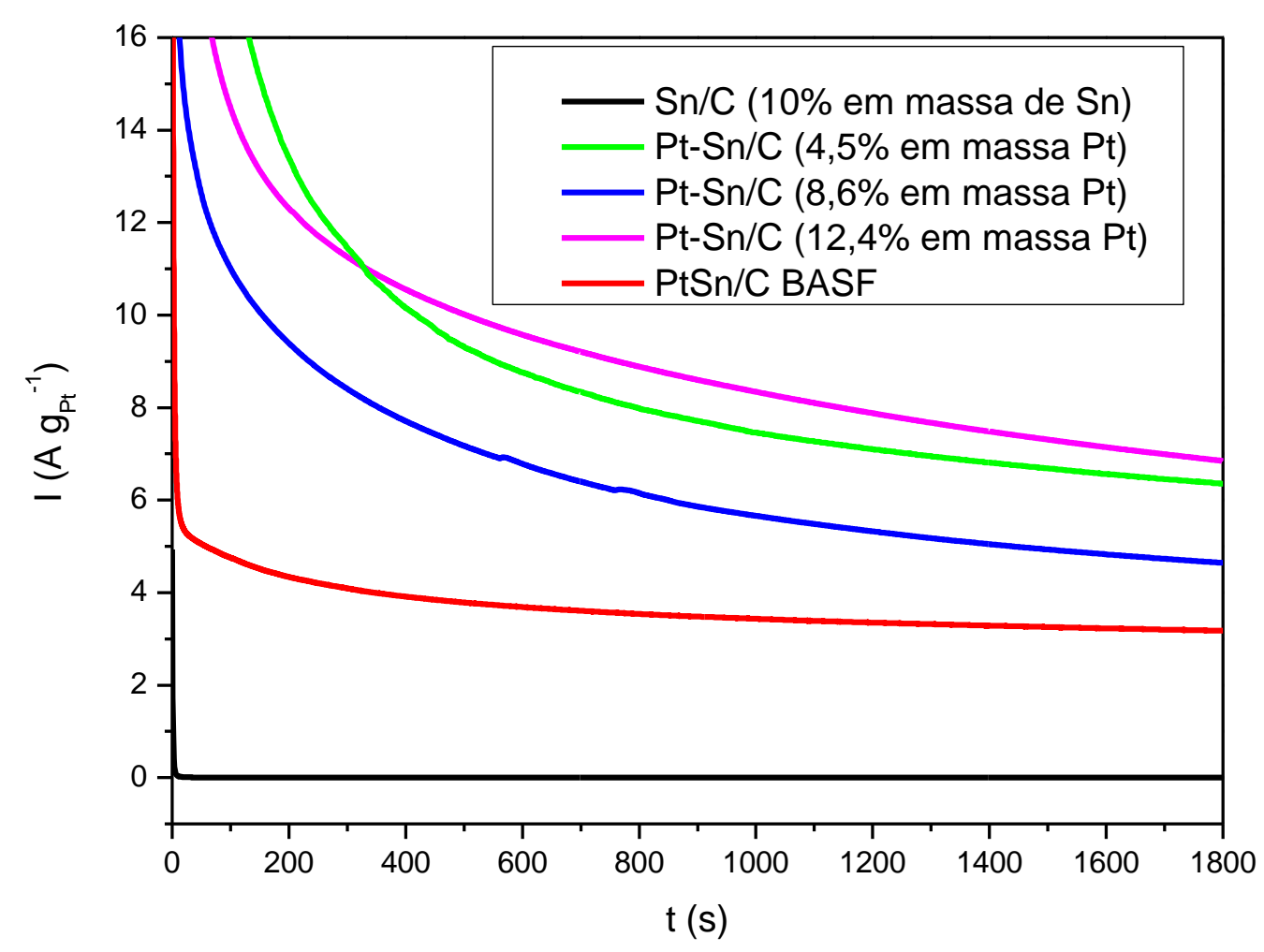

FIGURA 19 - Comparação das curvas cronoamperométricas, para os eletrocatalisadores PtSn/C BASF, Pt(MRA)-Sn(BH)/C e o suporte $\mathrm{Sn}(\mathrm{BH}) / \mathrm{C}$ com $10 \%$ em massa de $\mathrm{Sn}$ em $0.5 \mathrm{~mol} \mathrm{~L}^{-1} \mathrm{de}_{2} \mathrm{SO}_{4}$ contendo $1 \mathrm{~mol} \mathrm{~L}^{-1}$ de etanol e potencial fixo de $500 \mathrm{mV}$ por $30 \mathrm{~min}$ 
A FIGURA 20 apresenta os difratogramas dos eletrocatalisadores Pt(MRA)$\mathrm{Sn}(\mathrm{BH}) / \mathrm{C}(20 \%$ em massa de $\mathrm{Sn})$. Observa-se em todos os difratogramas um pico largo em aproximadamente $2 \theta=25^{\circ}$ o qual é associado ao suporte de carbono Vulcan XC-72. Para os materiais $\mathrm{Pt}(\mathrm{MRA})-\mathrm{Sn}(\mathrm{BH}) / \mathrm{C}$ observa-se os quatro picos de difração em aproximadamente $2 \theta=40^{\circ}, 47^{\circ}, 67^{\circ}$ e $82^{\circ}$ os quais são associados aos planos (111), (200), (220) e (311), respectivamente, da estrutura cúbica de face centrada (CFC) de platina e suas ligas [74]. Neste caso os picos da fase Sn metálico são claramente vistos no difratograma do Sn/C (20\% em massa Sn). No entanto, após a deposição da Pt neste material não se observa mais a presença desta fase nos difratogramas dos eletrocatalisadores $\mathrm{Pt}(\mathrm{MRA})-\mathrm{Sn}(\mathrm{BH}) / \mathrm{C}$ obtidos. Observa-se, no entanto, a presença de dois picos em, aproximadamente, $2 \theta=34$ e $52^{\circ}$, os quais são atribuídos à presença da fase $\mathrm{SnO}_{2}$ cassiterita [75]. Portanto, durante a etapa da deposição da Pt pelo método MRA, parte do Sn metálico é oxidado e redepositado na forma de $\mathrm{SnO}_{2}$. Portanto, por esta metodologia não foi possível depositar a Pt sobre o Sn metálico presente inicialmente no suporte Sn/C preparado pelo método $\mathrm{BH}$. 


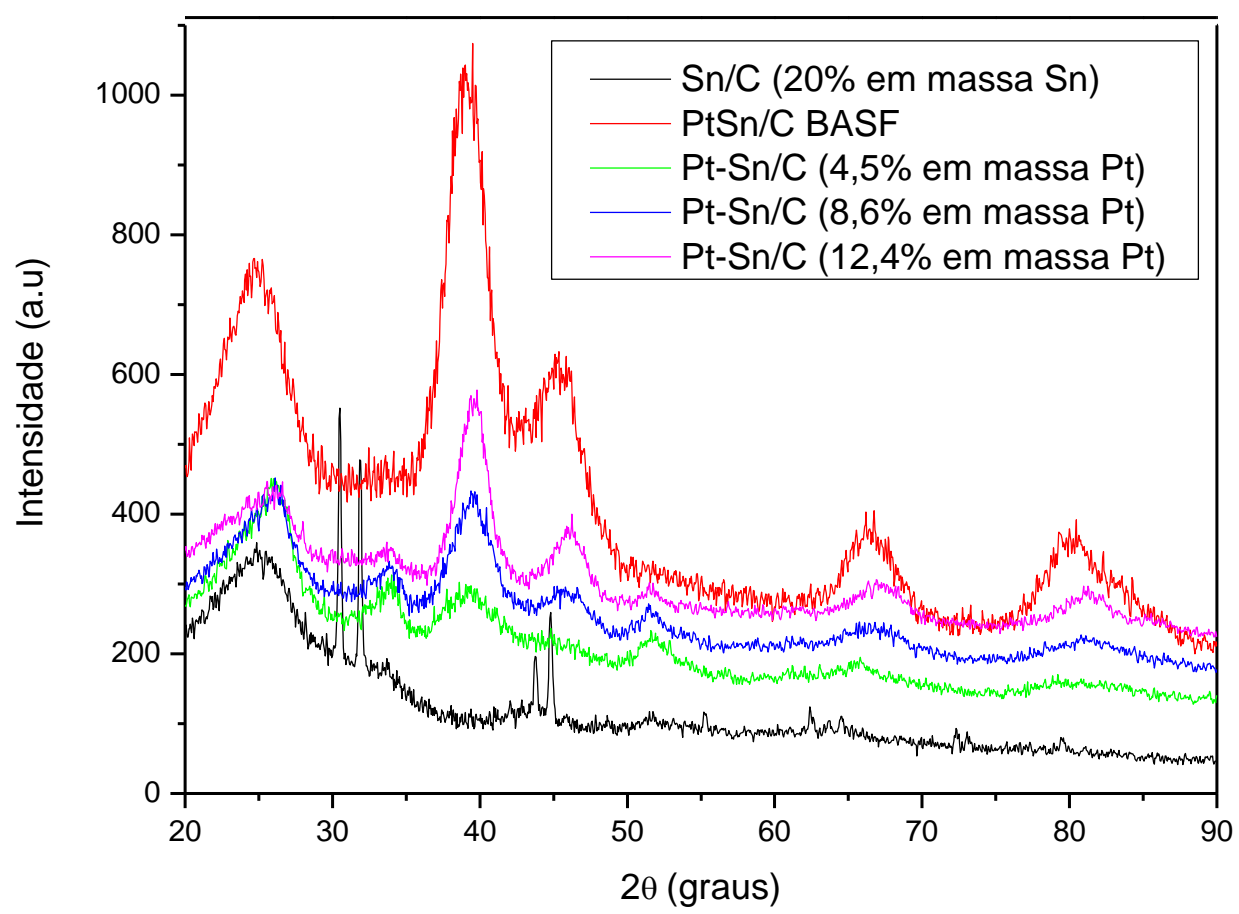

FIGURA 20 - Difratogramas de raios $X$ dos eletrocatalisadores PtSn/C BASF, $\mathrm{Pt}(\mathrm{MRA})-\mathrm{Sn}(\mathrm{BH}) / \mathrm{C}$ e o suporte $\mathrm{Sn}(\mathrm{BH}) / \mathrm{C}(20 \%$ massa de $\mathrm{Sn})$

A microscopia eletrônica de transmissão do eletrocatalisador Pt(MRA)$\mathrm{Sn}(\mathrm{BH}) / \mathrm{C}$ preparado utilizando o suporte $\mathrm{Sn}(\mathrm{BH}) / \mathrm{C}$ com $20 \%$ em massa de $\mathrm{Sn}$ e com 12,4\% em massa de Pt é mostrada na FIGURA 21. Observa-se uma boa distribuição das nanopartículas sobre o suporte de carbono e o tamanho médio das nanopartículas de 4,6 $\pm 2,0 \mathrm{~nm}$. Mais uma vez os aglomerados de $\mathrm{Sn}$ metálico não foram observados após a deposição da $\mathrm{Pt}$, sugerindo sua oxidação e redeposição na forma $\mathrm{SnO}_{2}$, como mostram os difratogramas de raios $\mathrm{X}$. 


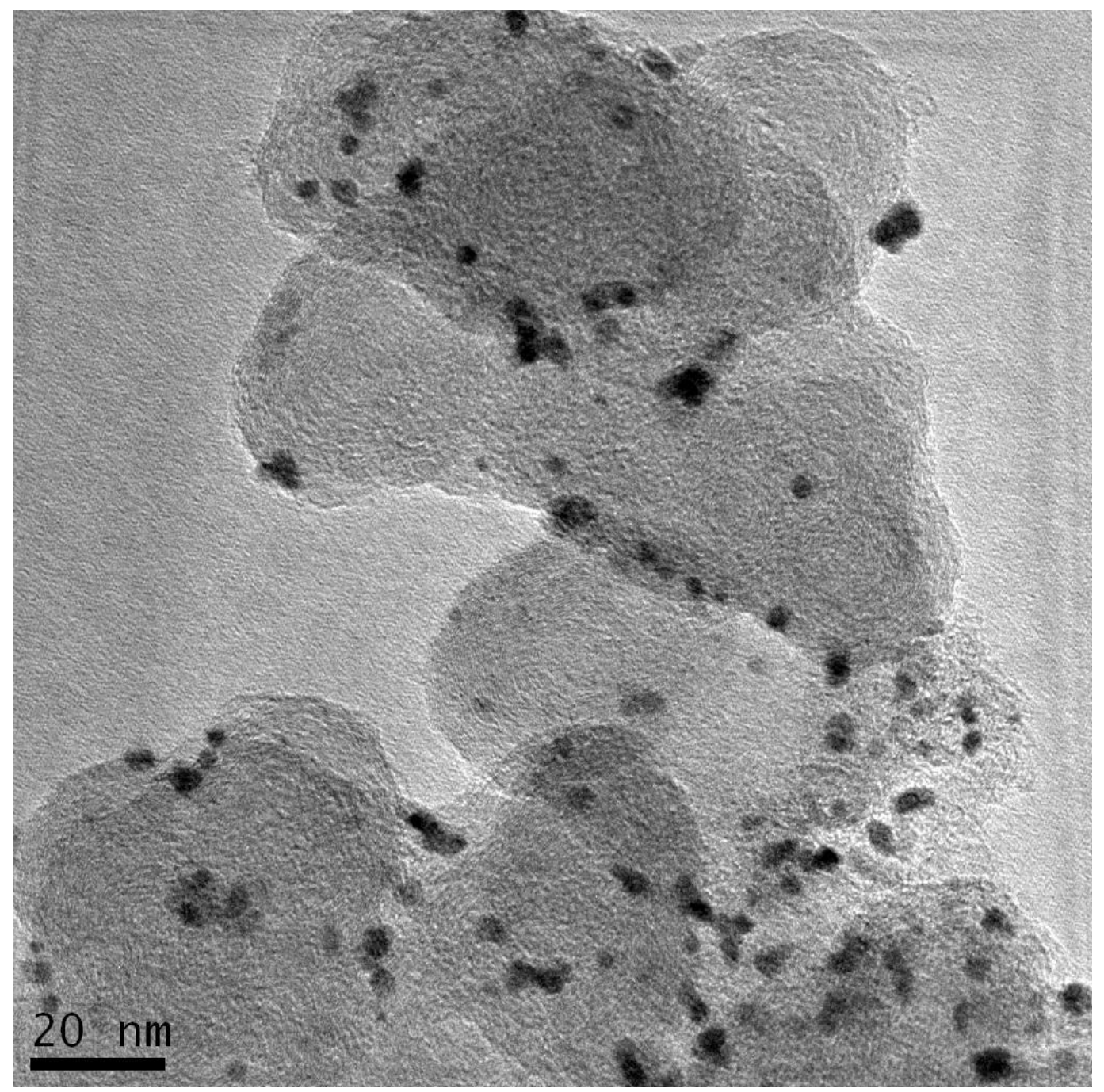

FIGURA 21 - Micrografia eletrônica de Transmissão do eletrocatalisador Pt-Sn/C (20\% em massa Sn e $12,4 \%$ em massa de Pt)

$\mathrm{Na}$ FIGURA 22 são apresentados os voltamogramas cíclicos dos eletrocatalisadores em solução $0,5 \mathrm{~mol} \mathrm{~L}^{-1} \mathrm{de}_{2} \mathrm{SO}_{4}$. Observa-se, para todos os eletrocatalisadores, a região de adsorção-desorção de hidrogênio $(0,0-0,4 \mathrm{~V})$ pouco definida a qual é característica de eletrocatalisadores bimetálicos contendo $\mathrm{Pt}$ [59]. Conforme a quantidade de Pt aumenta observa-se um menor alargamento na região de dupla-camada $(0,4-0,8 \mathrm{~V})$ o que é característico de catalisadores contendo menores quantidades de espécies contendo oxigênio na superfície do material [59]. 


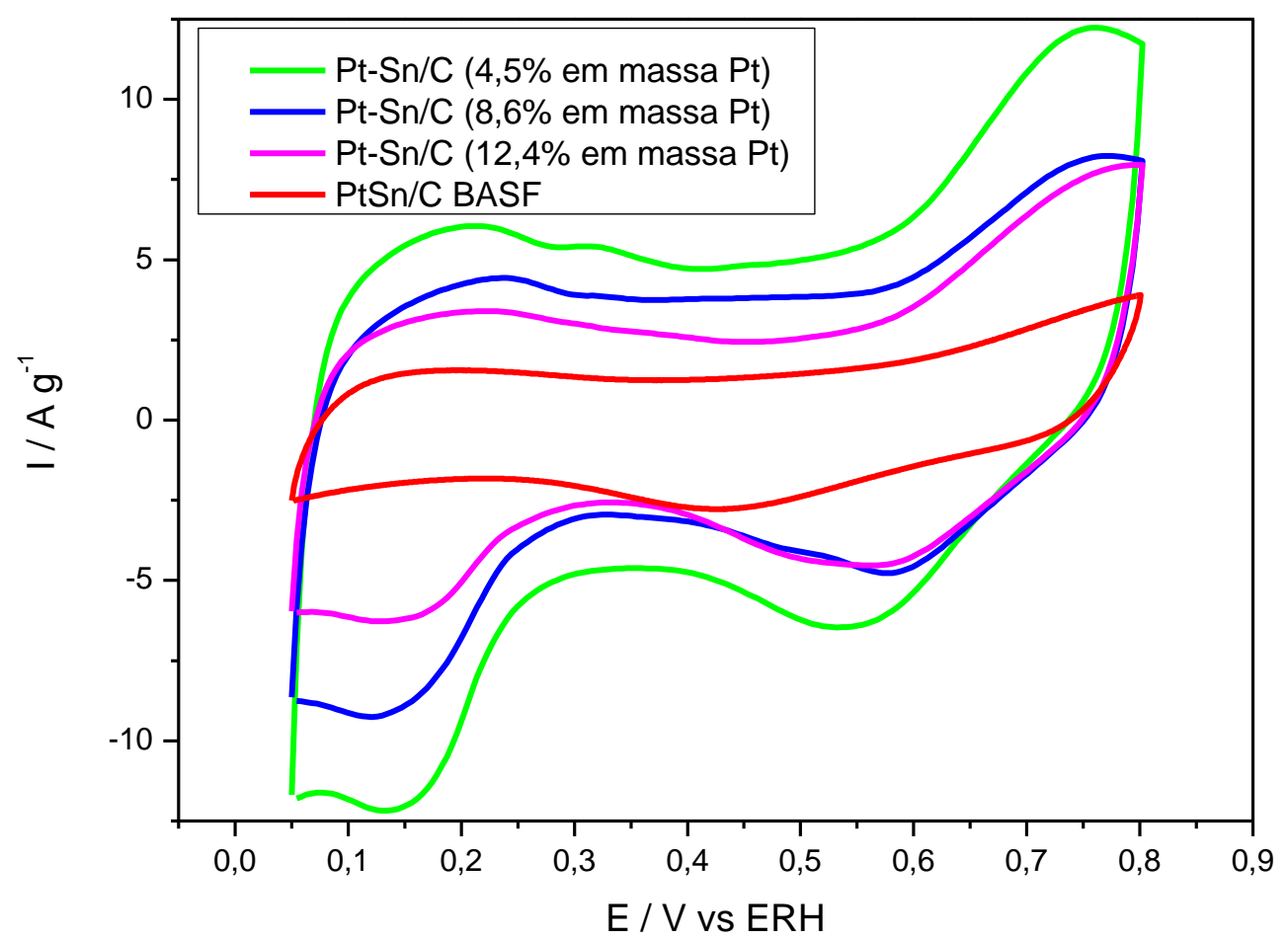

FIGURA 22 - Voltamogramas cíclicos obtidos em solução $0,5 \mathrm{~mol} \mathrm{~L}^{-1}$ de $\mathrm{H}_{2} \mathrm{SO}_{4}$ para os eletrocatalisadores $\mathrm{PtSn} / \mathrm{C}$ BASF e Pt(MRA)-Sn(BH)/C com $20 \%$ em massa de $\mathrm{Sn}$

Na FIGURA 23 são apresentadas as curvas cronoamperométricas para os eletrocatalisadores PtSn/C BASF e Pt(MRA)-Sn(BH)/C com 20\% em massa de Sn, e com 4,5, 8,6 e 12,4\% em massa de Pt. Novamente todos os eletrocatalisadores preparados também demonstraram um melhor desempenho quando comparados ao catalisador comercial PtSn/C BASF. 


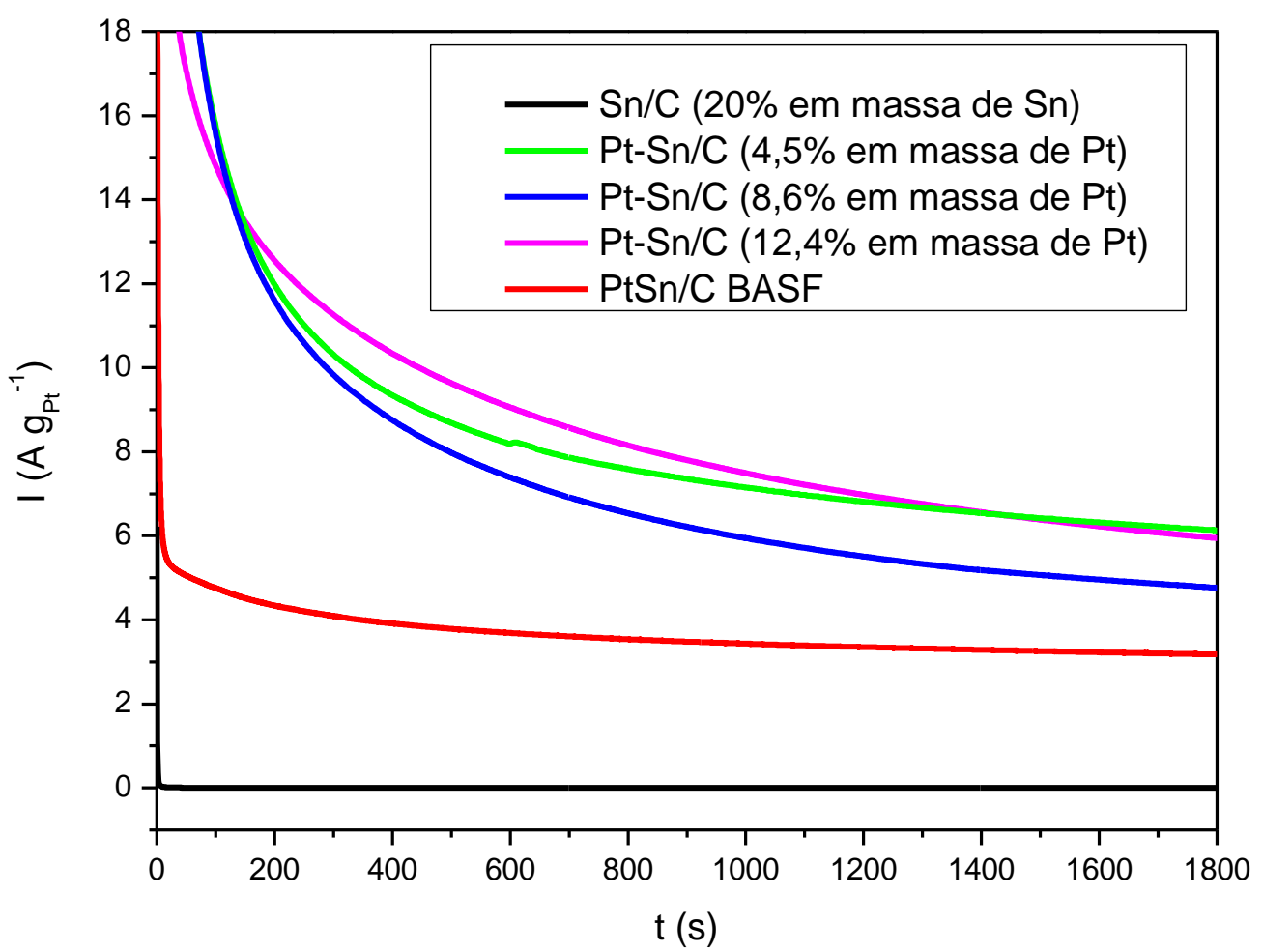

FIGURA 23 - Comparação das curvas cronoamperométricas para os eletrocatalisadores PtSn/C BASF e Pt(MRA)-Sn(BH)/C com 20\% em massa de Sn em etanol $1,0 \mathrm{~mol} \mathrm{~L}^{-1}$ e potencial fixo de $500 \mathrm{mV}$ por $30 \mathrm{~min}$.

$\mathrm{Na}$ FIGURA 24 são apresentadas as comparações das curvas cronoamperometricas para os eletrocatalisadores $\mathrm{Pt}(\mathrm{MRA})-\mathrm{Sn}(\mathrm{BH}) / \mathrm{C}$ preparados com 10, 20, 40,60\% em massa de Sn e com massa de Pt igual a 12,4\%. Os eletrocatalisadores preparados com 10 e $20 \%$ em massa de Sn apresentaram atividades semelhantes entre si e superiores aos eletrocatalisadores preparados com 40 e $60 \%$ em massa de Sn. Pode-se observar que quanto maior o teor de Sn, menor a atividade apresentada. Assim, estes resultados sugerem que uma carga de metal não nobre na faixa de 10 a $20 \%$ em massa parece ser a mais adequada nas condições estudadas. 


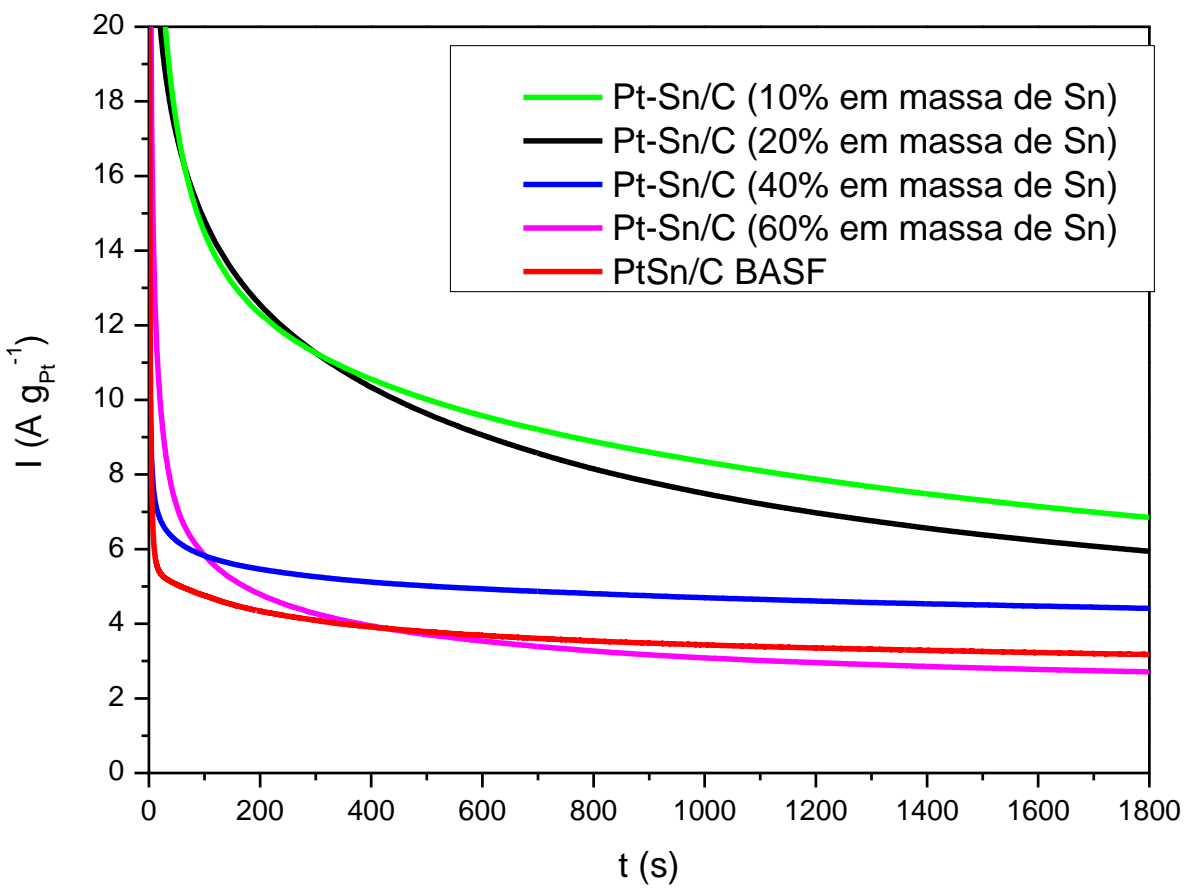

FIGURA 24 - Comparação das curvas cronoamperométricas dos eletrocatalisadores $\mathrm{Pt}-\mathrm{Sn} / \mathrm{C}$ preparados com diferentes \% em massa de $\mathrm{Sn}$ em etanol $1,0 \mathrm{~mol} \mathrm{~L}^{-1}$ e potencial fixo de $500 \mathrm{mV}$ por $30 \mathrm{~min}$

Os eletrocatalisadores $\mathrm{Pt}(\mathrm{MRA})-\mathrm{Sn}(\mathrm{BH}) / \mathrm{C}$ preparados com o suporte contendo $10 \%$ em massa de Sn e com diferentes quantidades de Pt foram avaliados na oxidação eletroquímica do monóxido do carbono (CO stripping). Esta análise pode fornecer informações interessantes a respeito da superfície do material. Os gráficos de corrente versus potencial são mostrados na FIGURA 25. Como pode ser observado no CO stripping de todos os eletrocatalisadores, a região de hidrogênio é fortemente suprimida, refletindo o bloqueio dos sítios de $\mathrm{Pt}$ devido à adsorção do $\mathrm{CO}$ [76]. Para todos os eletrocatalisadores Pt(MRA)$\mathrm{Sn}(\mathrm{BH}) / \mathrm{C}$, o início da oxidação do $\mathrm{CO}$ deu-se em, aproximadamente, 0,3 V. Para o eletrocatalisador comercial PtSn/C BASF a oxidação inicia-se em cerca de $0,25 \mathrm{~V}$, mostrando que a presença do Sn promove a oxidação eletroquímica do $\mathrm{CO}$ a potenciais mais baixos que o eletrocatalisador $\mathrm{Pt} / \mathrm{C}$ que, segundo a literatura, promove a oxidação eletroquímica do $\mathrm{CO}$ somente acima de $0,65 \vee[76]$. É também conhecido que a oxidação eletroquímica do $\mathrm{CO}$ por eletrocatalisadores 
PtSn ocorre segundo o mecanismo bifuncional no qual o $\mathrm{CO}$ adsorve nos sítios de $\mathrm{Pt}$, enquanto que, os sítios de $\mathrm{Sn}$ adsorvem espécies $\mathrm{OH}$ a potenciais mais baixos que o da Pt $[49,52,77]$

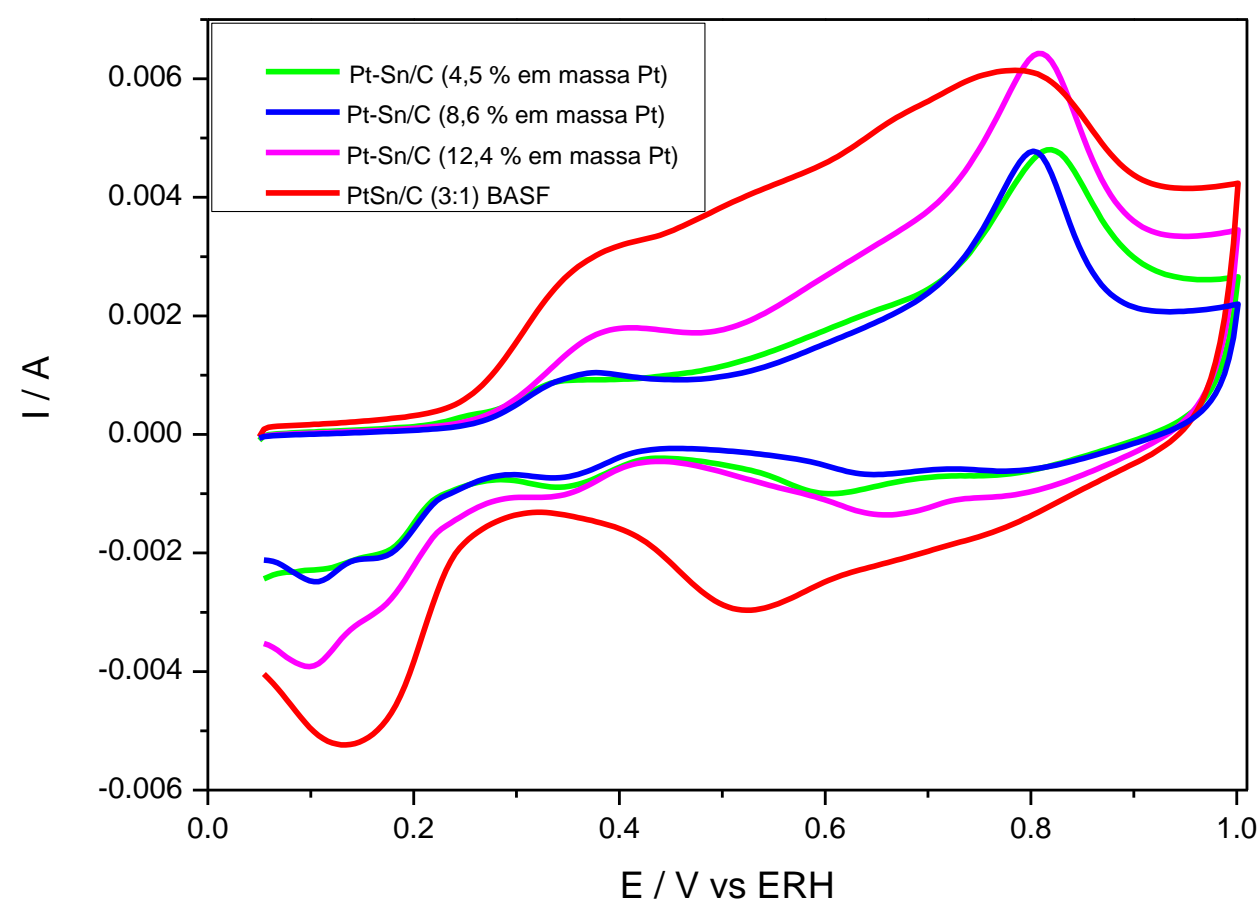

FIGURA 25 - Oxidação eletroquímica do $\mathrm{CO}$ (CO stripping) nos eletrocatalisadores $\mathrm{Pt}(\mathrm{MRA})-\mathrm{Sn}(\mathrm{BH}) / \mathrm{C}$ preparados no suporte $\mathrm{Sn} / \mathrm{C}$ com $10 \%$ em massa de $\mathrm{Sn}$

A análise dos resultados da preparação dos eletrocatalisadores Pt(MRA)$\mathrm{Sn}(\mathrm{BH}) / \mathrm{C}$ sugerem que durante a etapa de deposição da Pt ocorre a oxidação do $\mathrm{Sn}$ metálico, o qual pelo menos em parte é transformado em $\mathrm{SnO}_{2}$ (ver Fig. $20-$ DRX) e redeposita sobre o catalisador. Dessa forma, o material obtido contém a presença das fases $\mathrm{Pt}(\mathrm{fcc})$ e $\mathrm{SnO}_{2}$ com boa distribuição sobre o suporte de carbono. Assim, quando se utiliza estas metodologias e formas de preparação, os resultados sugerem que não ocorre a deposição de camadas de Pt sobre o Sn metálico presente no suporte $\mathrm{Sn}(\mathrm{BH}) / \mathrm{C}$. 


\subsubsection{Deposição de Pt pelo método $\mathrm{BH}$ nos suportes Sn/C obtidos pelo método $\mathrm{BH}$}

Nesta etapa foi realizada a deposição da Pt utilizando o método $\mathrm{BH}$ sobre os suportes Sn/C também preparados pelo método BH. Conforme comentado anteriormente, os materiais preparados usando suportes Sn/C com teor de estanho entre 10 e $20 \%$ foram os que apresentaram os melhores resultados e, por isso, utilizaram-se estes teores nesta etapa. Os resultados de razão atômica obtidos por EDX dos eletrocatalisadores obtidos são mostrados na TABELA 3.

TABELA 3 - Razão atômica Pt:Sn nominal e a determinada por EDX dos eletrocatalisadores $\mathrm{Pt}(\mathrm{BH})-\mathrm{Sn}(\mathrm{BH}) / \mathrm{C}$, com 10 e 20\% em massa de Sn e com diferentes razões atômicas de $\mathrm{Pt}$

\begin{tabular}{cccc}
\hline $\begin{array}{c}\text { Sn/C (\% em } \\
\text { massa) }\end{array}$ & Pt (\% em massa) & $\begin{array}{c}\text { Razão atômica } \\
\text { Pt:Sn (nominal) }\end{array}$ & $\begin{array}{c}\text { Razão atômica } \\
\text { Pt:Sn (EDX) }\end{array}$ \\
\hline 10 & 4,5 & $22: 78$ & $56: 44$ \\
10 & 8,6 & $36: 64$ & $80: 20$ \\
10 & 12,4 & $45: 55$ & $84: 16$ \\
20 & 4,5 & $12: 88$ & $30: 70$ \\
20 & 8,6 & $22: 78$ & $44: 56$ \\
20 & 12,4 & $30: 70$ & $52: 48$ \\
\hline
\end{tabular}

Os resultados das razões atômicas Pt:Sn obtidos por EDX mostram também um enriquecimento do material em Pt e a perda de parte do Sn como observado para a deposição pelo método MRA TABELA 3. Além disso, as razões atômicas Pt:Sn obtidas por EDX para os eletrocatalisadores, seja pela deposição da Pt pelo método MRA ou $\mathrm{BH}$, também são bastante semelhantes, sugerindo que mecanismos semelhantes de perda do Sn estão ocorrendo independente do agente redutor utilizado e das condições de síntese utilizadas.

Os difratogramas dos eletrocatalisadores $\mathrm{Pt}(\mathrm{BH})-\mathrm{Sn}(\mathrm{BH}) / \mathrm{C}$ (usando 0 suporte $\mathrm{Sn}(\mathrm{BH}) / \mathrm{C}$ com 10\% em massa $\mathrm{Sn}$ ) preparados com diferentes razões atômicas Pt:Sn são mostrados na FIGURA 26. 


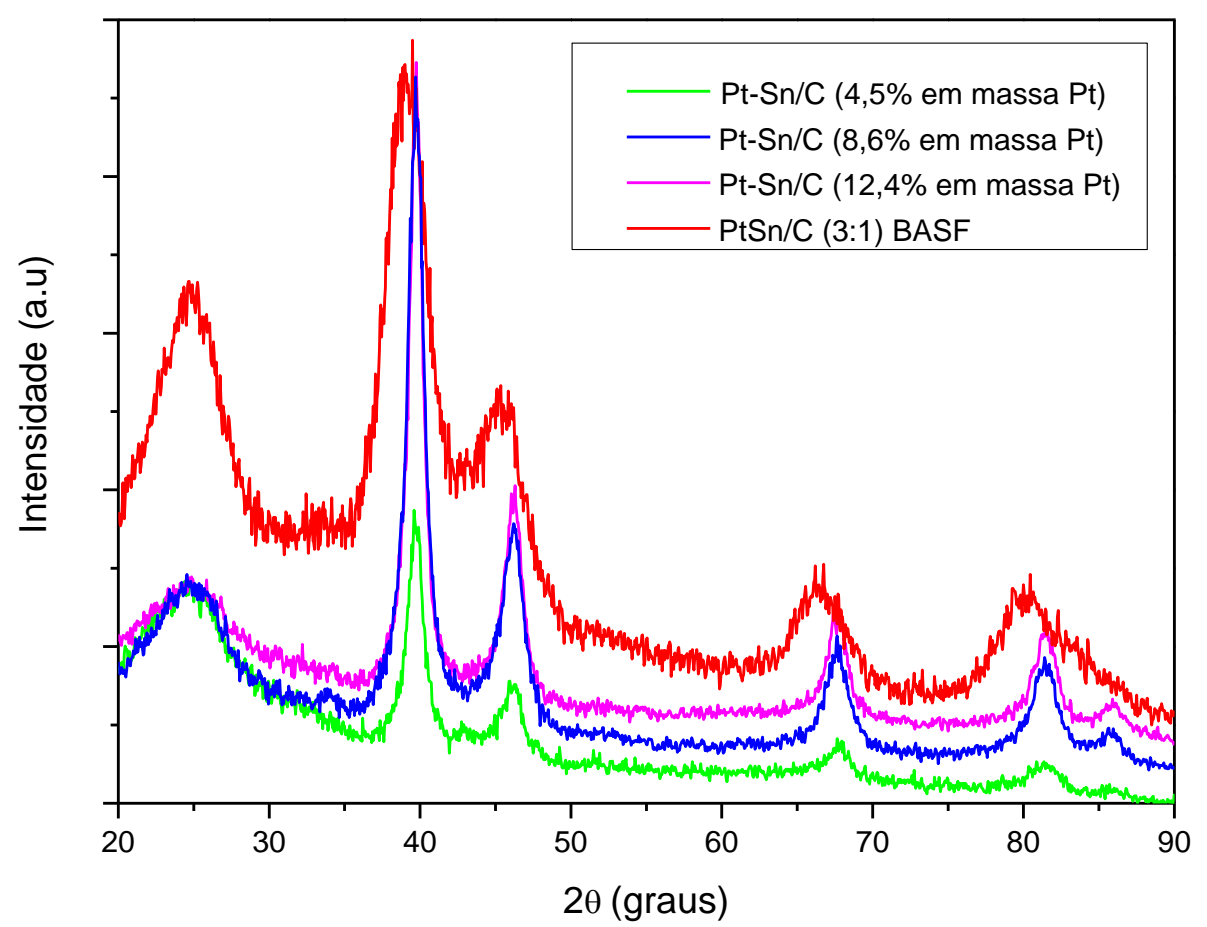

FIGURA 26 - Difratogramas de raios $\mathrm{X}$ dos eletrocatalisadores $\mathrm{Pt}(\mathrm{BH})-\mathrm{Sn}(\mathrm{BH}) / \mathrm{C}$ preparados com suporte $\mathrm{Sn} / \mathrm{C}$ com $10 \%$ em massa

Observa-se em todos os difratogramas um pico largo em, aproximadamente, $2 \theta=25^{\circ}$ o qual é associado ao suporte de carbono Vulcan XC72. Para os materiais $P t-S n / C$ observa-se os quatro picos de difração em aproximadamente $2 \theta=40^{\circ}, 47^{\circ}, 67^{\circ}$ e $82^{\circ}$ os quais são associados aos planos (111), (200), (220) e (311), respectivamente, da estrutura cúbica de face centrada (CFC) de platina e suas ligas [33]. As reflexões do plano (220) da estrutura cristalina da Pt (CFC) foram utilizadas para calcular o tamanho médio de cristalito através da equação de Scherrer e os valores encontrados foram de aproximadamente 5 .

Os difratogramas dos eletrocatalisadores $\mathrm{Pt}(\mathrm{BH})-\mathrm{Sn}(\mathrm{BH}) / \mathrm{C}$ (usando suporte com 20\% em massa Sn) preparados com diferentes razões atômicas Pt:Sn são mostrados na FIGURA 27. Para as amostras preparadas a partir do suporte $20 \%$ $\mathrm{Sn} / \mathrm{C}$, observa-se também os picos associados à fase $\mathrm{Pt}(\mathrm{fcc})$, no entanto, observa- 
se que a fase Sn metálico permanece após a deposição da Pt, ao contrário do observado quando a deposição Pt é realizada pelo método MRA.

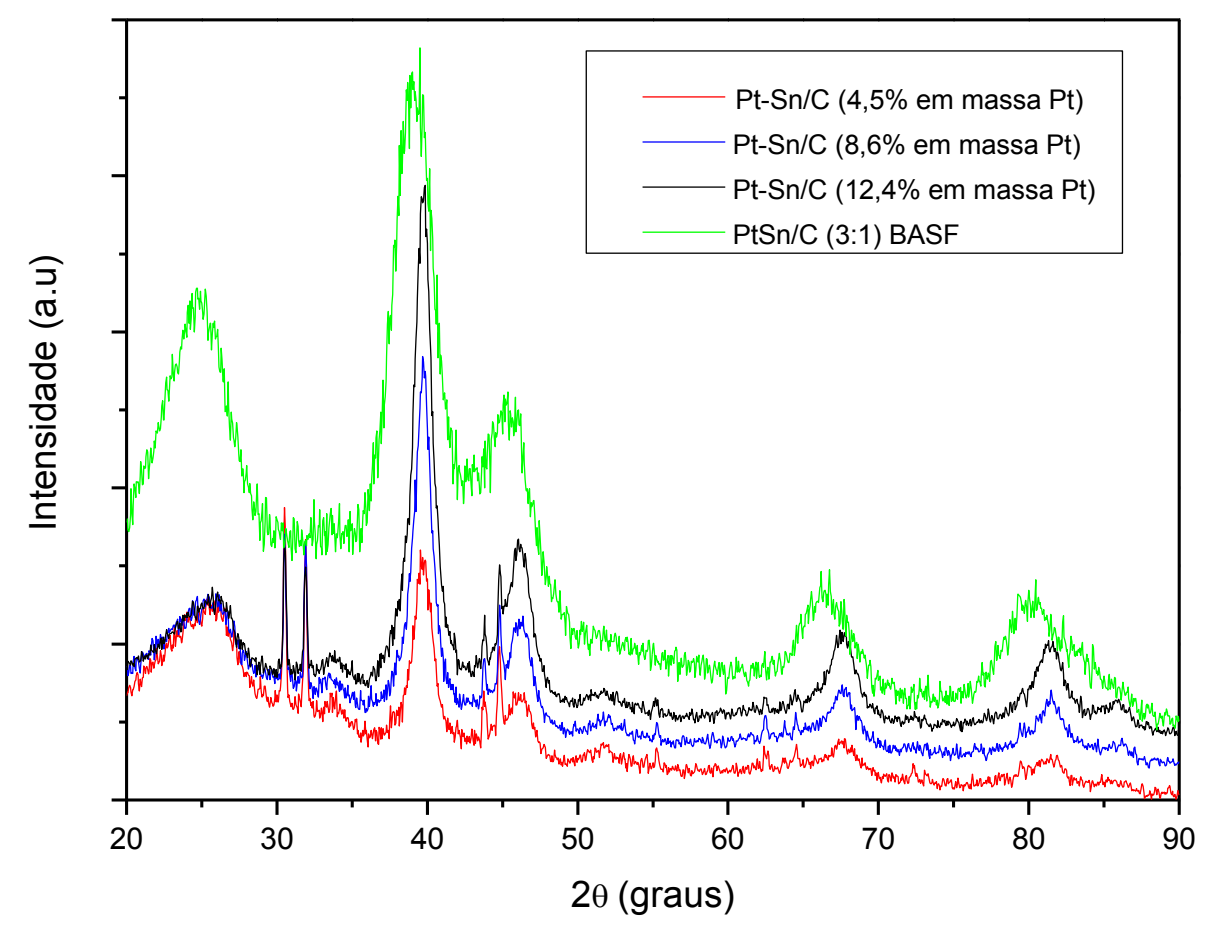

FIGURA 27 - Difratogramas de raios X dos eletrocatalisadores $\mathrm{Pt}(\mathrm{BH})-\mathrm{Sn}(\mathrm{BH}) / \mathrm{C}$ preparados com suporte $\mathrm{Sn} / \mathrm{C}$ com $20 \%$ em massa

As microscopias eletrônica de transmissão do eletrocatalisador $\operatorname{Pt}(\mathrm{BH})$ $\mathrm{Sn}(\mathrm{BH}) / \mathrm{C}$ preparado usando o suporte $\mathrm{Sn} / \mathrm{C}$ (com 10\% em massa de $\mathrm{Sn}$ ) e com 12,4\% em massa de Pt são mostradas na FIGURA 28.

As análises das micrografias de transmissão do eletrocatalisador $\operatorname{Pt}(\mathrm{BH})$ $\mathrm{Sn}(\mathrm{BH}) / \mathrm{C}$ apresentam-se bem diferentes das imagens do eletrocatalisador $\operatorname{Pt}(\mathrm{MRA})-\mathrm{Sn}(\mathrm{BH}) / \mathrm{C}$ (FIGURA 28). No caso dos eletrocatalisadores Pt(MRA)$\mathrm{Sn}(\mathrm{BH}) / \mathrm{C}$, as nanopartículas apresentaram-se bem dispersas sobre o suporte e apresentam um tamanho na faixa 3 a $5 \mathrm{~nm}$. Além disso, como mostrado, não se observa a presença dos aglomerados da fase Sn metálico, a qual também não era mais observada nos difratogramas de raios-X (FIG. 27). Pode-se verificar na micrografia do eletrocatalisador $\mathrm{Pt}(\mathrm{BH})-\mathrm{Sn}(\mathrm{BH}) / \mathrm{C}$ que as nanopartículas de $\mathrm{Pt}$ encontram-se aglomeradas, além da presença de um grande aglomerado, 
provavelmente, do Sn metálico recoberto por partículas menores de Pt FIG. 28 B. $\mathrm{Na}$ FIGURA 28 B verifica-se também que as nanopartículas formadas apresentam tamanhos de, aproximadamente, $15 \mathrm{~nm}$, ou seja, maiores que as observadas para os materiais $\mathrm{Pt}(\mathrm{MRA})-\mathrm{Sn}(\mathrm{BH}) / \mathrm{C}$. Assim, as imagens mostram que, neste caso, a deposição de Pt parece ocorrer preferencialmente sobre a fase Sn metálico, a qual permanece no material após a deposição da $\mathrm{Pt}$, como pode ser visto nos difratogramas de raios-X FIGURA 27 após a deposição da Pt.

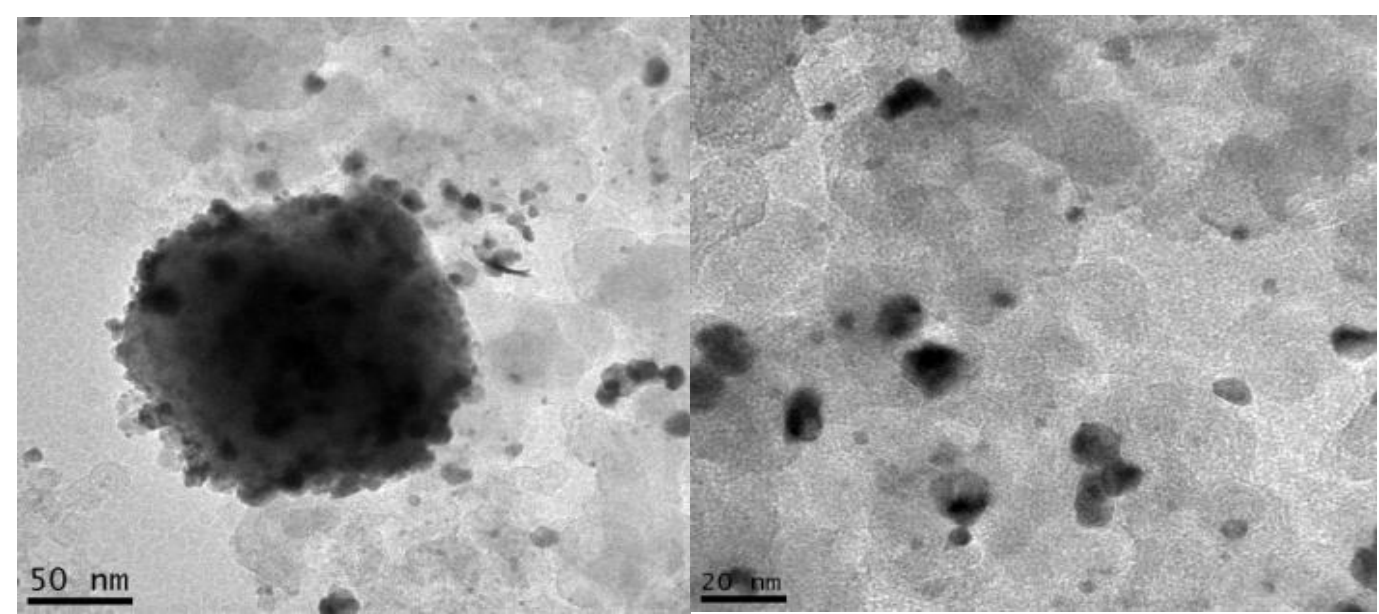

FIGURA 28 - Micrografias eletrônica de Transmissão do eletrocatalisador $\mathrm{Pt}(\mathrm{BH})$ $\mathrm{Sn}(\mathrm{BH}) / \mathrm{C}(10 \%$ em massa Sn e $12,4 \%$ em massa de Pt)

Os voltamogramas cíclicos dos eletrocatalisadores $\mathrm{Pt}(\mathrm{BH})-\mathrm{Sn}(\mathrm{BH}) / \mathrm{C}$, preparados com suportes $\mathrm{Sn} / \mathrm{C}$ contendo $20 \%$ de massa de $\mathrm{Sn}$, em solução 0,5 mol.L ${ }^{-1}$ de $\mathrm{H}_{2} \mathrm{SO}_{4}$ são mostrados na FIGURA 29 


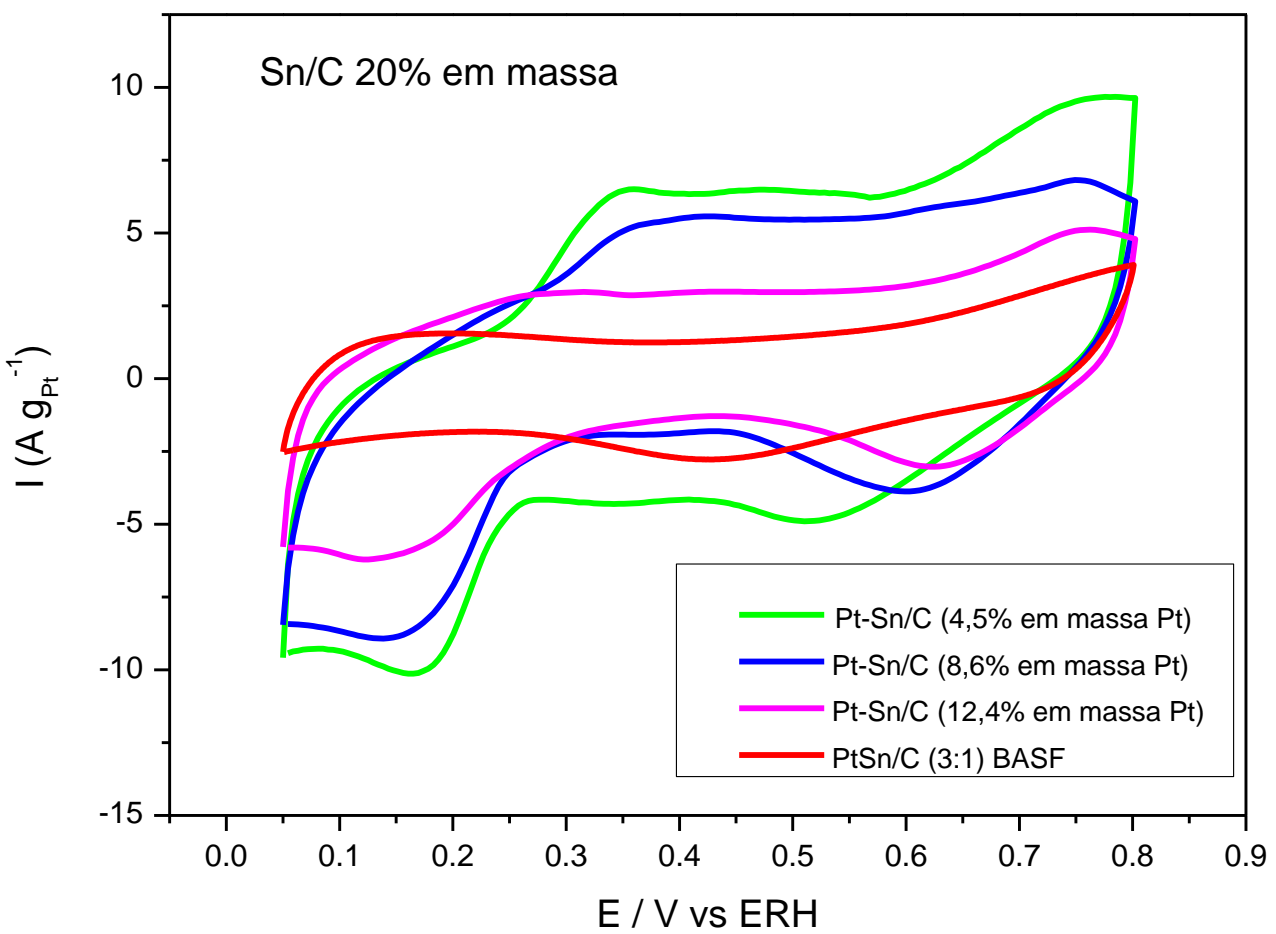

FIGURA 29 - Voltamogramas cíclicos obtidos em solução $0,5 \mathrm{~mol} \mathrm{~L}^{-1}$ de $\mathrm{H}_{2} \mathrm{SO}_{4}$ para os eletrocatalisadores $\mathrm{PtSn} / \mathrm{C}$ BASF e $\mathrm{Pt}(\mathrm{BH})-\mathrm{Sn}(\mathrm{BH}) / \mathrm{C}$ com $20 \%$ em massa de Sn

Observa-se, para todos eletrocatalisadores, a região de adsorção-desorção de hidrogênio $(0,0-0,4 \mathrm{~V})$ pouco definida, a qual é característica de eletrocatalisadores bimetálicos contendo Pt [59]. Observa-se também um menor alargamento na região de dupla-camada $(0,4-0,8 \mathrm{~V})$ conforme a quantidade de Pt aumenta, sendo este comportamento característico de catalisadores contendo menores quantidades de espécies oxigenadas na superfície do material [59]. Por outro lado, o perfil voltamétrico dos eletrocatalisadores $\mathrm{Pt}(\mathrm{BH})-\mathrm{Sn}(\mathrm{BH}) / \mathrm{C}$ apresentam-se diferentes dos obtidos para os eletrocatalisadores $\operatorname{Pt}(\mathrm{MRA})$ $\mathrm{Sn}(\mathrm{BH}) / \mathrm{C}$ FIGURA 29 sugerindo superfícies diferentes para os diferentes catalisadores. 

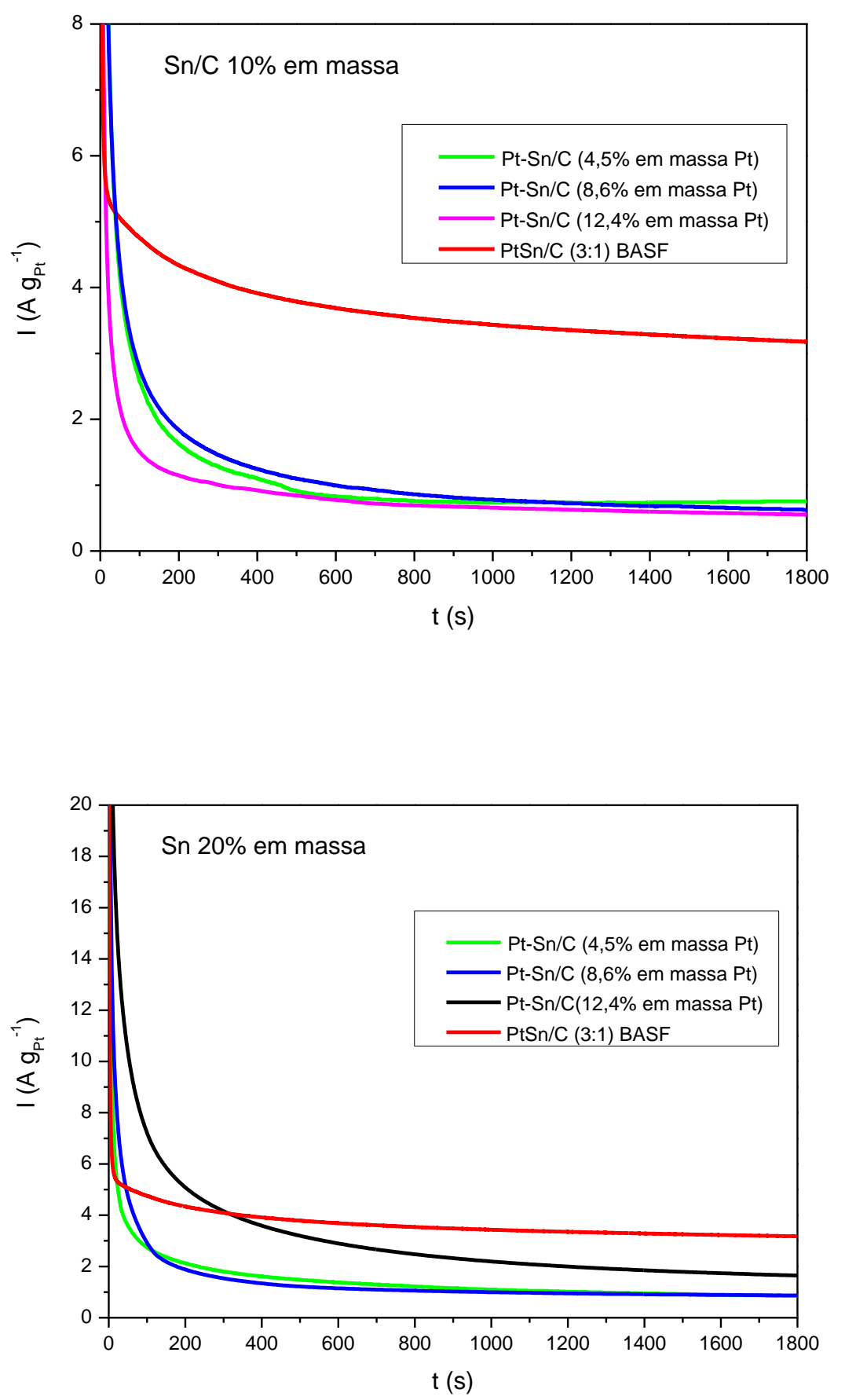

FIGURA 30 - Comparação das curvas cronoamperométricas dos eletrocatalisadores $\mathrm{Pt}(\mathrm{BH})-\mathrm{Sn}(\mathrm{BH}) / \mathrm{C}$ preparados com diferentes \% em massa de Sn em etanol $1,0 \mathrm{~mol} \mathrm{~L}^{-1}$ e potencial fixo de $500 \mathrm{mV}$ por $30 \mathrm{~min}$, a) $\mathrm{Sn} / \mathrm{C} 10 \%$ em massa e b) $\mathrm{Sn} / \mathrm{C} 20 \%$ em massa 
Os estudos de cronoamperometria em $500 \mathrm{mV}$ por $30 \mathrm{~min}$ dos eletrocatalisadores $\mathrm{Pt}(\mathrm{BH})-\mathrm{Sn}(\mathrm{BH}) / \mathrm{C}$ são mostrados na FIG. 30. Os resultados mostraram que para os eletrocatalisadores $\mathrm{Pt}(\mathrm{BH})-\mathrm{Sn}(\mathrm{BH}) / \mathrm{C}$ preparados a partir dos suportes com 10 e $20 \%$ em massa de Sn apresentaram um desempenho (por grama de Pt) inferior ao do catalisador comercial PtSn/C BASF; ao contrário do observado para os eletrocatalisadores Pt(MRA)-Sn(BH)/C.

Os eletrocatalisadores $\mathrm{Pt}(\mathrm{BH})-\mathrm{Sn}(\mathrm{BH}) / \mathrm{C}$ FIG 30 preparados com os suportes contendo 10 e $20 \%$ em massa de Sn e com diferentes quantidades de Pt foram avaliados na oxidação eletroquímica do monóxido do carbono ( $C O$ stripping). Os gráficos de corrente versus potencial são mostrados na FIG. 31. Como pode ser observado no CO stripping, de todos os eletrocatalisadores apresentam a região de hidrogênio fortemente suprimida, refletindo o bloqueio dos sítios de Pt devido a adsorção do CO [76]. Para os eletrocatalisadores PtSn/C a oxidação do CO inicia-se em cerca de $0,25 \mathrm{~V}$, mostrando que a presença do $\mathrm{Sn}$ promove a oxidação eletroquímica do $\mathrm{CO}$ a mais baixos potenciais que o eletrocatalisador $\mathrm{Pt} / \mathrm{C}$ o qual, segundo a literatura, promove a oxidação eletroquímica do $\mathrm{CO}$ somente acima de 0,65 V [76]. Eletrocatalisadores $\mathrm{Pt}(\mathrm{BH})$ $\mathrm{Sn}(\mathrm{BH}) / \mathrm{C}$ preparados utilizando os suportes $\mathrm{Sn} / \mathrm{C}$ com 10 e $20 \%$ em massa apresentaram resultados semelhantes. Os catalisadores preparados com 4,5\% em massa de $\mathrm{Pt}$ apresentaram na região entre $0,25 \mathrm{~V}$ e 0,60 $\mathrm{V}$ relativamente pronunciada em relação aos materiais preparados com 8,6 e 12,4\% em massa de Pt. Isto se deve, provavelmente, à presença de uma maior quantidade de espécies de $\mathrm{Sn}$ na superfície do catalisador, as quais facilitam a oxidação do $\mathrm{CO}$ a baixos potenciais. À medida que a quantidade de Pt é aumentada nos catalisadores, no caso dos materiais com 8,6 e 12,4\% de Pt, observa-se uma redução das áreas nesta região, sugerindo que os sítios de Sn estão sendo recobertos pelos átomos de $\mathrm{Pt}$ tornando a superfície mais rica nesta espécie. Assim, os voltomogramas obtidos passam a apresentar um perfil mais característico de $\mathrm{Pt}$, ou seja, com área relativamente menor na região 0,25 e 0,60V e um aumento de área a partir $0,60 \mathrm{~V}$ [76]. No caso do catalisador Pt(MRA)-Sn(BH)/C 

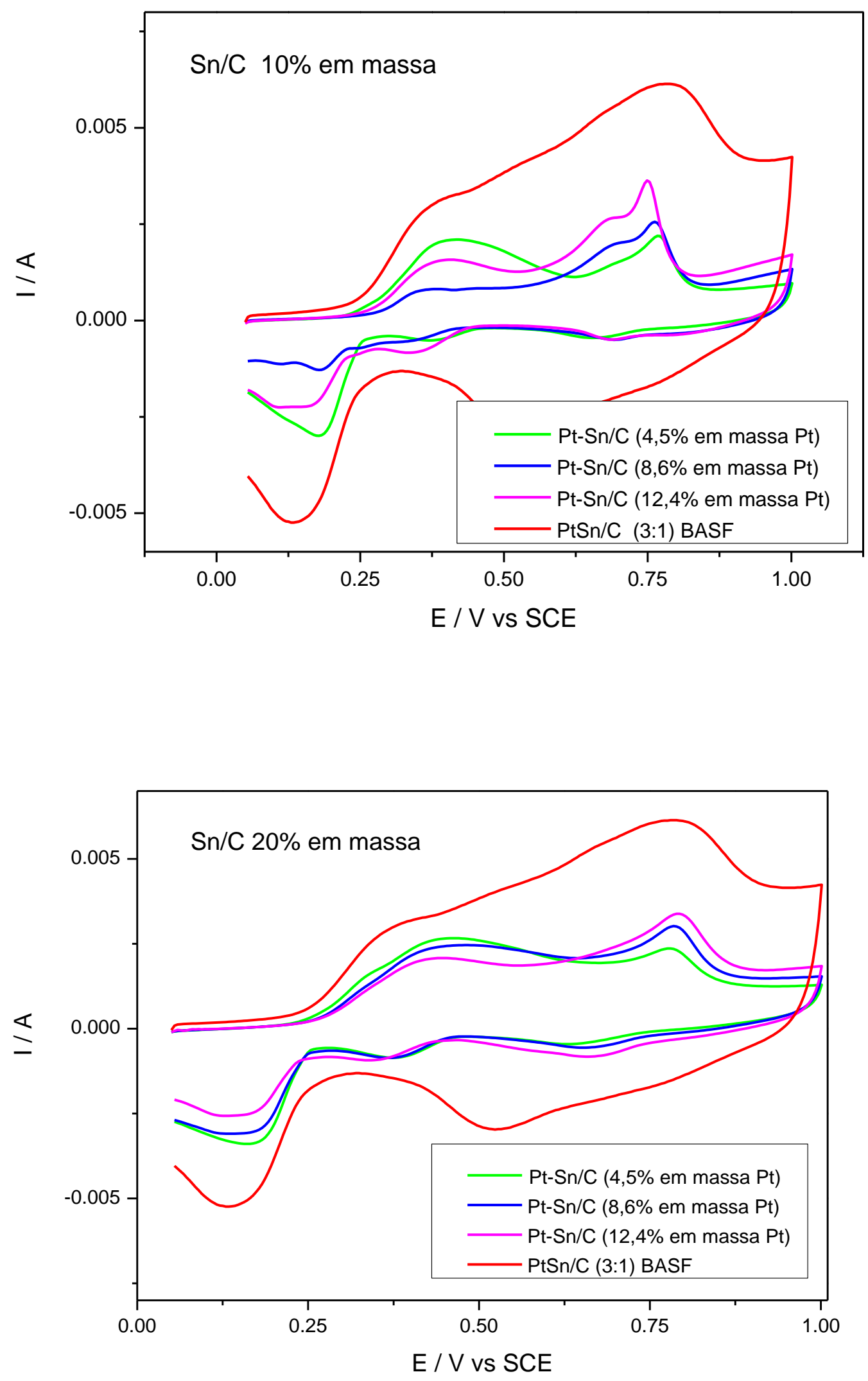
FIGURA 31, no qual a distribuição dos sítios de Pt e Sn na superfície do catalisador parece ser mais uniforme, observou-se um aumento de área em ambas faixas de potencial.

Para o catalisador $\mathrm{Pt}(\mathrm{BH})-\mathrm{Sn}(\mathrm{BH}) / \mathrm{C}$ preparado com $\mathrm{Sn} / \mathrm{C}$ com $20 \%$ de massa de $\mathrm{Sn}$, os resultados são similares ao material preparado com Sn/C contendo $10 \%$ em massa de Sn, ou seja, à medida que se aumenta a quantidade de Pt no catalisador, observa-se uma diminuição na área da região entre $0,25 \mathrm{e}$ $0,60 \mathrm{~V}$ e um aumento na área a partir de $0,60 \mathrm{~V}$, sugerindo também que a superfície do catalisador se torna mais rica em átomos de Pt.

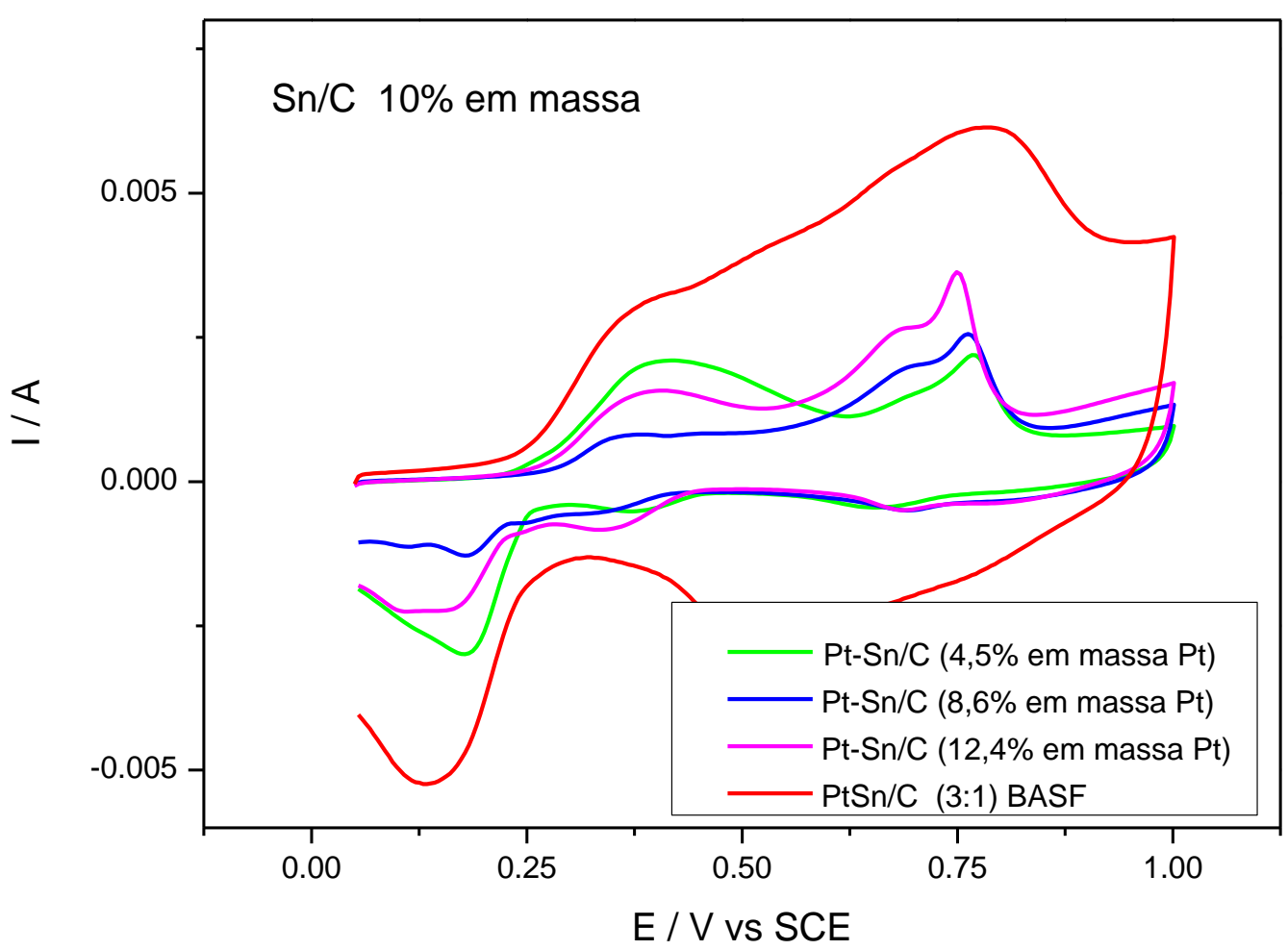




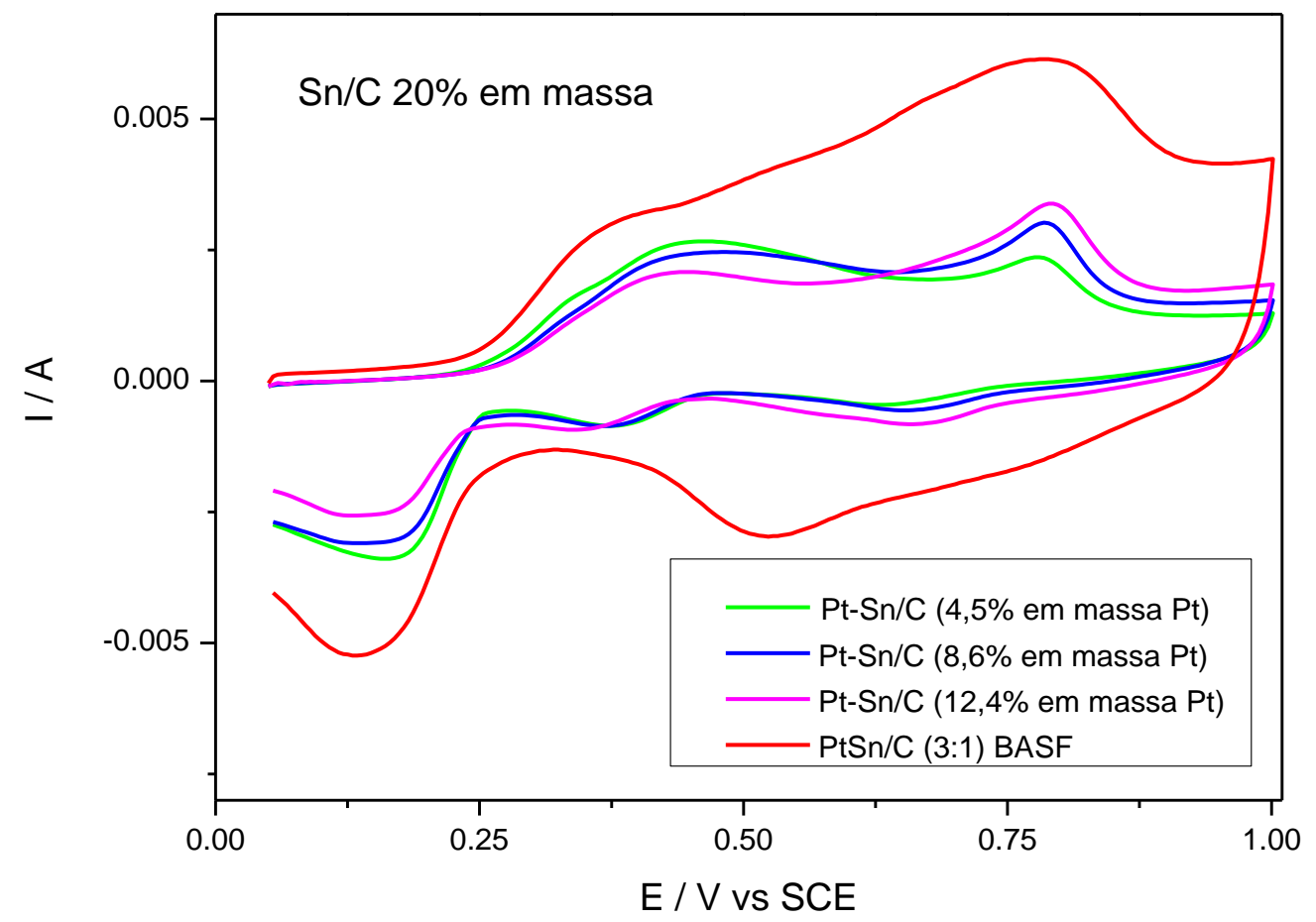

FIGURA 31 - Oxidação eletroquímica do CO (CO stripping) nos eletrocatalisadores $\mathrm{Pt}(\mathrm{BH})-\mathrm{Sn}(\mathrm{BH}) / \mathrm{C}$ preparados utilizando suporte $\mathrm{Sn}(\mathrm{BH}) / \mathrm{C}$ com 10 e $20 \%$ em massa de $\mathrm{Sn}$

Assim, os resultados sugerem que, para os catalisadores $\mathrm{Pt}(\mathrm{BH})-\mathrm{Sn}(\mathrm{BH}) / \mathrm{C}$ cujas atividades foram inferiores ao catalisador comercial PtSn/C BASF, a deposição da Pt ocorre preferencialmente sobre as nanopartículas de Sn metálico, tornando a superficíe rica em Pt. Dessa forma, o material torna-se menos ativo para a oxidação eletroquímica do etanol, pois, como se sabe, a presença de sítios de Pt e Sn na superfície são mais adequados para oxidação do etanol pelo mecanismo bifuncional. Por outro lado, na preparação dos eletrocatalisadores $\mathrm{Pt}(\mathrm{MRA})-\mathrm{Sn}(\mathrm{BH}) / \mathrm{C}$, como já relatado, o $\mathrm{Sn}$ metálico é transformado em $\mathrm{SnO} 2$ durante a etapa de deposição da Pt e o catalisador resultante parece apresentar uma distribuição mais homogênea de Pt e Sn em sua superfície o que o torna mais ativo para a oxidação do etanol e, neste caso, os materiais obtidos são mais 
ativos que o catalisador comercial $\mathrm{PtSn} / \mathrm{C} \mathrm{BASF}$, conforme mostrado na comparação FIG. 32.

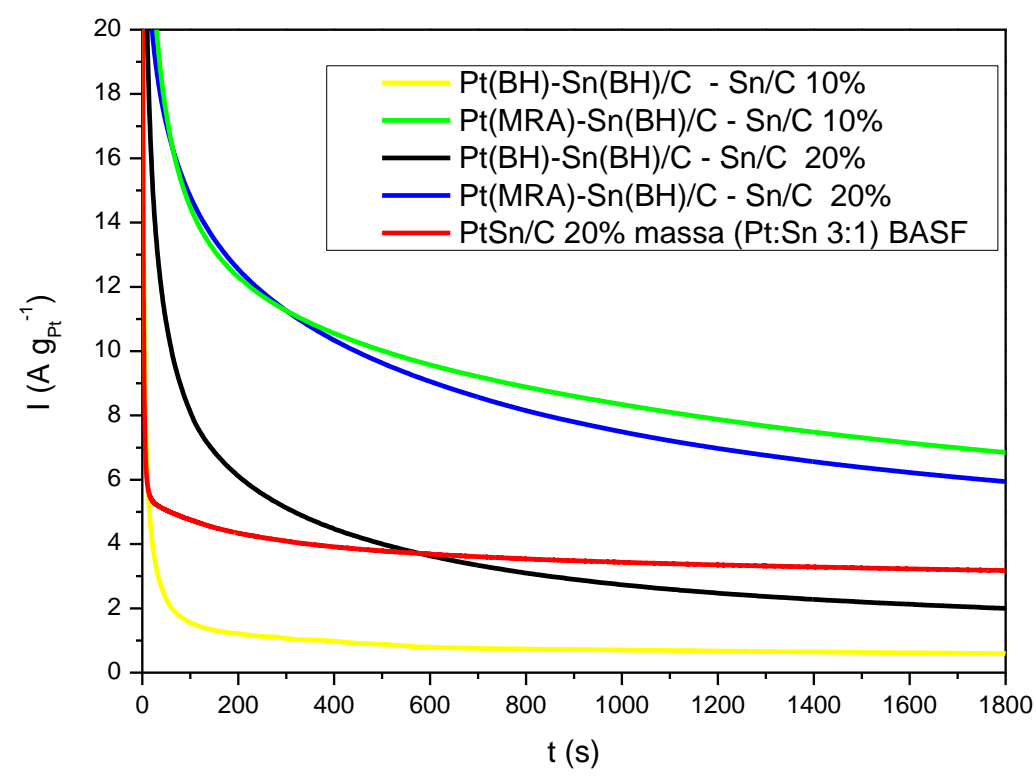

FIGURA 32 - Comparação das curvas cronoamperométricas dos eletrocatalisadores $\mathrm{Pt}(\mathrm{BH})-\mathrm{Sn}(\mathrm{BH}) / \mathrm{C}$ e $\mathrm{Pt}(\mathrm{MRA})-\mathrm{Sn}(\mathrm{BH}) / \mathrm{C}$ preparados com diferentes $12,5 \%$ em massa de Pt em etanol 1,0 $\mathrm{mol} \mathrm{L}^{-1}$ e potencial fixo de $500 \mathrm{mV}$ por $30 \mathrm{~min}$

\subsubsection{Preparação de Sn/C com diferentes \% em massa de Sn utilizando o método da redução por álcool (MRA)}

Nesta etapa foram preparamos suportes Sn/C com 10 e 20\% em massa de Sn pelo método da redução por álcool. Os difratogramas de raios $X$ são mostrados na FIG. 33. 


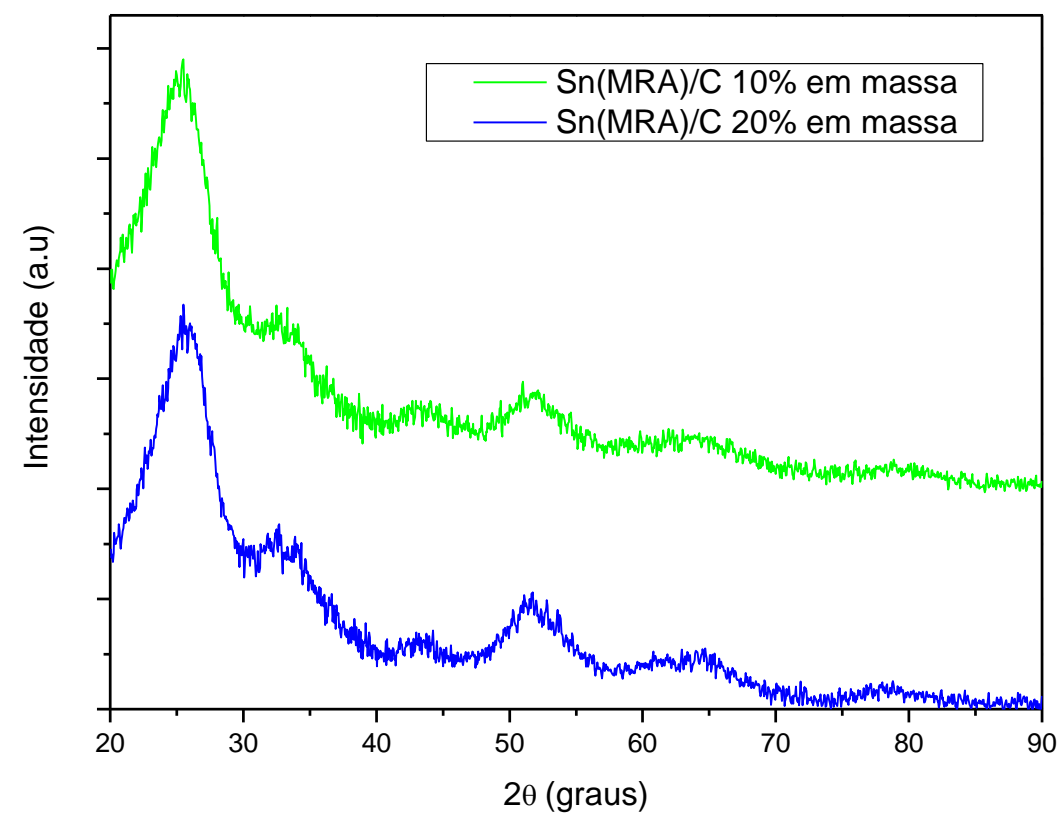

FIGURA 33 - Difratogramas de raios $X$ para os catalisadores $\mathrm{Sn} / \mathrm{C}$ pelo método MRA com 10 e $20 \%$ em massa de $S n$

Como pode-se verificar, os suportes $\mathrm{Sn} / \mathrm{C}$ preparados pelo método MRA não apresentam a formação da fase Sn metálico observada na preparação do $\mathrm{Sn} / \mathrm{C}$ pelo método do BH (FIG. 12). Na síntese pelo método MRA a presença de água no meio reacional ocasiona a hidrólise do precursor $\mathrm{SnCl}_{2} .2 \mathrm{H}_{2} \mathrm{O}$ levando à formação de uma fase $\mathrm{SnO}_{2}$ cassiterita [75], o qual é identificada pela presença de dois picos em, $2 \theta$ aproxidamente, $2 \theta=34^{\circ}$ e $52^{\circ}$. Os outros picos presentes nos difratogramas são do suporte de carbono Vulcan XC-72. A estimativa do tamanho de cristalito pela equação de Scherrer da fase $\mathrm{SnO}_{2}$ mostra um tamanho de cerca de $2 \mathrm{~nm}$.

\subsubsection{Deposição da Pt pelos métodos MRA e BH sobre os suportes Sn/C obtidos pelo método MRA}

A deposição de diferentes quantidades de Pt nos suportes $\mathrm{Sn} / \mathrm{C}$ preparados pelo método MRA foi efetuada pelo métodos MRA e BH. Os resultados de razão atômica são mostrados na TAB. 4. 
TABELA 4 - Razão atômica Pt:Sn nomimal e a obtida por EDX para os eletrocatalisadores preparados pela deposição de Pt pelos métodos MRA e BH nos suportes $\mathrm{Sn} / \mathrm{C}$ preparados pelo método MRA

\begin{tabular}{cccc}
\hline $\begin{array}{c}\text { Suporte } \\
\text { Sn(MRA)/C } \\
\text { (\% Sn massa) }\end{array}$ & $\begin{array}{c}\text { Método } \\
\text { Deposição Pt / } \\
\text { Pt em massa }\end{array}$ & $\begin{array}{c}\text { Pt:Sn } \\
\text { (nominal) }\end{array}$ & $\begin{array}{c}\text { Pt:Sn } \\
\text { (EDX) }\end{array}$ \\
\hline 10 & MRA / 8,6 & $36: 64$ & $53: 47$ \\
10 & MRA / 12,4 & $45: 55$ & $62: 38$ \\
20 & MRA / 8,6 & $44: 56$ & $43: 57$ \\
20 & $\mathrm{MRA} / 12,4$ & $52: 48$ & $54: 46$ \\
10 & $\mathrm{BH} / 8,6$ & $36: 64$ & $42: 58$ \\
10 & $\mathrm{BH} / 12,4$ & $45: 55$ & $52: 48$ \\
20 & $\mathrm{BH} / 8,6$ & $44: 56$ & $33: 67$ \\
20 & $\mathrm{BH} / 12,4$ & $52: 48$ & $40: 61$ \\
\hline
\end{tabular}

No caso da deposição de Pt pelos métodos MRA e BH sobre os suportes $\mathrm{Sn} / \mathrm{C}$ preparados pelo método MRA, as razões atômicas Pt:Sn obtidas por EDX apresentam-se bem próximas as razões atômicas nominais. Este dado pode ser explicado pelo fato de o $\mathrm{Sn}$ presente no suporte encontrar-se na forma de $\mathrm{SnO}_{2}$, um composto notavelmente inerte a ataques químicos [68] o que diminui ou extingue a perda de estanho do suporte. Assim, ocorreu o contrário do observado quando se utilizou o $\mathrm{Sn} / \mathrm{C}$ preparado pelo método $\mathrm{BH}$.

Os difratogramas de raios $X$ dos eletrocatalisadores preparados pela deposição de diferentes quantidades de Pt pelos métodos MRA e BH sobre os suportes Sn(MRA)/C, com 10 e 20\% em massa de Sn, são mostrados nas FIG. $34 \mathrm{~A}$ e B. 

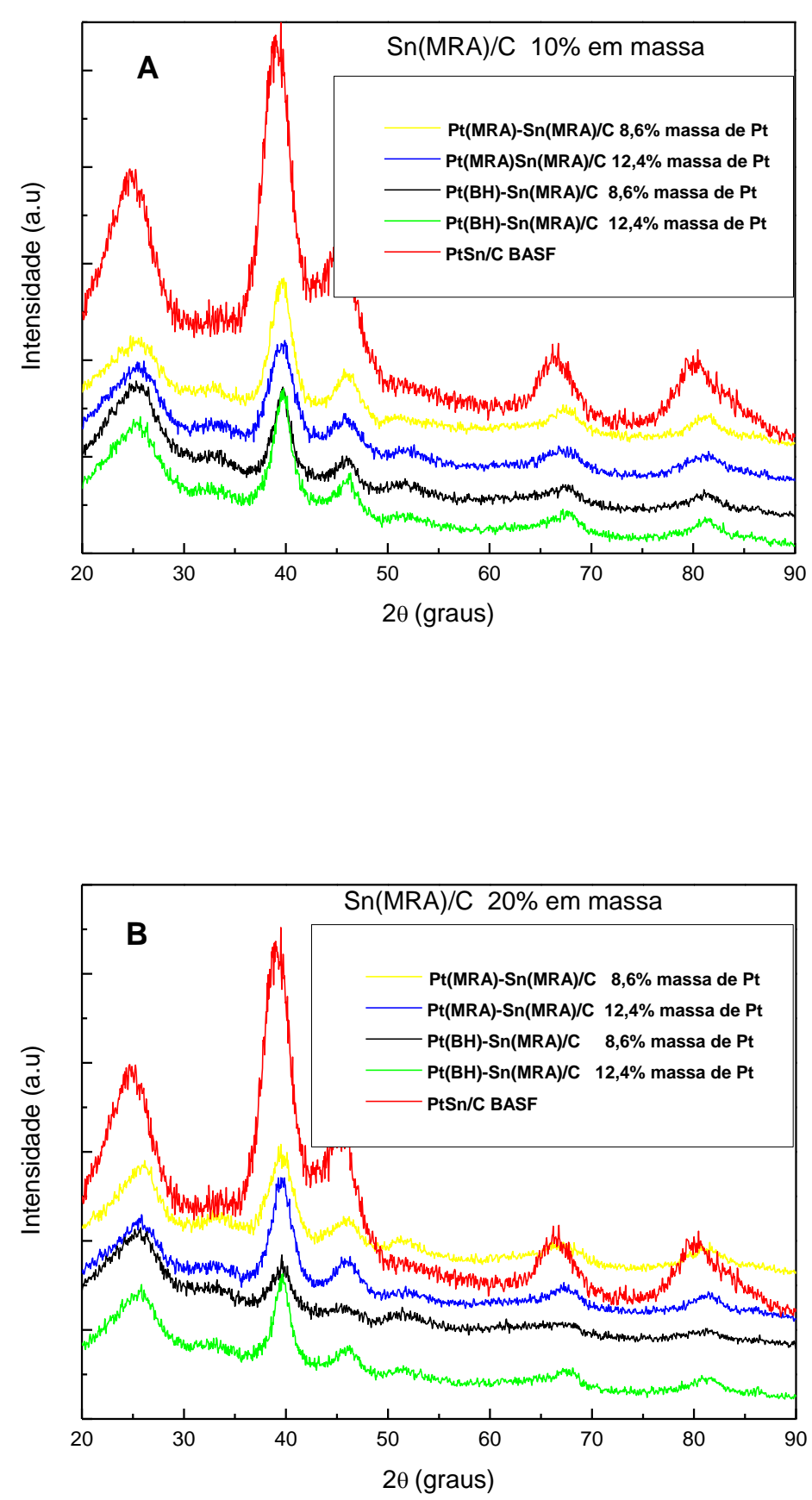

FIGURA 34 - Difratogramas de raios $X$ dos eletrocatalisadores preparados pela deposição de Pt pelos métodos MRA e BH sobre o Sn(MRA)/C com 10 (A) e 20\% (B) em massa de Sn 
Observa-se em todos os difratogramas um pico largo em aproximadamente, $2 \theta=25^{\circ}$ o qual é associado ao suporte de carbono Vulcan XC-72. Para todos os eletrocatalisadores obtidos observa-se quatro picos de difração em, aproximadamente, $2 \theta=40^{\circ}, 47^{\circ}, 67^{\circ}$ e $82^{\circ}$ os quais são associados aos planos (111), (200), (220) e (311), respectivamente, da estrutura cúbica de face centrada (CFC) de platina [74]. Todos os materiais também apresentam dois picos em, aproximadamente, $2 \theta=34$ e $52^{\circ}$, atribuídos à presença da fase $\mathrm{SnO}_{2}$ cassiterita [75]. Assim, os resultados de difração de raios $X$ mostram que todos os eletrocatalisadores obtidos apresentam uma mistura da fase $\mathrm{Pt}(\mathrm{fcc})$ e da fase $\mathrm{SnO}_{2}$. A atividade eletrocatalítica e estabilidade dos materiais obtidos na oxidação eletroquímica do etanol foram estudadas por cronoamperometria. Os resultados são mostrados nas FIG. 35 A e B.

Os resultados mostram que os eletrocatalisadores Pt(MRA)-Sn(MRA)/C apresentaram atividades superiores ao eletrocatlisador comercial PtSn/C BASF, enquanto que 0 desempenho dos eletrocatalisadores $\mathrm{Pt}(\mathrm{BH})$-Sn(MRA)/C foi inferior. Assim, como observado para o suporte $\mathrm{Sn}(\mathrm{BH}) / \mathrm{C}$, a deposição da Pt pelo método MRA mostrou-se mais efetiva em termos de desempenho dos eletrocatalisadores.

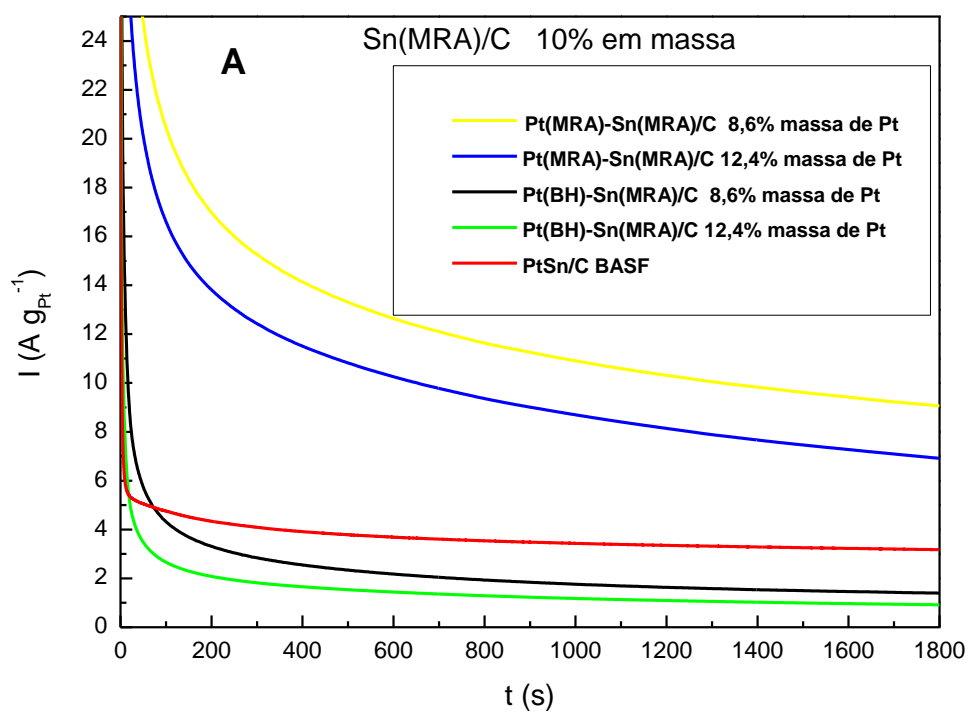




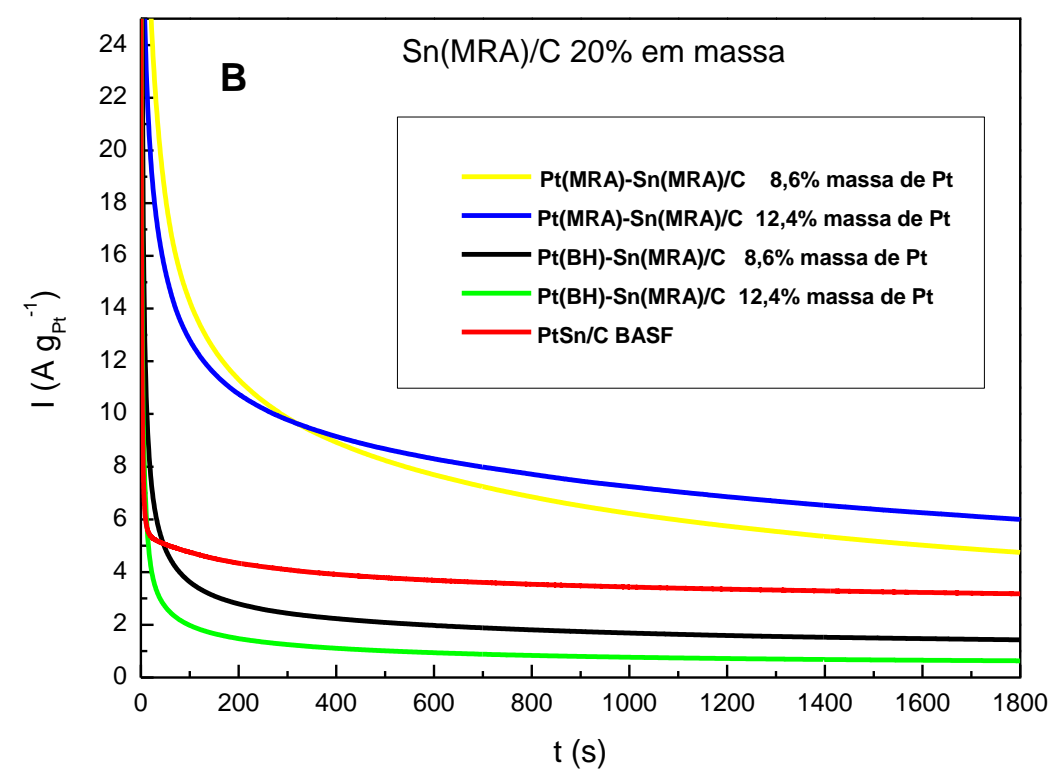

FIGURA 35 - Comparação das curvas cronoamperométricas dos eletrocatalisadores $\mathrm{Pt}(\mathrm{MRA})-\mathrm{Sn}(\mathrm{MRA}) / \mathrm{C}$ e $\mathrm{Pt}(\mathrm{BH})-\mathrm{Sn}(\mathrm{MRA}) / \mathrm{C}$ preparados com $10 \%$ (A) e $20 \%$ (B) em massa de Sn em etanol 1,0 $\mathrm{mol} \mathrm{L}^{-1}$ e potencial fixo de 500 $\mathrm{mV}$ por $30 \mathrm{~min}$

\subsection{Comparação $\mathrm{PtSn} / \mathrm{C}$ preparados por co-redução (única etapa de síntese) e redução sucessiva (deposição Pt na segunda etapa de síntese) pelos métodos MRA e BH em diferentes condições}

Os resultados anteriores mostraram que os eletrocatalisadores $\mathrm{Pt}-\mathrm{Sn} / \mathrm{C}$ preparados por redução sucessiva, em que a etapa de deposição da $\mathrm{Pt}$ foi realizada pelo método MRA, apresentaram atividades superiores ao eletrocatalisador comercial PtSn/C BASF na oxidação eletroquímica do etanol, provavelmente, devido a uma boa distribuição dos sítios de $\mathrm{Pt}$ e $\mathrm{SnO}_{2}$ na superfície do eletrocatalisador. Porém, resta ainda comparar o desempenho destes materiais com o material preparado em uma única etapa (co-redução dos íons Pt e Sn) a fim de verificar se existem vantagens da realização da síntese em duas etapas nas condições estudadas. A comparação de atividade dos diferentes catalisadores preparados por redução sucessiva (depositando Pt na segunda 
etapa) com os materiais preparados por co-redução (pelos métodos MRA e BH) é mostrada FIG. 36.

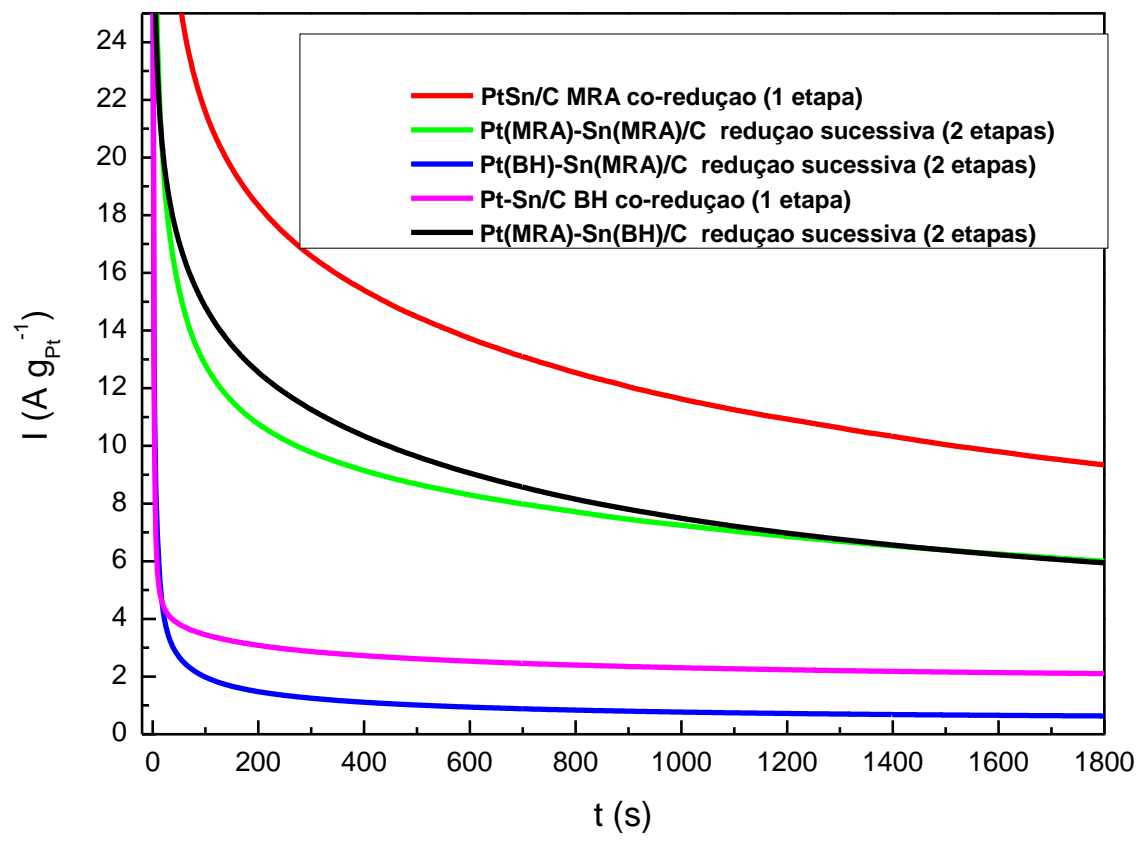

FIGURA 36 - Comparação das curvas cronoamperométricas dos diferentes eletrocatalisadores $\mathrm{PtSn} / \mathrm{C}$ (12,4\% em massa de Pt e $20 \%$ massa Sn) preparados por co-redução e redução sucessiva em etanol $1,0 \mathrm{~mol} \mathrm{~L}^{-1}$ e potencial fixo de 500 $\mathrm{mV}$ por $30 \mathrm{~min}$

Os estudos por cronoamperometria mostraram que o eletrocatalisador $\mathrm{PtSn} / \mathrm{C}$ preparado pela co-redução dos íons Pt e Sn pelo método MRA apresentou a maior atividade eletrocatalítica para a oxidação do etanol. $O$ eletrocatalisador $\mathrm{PtSn} / \mathrm{C}$ preparado pela co-redução dos íons $\mathrm{Pt}$ e Sn pelo método BH apresentou atividade semelhante ao eletrocatalisador $\mathrm{Pt}(\mathrm{MRA})-\mathrm{Sn}(\mathrm{MRA}) / \mathrm{C}$, sendo ambos superiores aos eletrocatalisadores $\mathrm{Pt}(\mathrm{BH})-\mathrm{Sn}(\mathrm{MRA}) / \mathrm{C}$ e $\mathrm{Pt}(\mathrm{MRA})-\mathrm{Sn}(\mathrm{RH}) / \mathrm{C}$. Resultados similares foram descritos recentemente por López-Suárez et al [78] que prepararam uma série de eletrocatalisadores $\mathrm{PtSn} / \mathrm{C}$ usando boroidreto como agente redutor para a oxidação eletroquímica do etanol. Foi também observado que a ordem de adição dos precursores metálicos afeta fortemente a atividade 
eletrocatalítica e as características físico-químicas dos materiais obtidos; sendo que o catalisador preparado pela co-redução de ambos os metais apresentou-se, de um modo geral, mais ativo que os catalisadores preparados pela deposição sequencial de Sn e Pt.

Assim, nas condições estudadas, o eletrocatalisador $\mathrm{PtSn} / \mathrm{C}$ preparado em uma única etapa pelo método MRA apresentou-se mais ativo que os respectivos eletrocatalisadores preparados em duas etapas, onde se esperava que a deposição de Pt na superfície pudesse torná-los mais ativos. A fim de compreender melhor estes resultados, as superfícies de alguns eletrocatalisadores foram analisadas por TEM-line scan.

\subsubsection{Análise da superfície dos eletrocatalisadores pela técnica TEM-EDX line- scan}

Para a análise da superfície dos eletrocatalisadores pela técnica TEM-EDX line-scan foram escolhidos três eletrocatalisadores: $\mathrm{Pt}(\mathrm{BH})-\mathrm{Sn}(\mathrm{BH}) / \mathrm{C}$, o qual apresentou o pior desempenho entre os catalisadores, o $\operatorname{Pt}(\mathrm{MRA})-\mathrm{Sn}(\mathrm{MRA}) / \mathrm{C}$, o qual apresentou um bom desempenho, no entanto, inferior ao do PtSn/C MRA preparado por co-redução. As micrografias de transmissão com o EDX line-scan destes catalisadores são mostrados na FIG. 37-39.

Para o eletrocatalisador $\mathrm{Pt}(\mathrm{BH})-\mathrm{Sn}(\mathrm{BH}) / \mathrm{C}$ (FIGURA 37) observa-se em toda a extensão que a intensidade do sinal de Pt é muito maior que o sinal do Sn, confirmando a indicação dos resultados anteriores que sugeriam uma superfície mais rica em Pt para este eletrocatalisador. Dessa forma, sua baixa atividade pode estar relacionada à pequena existência de espécies de Sn vizinhas aos sítios de $\mathrm{Pt}$, condição fundamental para um bom desenpenho do catalisador pelo mecanismo bifuncional.

Para o eletrocatalisador Pt(MRA)-Sn(MRA)/C (FIGURA 38), onde a Pt foi também depositada na segunda etapa de síntese, observa-se em toda a extensão do line-scan que a intensidade do sinal de Pt é somente um pouco maior que a do Sn, sugerindo, a existência das duas espécies na superfície do catalisador.

Para o eletrocatalisador $\mathrm{PtSn} / \mathrm{C}$ preparado por co-redução pelo método MRA (FIGURA 39), os sinais de Pt e Sn são bastante similares em toda a extensão 
do line-scan indicando uma distribuição bastante homogênea dos sítios de Pt e Sn, os quais são fundamentais para a oxidação eletroquímica do etanol.

A partir destes resultados pode-se concluir que a deposição de Pt na superfície de eletrocatalisadores objetivando catalisadores mais eficientes e utilizando menores quantidades de Pt nem sempre é possível ou de fácil realização, pois, como relatado na literatura, as tentativas de economizar Pt por meio de sua deposição em um suporte nem sempre são eficazes, pois os átomos de Pt nem sempre encontram-se nas posições "ideais" para determinadas reações e acabam não sendo eficientes para as mesmas [71].

Recentemente, Zhang et al [79] demonstraram uma rota química, sem adição de surfactantes ou agentes estabilizantes, para cobrir nanopartículas de $\mathrm{Pd}$ com uma monocamada atômica de Pt. A cobertura completa e uniforme foi efetuada por um processo de cobertura com cinética bastante lenta e temperatura de reação de $70^{\circ} \mathrm{C}$ usando etanol como agente redutor. Neste caso, os autores esclarecem que a nucleação da Pt não ocorre até que a temperatura seja maior que $78^{\circ} \mathrm{C}$, a qual é também o ponto de ebulição do etanol e, que o poder redutor do etanol a $70{ }^{\circ} \mathrm{C}$ é suficiente para reduzir os íons $\mathrm{Pt}(\mathrm{IV})$ a $\mathrm{Pt}(0)$ na presença das nanopartículas de $\mathrm{Pd}$. As nanopartículas obtidas na forma core-shell apresentaram excelente atividade para a reação de redução do oxigênio, até melhores que materiais similares preparados por substituição galvânica. Assim, estes resultados sugerem que a realização de novos estudos de deposição $\mathrm{Pt}$ sobre Sn/C utilizando diferentes condições e agentes redutores talvez possam levar a materiais mais ativos para a oxidação eletroquímica do etanol. 
PtSnC amostra9-9(1)

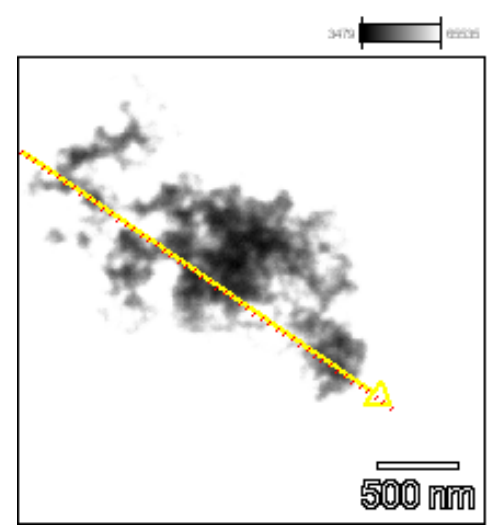

PtSnC amostra9-9(8)

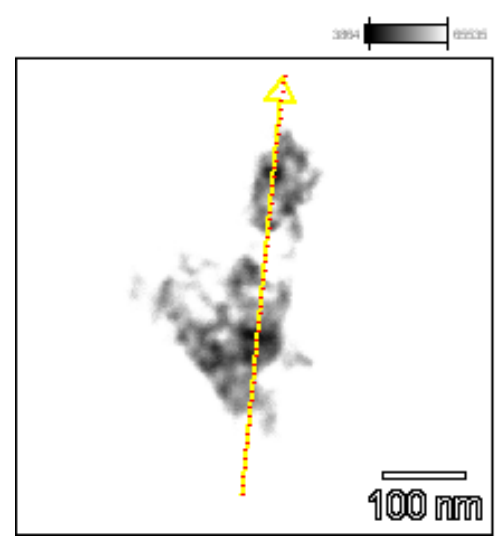

PtSnC amostra9-9(1)

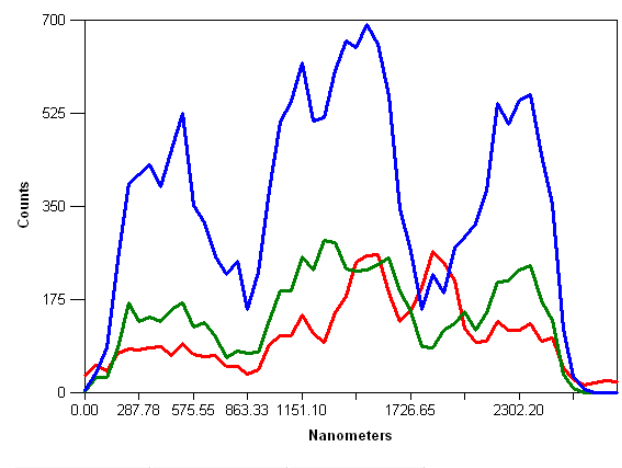

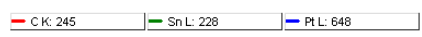

PtSnC amostra9-9(8)

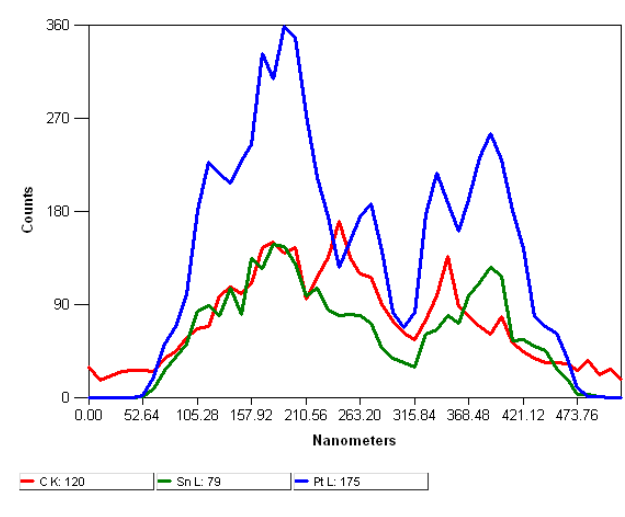

FIGURA 37 - Micrografias eletrônicas de transmissão com o correspondente localização do line-scan e os gráficos mostrando as intensidades dos elementos com a posição da linha para o eletrocatalisador $\mathrm{Pt}(\mathrm{BH})-\mathrm{Sn}(\mathrm{BH}) / \mathrm{C}$ 
PtSnC amostra3-3(1)

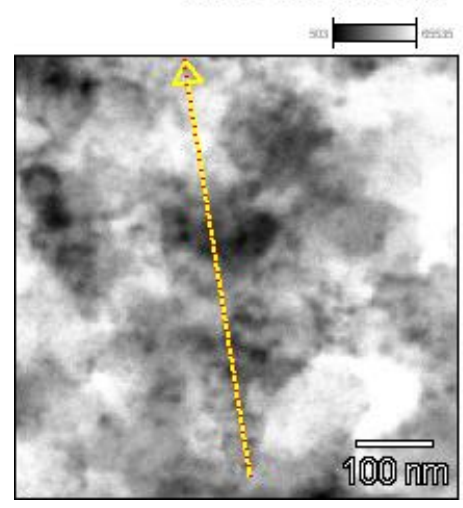

PtSnC amostra3-3

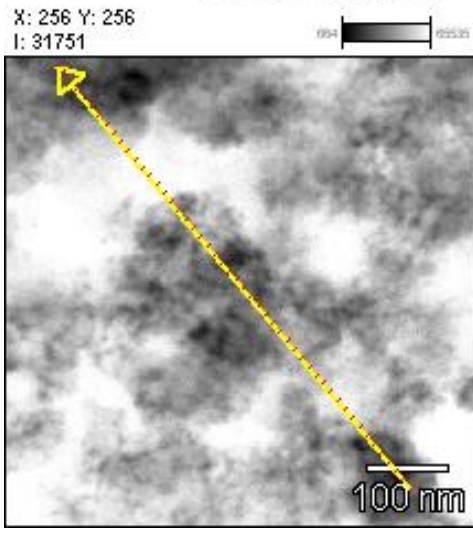

PtSnC amostra3-3(5)

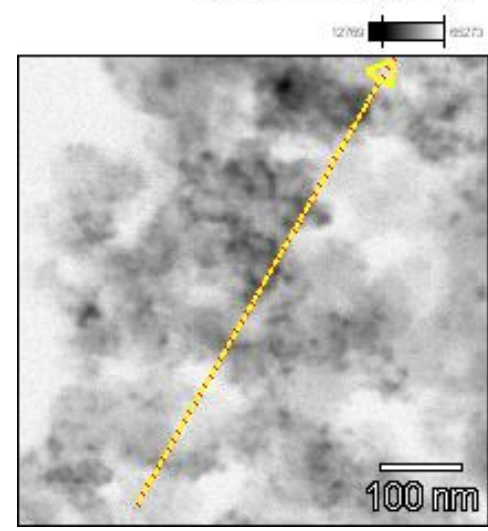

PtSnC amostra3-3(1)
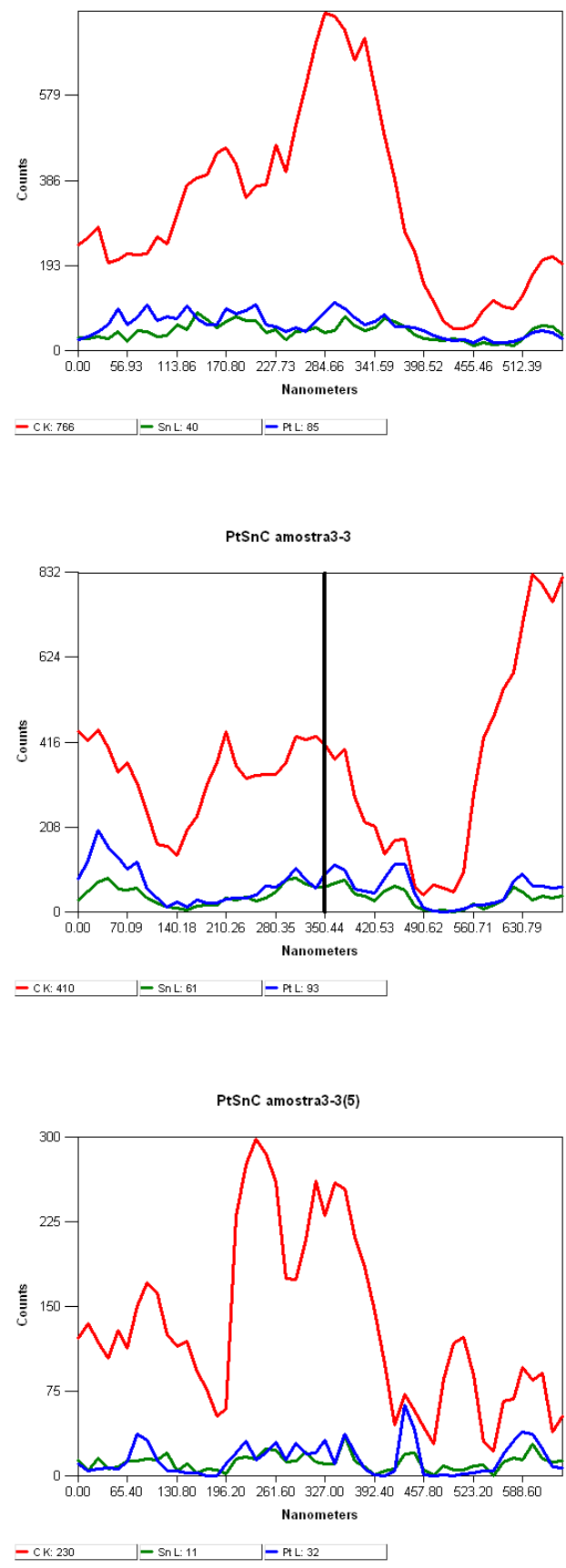

FIGURA 38 - Micrografias eletrônicas de transmissão com o correspondente localização do line-scan e os gráficos mostrando as intensidades dos elementos com a posição da linha para o eletrocatalisador Pt(MRA)-Sn(MRA)/C 
PtSnC amostra1-1(3)

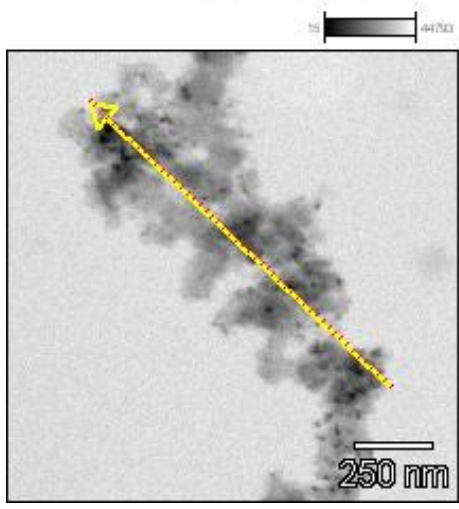

PtSnC amostra1-1(4)

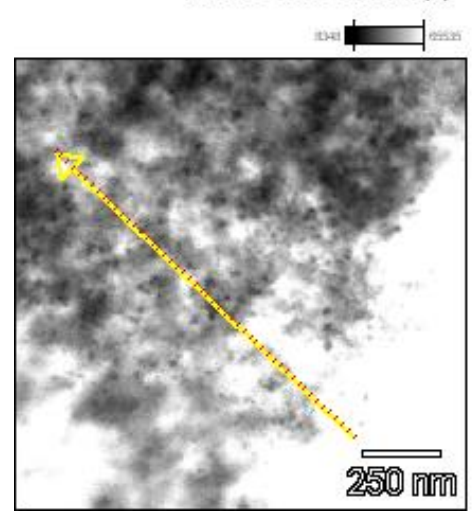

PtSnC amostra1-1(5)

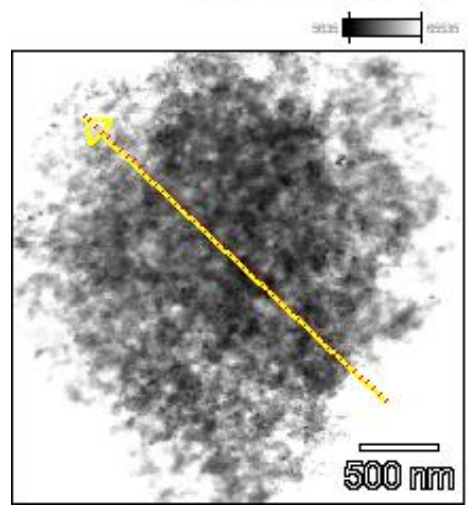

PtSnC amostra1-1(3)

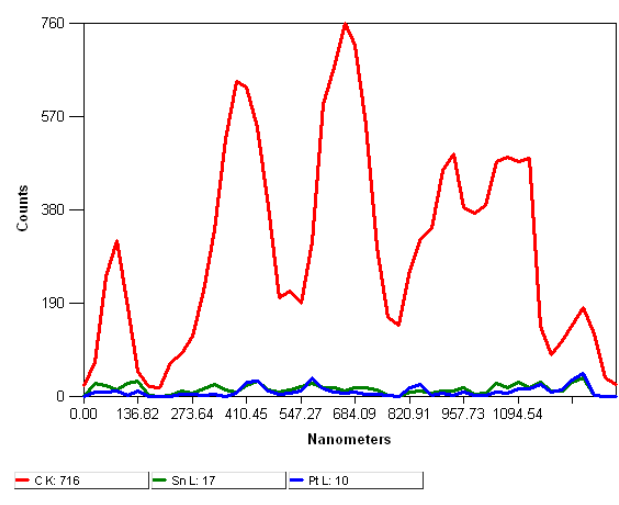

PtSnC amostra1-1(4)

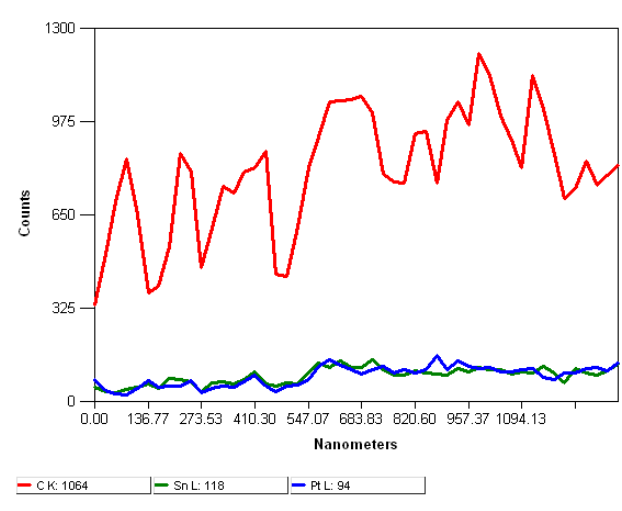

PtSnC amostra1-1(5)

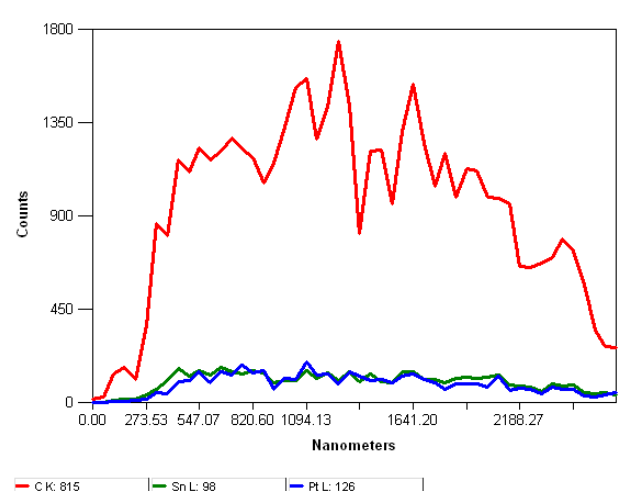

FIGURA 39 - Micrografias eletrônicas de transmissão com o correspondente localização do line-scan e os gráficos mostrando as intensidades dos elementos com a posição da linha para o eletrocatalisador $\mathrm{PtSn} / \mathrm{C}$ preparado por co-redução pelo método MRA 


\section{CONCLUSÕES}

Neste estudo, foram preparados eletrocatalisadores PtSn/C dando enfoque à deposição de $\mathrm{Pt}$ na superfície de suportes $\mathrm{Sn} / \mathrm{C}$ utilizando métodos de síntese simples e que não necessitassem de condições complexas de operação como, por exemplo, uso de atmosfera inerte, solvente orgânicos especiais e uso de agentes estabilizantes.

$\mathrm{Na}$ preparação do eletrocatalisador $\mathrm{Pt}-\mathrm{Sn} / \mathrm{C}$ pelo processo de troca galvânica foi possível depositar Pt na superfície de Sn/C, apesar da síntese ser realizada em atmosfera aberta ao ar. No entanto, apenas uma pequena quantidade de Pt foi depositada 15\% da Pt disponível para deposição resultando em um catalisador com 2,2\% em massa de Pt. Devido às condições de síntese, a superfície do suporte $S n / C$ apresenta $S n$ na forma oxidada o que, provavelmente, dificulta a troca galvânica entre os íons $\mathrm{Pt}(\mathrm{IV})$ e as espécies oxidadas de Sn. A atividade apresentada para a oxidação eletroquímica do etanol foi muito inferior ao catalisador comercial PtSn/C BASF.

Quando a deposição da $\mathrm{Pt}$ foi realizada utilizando diferentes agentes redutores como boroidreto de sódio $(\mathrm{BH})$ e etilenoglicol (MRA) foi possível depositar diferentes quantidades de Pt na superfície do suportes $\mathrm{Sn} / \mathrm{C}$ preparados pelas metodologias $\mathrm{BH}$ e MRA.

A preparação dos eletrocatalisadores $\mathrm{Pt}(\mathrm{MRA})-\mathrm{Sn}(\mathrm{BH}) / \mathrm{C}$ por meio da deposição de Pt pelo método MRA sobre o suporte $\mathrm{Sn} / \mathrm{C}$ preparado pelo método $\mathrm{BH}$ sugerem que durante a etapa de deposição da $\mathrm{Pt}$, ocorre a oxidação do $\mathrm{Sn}$ metálico, o qual em parte é transformado em $\mathrm{SnO}_{2}$ e redeposita sobre o suporte de carbono. Assim, o material obtido apresenta uma mistura de fases $\mathrm{Pt}(\mathrm{fcc})$ e $\mathrm{SnO}_{2}$ com boa distribuição sobre o suporte de carbono, apresentando desempenho superior ao catalisador comercial PtSn/C BASF.

Para os catalisadores $\mathrm{Pt}(\mathrm{BH})-\mathrm{Sn}(\mathrm{BH}) / \mathrm{C}$, os quais apresentaram desempenhos inferiores ao catalisador comercial PtSn/C BASF, a deposição da Pt parece ocorrer preferencialmente sobre as nanopartículas de Sn metálico, 
tornando a superficíe do catalisador rica em Pt. Dessa forma, o material torna-se menos ativo para a oxidação eletroquímica do etanol, pois, como conhecido, a presença de sítios superficiais de Pt e Sn são mais adequados para oxidação do etanol pelo mecanismo bifuncional.

Os eletrocatalisadores Pt(MRA)-Sn(MRA)/C apresentaram desempenhos superiores ao do eletrocatlisador comercial $\mathrm{PtSn} / \mathrm{C} B A S F$, enquanto que o desempenho dos eletrocatalisadores $\mathrm{Pt}(\mathrm{BH})-\mathrm{Sn}(\mathrm{MRA}) / \mathrm{C}$ foi inferior. Assim, como observado para o suporte $\mathrm{Sn}(\mathrm{BH}) / \mathrm{C}$ a deposição da Pt pelo método MRA mostrouse mais efetiva em termos de desempenho dos eletrocatalisadores.

No entanto, o melhor desempenho foi observado para o eletrocatalisador $\mathrm{PtSn} / \mathrm{C}$ preparado em uma única etapa (co-redução) pelo método MRA . A análise da superfície deste catalisador mostrou que os sinais de Pt e Sn são bastante similares em toda a extensão do line-scan indicando uma distribuição bastante homogênea dos sítios de $\mathrm{Pt}$ e $\mathrm{Sn}$, os quais são fundamentais para a oxidação eletroquímica do etanol, enquanto que para o eletrocatalisador que apresentou o pior desempenho $\mathrm{Pt}(\mathrm{BH})-\mathrm{Sn}(\mathrm{BH}) / \mathrm{C}$, a análise de sua superfície mostrou uma intensidade do sinal de Pt muito maior que a do Sn. Dessa forma, sua baixa atividade pode estar relacionada à baixa existência de vizinhanças de espécies $\mathrm{Pt}$ e $\mathrm{Sn}$ em sua superfície as quais são fundamentais para um bom desempenho do catalisador pelo mecanismo bifuncional, onde a quebra da moléculas de etanol ocorrem nos sítios de Pt e as espécies de Sn oxigenadas favorecem a oxidação dos intermediários formados a baixos potenciais.

Assim, nas condições estudadas, a deposição de Pt na superfície do $\mathrm{Sn} / \mathrm{C}$, apesar de que alguns casos, os materiais obtidos apresentarem melhor atividade que o catalisador PtSn/C comercial, estes apresentaram-se menos ativos que os materiais preparados em uma única etapa por co-redução usando o MRA. Dessa forma, a realização de novos estudos de deposição Pt utilizando diferentes condições de temperatura e agentes redutores talvez possa levar a materiais mais ativos para a oxidação eletroquímica do etanol. 


\section{TRABALHOS PUBLICADOS}

\section{Artigos completos publicados em periódicos}

Ribeiro, V. A. ; Sekol, R. C. ; Taylor, A. D. ; Neto, A. O. ; Spinace, E. V. . Preparation of PtSn/C Electrocatalysts by an Alcohol-Reduction Process Using Different Conditions for Ethanol Electro-Oxidation. ECS Transactions (Online), v. 58, p. 141-145, 2014.

Ribeiro, Vilmaria A. ; Oliveira Neto, A., Oliveira Neto-Almir ou Neto AO ; Linardi, M. ; Spinacé, E. V. . Preparation of PtSn/C Electrocatalyst by Successive Reduction for Ethanol Electrooxidation. ECS transactions (Online), v. 43, p. 339-344, 2012.

Ribeiro, V. A. ; Oliveira Neto, A., Oliveira Neto-Almir ou Neto AO ; Linardi, M. ; Spinacé, Estevam V. . Preparation of Pt electrocatalysts by galvanic displacement. Nanomaterials and Energy, v. 1, p. 77-80, 2012.

\section{Trabalhos completos publicados em anais de congressos}

Ribeiro, Vilmaria A. ; Oliveira Neto, A., Oliveira Neto-Almir ou Neto AO ; Linardi, Marcelo ; Spinacé, E. V. . Electrocatalizadores PtSn/C preparados mediante la depocisón de Pt sobre Sn/C para la oxidacion electrochimica del etanol. In: XII Congreso Iberoamericano de Materiales, 2012, Alicante. XII Congreso Iberoamericano de Materiales, 2012. v. 1. p. 1-4.

Ribeiro, V. A. ; Oliveira Neto, A., Oliveira Neto-Almir ou Neto AO ; Linardi, M. ; Spinace, E.V. . Preparação do Eletrocatalisador PtSn/C por redução sucessiva para a oxidação eletroquímica do etanol. In: XVIII Sibee, 2011, Bento Gonçalves. XVIII Sibee, 2011. v. EC. p. 222-224. 
Resumos publicados em anais de congressos

Spinacé, Estevam V. ; Vilmaria A. Ribeiro ; Neto, Almir O. ; Linardi, Marcelo . Preparation of Pt-based electrocatalysts by spontaneous deposition of Pt on Sn, Ni and SnNi nanoparticles supported on carbon for ethanol electrooxidation. In: Euromat 2011, 2011, Montpellier. Euromat, 2011. 


\section{REFERÊNCIAS BIBLIOGRÁFICAS}

1. Conferência das Nações Unidas sobre Desenvolvimento Sustentável. v., n., 2012. Disponível em:

$<$ http://www.rio20.gov.br/sobre a rio mais 20/rio-20-como-chegamos-ateaqui.html >

2. KYOTO, JAPAN. The Kyoto Protocol. 1997. Disponível em: <http://unfccc.int/resource/docs/convkp/kpeng.pdf>

3. GONZALEZ, E.R., Eletrocatálise e poluição ambiental. Química Nova, v. 23, n., p. 262-266, 2000.

4. WENDT, H.; SPINACÉ, E.V.; OLIVEIRA NETO, A. and LINARDI, M., Electrocatalysis and electrocatalysts for low temperature fuel cells: fundamentals, state of the art, research and development. Química Nova, v. 28, n., p. 1066-1075, 2005.

5. DEVANATHAN, R., Recent developments in proton exchange membranes for fuel cells. Energy \& Environmental Science, v. 1, n. 1, p. 101-119, 2008.

6. CARMO, M.D. Preparação e avaliação de eletrocatalisadores suportados em nanotubos de carbono para a oxidação de metanol, 2003. Disertação (Mestrado) - São Carlos Universidade de São Paulo, São Paulo.

7. WENDT, H.; GÖTZ, M. and LINARDI, M., Tecnologia de células a combustível. Química Nova, v. 23, n., p. 538-546, 2000.

8. TICIANELLI, E.A.; CAMARA, G.A. and SANTOS, L.G.R.A., Eletrocatálise das reações de oxidação de hidrogênio e de redução de oxigênio. Química Nova, v. 28, n., p. 664-669, 2005.

9. VIELSTICH, W.A., LAMM AND HUBERT A., GASTEIGER, Handbook of Fuel Cells : Fundamentals, Technology, and Applications. Vol. 1 e 3. Chichester, England, 2003.

10. ZEGERS, P., Fuel cell commercialization: The key to a hydrogen economy. Journal of Power Sources, v. 154, n. 2, p. 497-502, 2006.

11. WANG, Z.B.; YIN, G.P.; SHI, P.F. and SUN, Y.C., Novel Pt-Ru-Ni/C Catalysts for Methanol Electro-oxidation in Acid Medium. Electrochemical and Solid-State Letters, v. 9, n. 1, p. A13-A15, 2006.

12. IWASITA, T., Electrocatalysis of methanol oxidation. Electrochimica Acta, v. 47, n. 22-23, p. 3663-3674, 2002. 
13. WATANABE, M. and MOTOO, S., Electrocatalysis by ad-atoms: Part III. Enhancement of the oxidation of carbon monoxide on platinum by ruthenium ad-atoms. Journal of Electroanalytical Chemistry and Interfacial Electrochemistry, v. 60, n. 3, p. 275-283, 1975.

14. HAMNETT, A., Mechanism and electrocatalysis in the direct methanol fuel cell. Catalysis Today, v. 38, n. 4, p. 445-457, 1997.

15. FRELINK, T.; VISSCHER, W. and VAN VEEN, J.A.R., On the role of Ru and $\mathrm{Sn}$ as promotors of methanol electro-oxidation over Pt. Surface Science, v. 335, n., p. 353-360, 1995.

16. CHAN, K.-Y.; DING, J.; REN, J.; CHENG, S. and TSANG, K.Y., Supported mixed metal nanoparticles as electrocatalysts in low temperature fuel cells. Journal of Materials Chemistry, v. 14, n. 4, p. 505-516, 2004.

17. ROUSSEAU, S.; COUTANCEAU, C.; LAMY, C. and LÉGER, J.M., Direct ethanol fuel cell (DEFC): Electrical performances and reaction products distribution under operating conditions with different platinum-based anodes. Journal of Power Sources, v. 158, n. 1, p. 18-24, 2006.

18. NETO, A.O.; VASCONCELOS, T.R.R.; SILVA, R.W.R.V.D.; LINARDI, M. and SPINACÉ, E.V., Electro-oxidation of ethylene glycol on PtRu/C and $\mathrm{PtSn} / \mathrm{C}$ electrocatalysts prepared by alcohol-reduction process. Journal of Applied Electrochemistry, v. 35, n. 2, p. 193-198, 2005.

19. VIGIER, F.; COUTANCEAU, C.; PERRARD, A.; BELGSIR, E.M. and LAMY, C., Development of anode catalysts for a direct ethanol fuel cell. Journal of Applied Electrochemistry, v. 34, n. 4, p. 439-446, 2004.

20. LAMY, C.; ROUSSEAU, S.; BELGSIR, E.M.; COUTANCEAU, C. and LEEGER, J.M., Recent progress in the direct ethanol fuel cell: development of new platinum-tin electrocatalysts. Electrochimica Acta, v. 49, n. 22-23, p. 3901-3908, 2004.

21. ZHOU, W.J.; SONG, S.Q.; LI, W.Z.; ZHOU, Z.H.; SUN, G.Q.; XIN, Q.; DOUVARTZIDES, S. and TSIAKARAS, P., Direct ethanol fuel cells based on PtSn anodes: the effect of Sn content on the fuel cell performance. Journal of Power Sources, v. 140, n. 1, p. 50-58, 2005.

22. JIANG, L.; ZHOU, Z.; LI, W.; ZHOU, W.; SONG, S.; LI, H.; SUN, G. and XIN, Q., Effects of Treatment in Different Atmosphere on Pt3Sn/C Electrocatalysts for Ethanol Electro-oxidation. Energy \& Fuels, v. 18, n. 3, p. 866-871, 2004.

23. JIANG, L.; SUN, G.; ZHOU, Z.; SUN, S.; WANG, Q.; YAN, S.; LI, H.; TIAN, J.; GUO, J.; ZHOU, B. and XIN, Q., Size-Controllable Synthesis of Monodispersed $\mathrm{SnO} 2$ Nanoparticles and Application in Electrocatalysts. The Journal of Physical Chemistry B, v. 109, n. 18, p. 8774-8778, 2005. 
24. JIANG, L.; SUN, G.; SUN, S.; LIU, J.; TANG, S.; LI, H.; ZHOU, B. and XIN, Q., Structure and chemical composition of supported Pt-Sn electrocatalysts for ethanol oxidation. Electrochimica Acta, v. 50, n. 27, p. 5384-5389, 2005.

25. MANN, J.; YAO, N. and BOCARSLY, A.B., Characterization and Analysis of New Catalysts for a Direct Ethanol Fuel Cell †. Langmuir, v. 22, n. 25, p. 10432-10436, 2006.

26. NETO, A.O.; DIAS, R.R.; TUSI, M.M.; LINARDI, M. and SPINACÉ, E.V., Electro-oxidation of methanol and ethanol using PtRu/C, PtSn/C and $\mathrm{PtSnRu} / \mathrm{C}$ electrocatalysts prepared by an alcohol-reduction process. Journal of Power Sources, v. 166, n. 1, p. 87-91, 2007.

27. COLMATI, F.; ANTOLINI, E. and GONALEZ, E.R., Ethanol Oxidation on Carbon Supported Pt-Sn Electrocatalysts Prepared by Reduction with Formic Acid. Journal of The Electrochemical Society, v. 154, n. 1, p. B39B47, 2007.

28. JIANG, L.; COLMENARES, L.; JUSYS, Z.; SUN, G.Q. and BEHM, R.J., Ethanol electrooxidation on novel carbon supported $\mathrm{Pt} / \mathrm{SnOx} / \mathrm{C}$ catalysts with varied Pt:Sn ratio. Electrochimica Acta, v. 53, n. 2, p. 377-389, 2007.

29. COLMATI, F.; ANTOLINI, E. and GONZALEZ, E.R., Ethanol oxidation on a carbon-supported Pt75Sn25 electrocatalyst prepared by reduction with formic acid: Effect of thermal treatment. Applied Catalysis B: Environmental, v. 73, n. 1-2, p. 106-115, 2007.

30. ZHU, M.; SUN, G. and XIN, Q., Effect of alloying degree in PtSn catalyst on the catalytic behavior for ethanol electro-oxidation. Electrochimica Acta, v. 54, n. 5, p. 1511-1518, 2009.

31. PURGATO, F.L.S.; OLIVI, P.; LÉGER, J.M.; DE ANDRADE, A.R.; TREMILIOSI-FILHO, G.; GONZALEZ, E.R.; LAMY, C. and KOKOH, K.B., Activity of platinum-tin catalysts prepared by the Pechini-Adams method for the electrooxidation of ethanol. Journal of Electroanalytical Chemistry, v. 628, n. 1-2, p. 81-89, 2009.

32. ANTOLINI, E.; COLMATI, F. and GONZALEZ, E.R., Ethanol oxidation on carbon supported (PtSn)alloy/SnO2 and (PtSnPd)alloy/SnO2 catalysts with a fixed $\mathrm{Pt} / \mathrm{SnO} 2$ atomic ratio: Effect of the alloy phase characteristics. Journal of Power Sources, v. 193, n. 2, p. 555-561, 2009.

33. GODOI, D.R.M.; PEREZ, J. and VILLULLAS, H.M., Alloys and oxides on carbon-supported Pt-Sn electrocatalysts for ethanol oxidation. Journal of Power Sources, v. 195, n. 11, p. 3394-3401, 2010.

34. BARANOVA, E.; AMIR, T.; MERCIER, P.J.; PATARACHAO, B.; WANG, D. and LE PAGE, Y., Single-step polyol synthesis of alloy Pt7Sn3 versus biphase $\mathrm{Pt} / \mathrm{SnOx}$ nano-catalysts of controlled size for ethanol electro- 
oxidation. Journal of Applied Electrochemistry, v. 40, n. 10, p. 17671777, 2010.

35. DE SOUZA, R.F.B.; PARREIRA, L.S.; RASCIO, D.C.; SILVA, J.C.M.; TEIXEIRA-NETO, E.; CALEGARO, M.L.; SPINACE, E.V.; NETO, A.O. and SANTOS, M.C., Study of ethanol electro-oxidation in acid environment on $\mathrm{Pt} 3 \mathrm{Sn} / \mathrm{C}$ anode catalysts prepared by a modified polymeric precursor method under controlled synthesis conditions. Journal of Power Sources, v. 195, n. 6, p. 1589-1593, 2010.

36. LI, L.; HUANG, M.; LIU, J. and GUO, Y., PtxSn/C electrocatalysts synthesized by improved microemulsion method and their catalytic activity for ethanol oxidation. Journal of Power Sources, v. 196, n. 3, p. 10901096, 2011.

37. LIU, B.; CHIA, Z.W.; LEE, Z.Y.; CHENG, C.H.; LEE, J.Y. and LIU, Z.L., A General Protocol for the Synthesis of Pt-Sn/C Catalysts for the Ethanol Electrooxidation Reaction. Fuel Cells, v. 12, n. 4, p. 670-676, 2012.

38. LIU, B.; CHIA, Z.-W.; LEE, Z.-Y.; CHENG, C.-H.; LEE, J.-Y. and LIU, Z.-L., The importance of water in the polyol synthesis of carbon supported platinum-tin oxide catalysts for ethanol electrooxidation. Journal of Power Sources, v. 206, n. 0, p. 97-102, 2012.

39. ZIGNANI, S.C.; BAGLIO, V.; LINARES, J.J.; MONFORTE, G.; GONZALEZ, E.R. and ARICOे, A.S., Performance and selectivity of PtxSn/C electrocatalysts for ethanol oxidation prepared by reduction with different formic acid concentrations. Electrochimica Acta, v. 70, n., p. 255-265, 2012.

40. WANG, Y.; WU, G.; WANG, Y. and WANG, X., Effect of water content on the ethanol electro-oxidation activity of Pt-Sn/graphene catalysts prepared by the polyalcohol method. Electrochimica Acta, v. 130, n. 0, p. 135-140, 2014.

41. HIGUCHI, E.; MIYATA, K.; TAKASE, T. and INOUE, H., Ethanol oxidation reaction activity of highly dispersed $\mathrm{Pt} / \mathrm{SnO} 2$ double nanoparticles on carbon black. Journal of Power Sources, v. 196, n. 4, p. 1730-1737, 2011.

42. LI, J.J.; WANG, J.S.; GUO, X.; ZHAO, J.H.; SONG, C.Y. and WANG, L.C., Improving the Stability and Ethanol Electro-Oxidation Activity of Pt Catalysts by Selectively Anchoring Pt Particles on Carbon-Nanotubes-SupportedSnO2. Fuel Cells, v. 12, n. 5, p. 898-903, 2012.

43. ZHOU, W.-P.; AXNANDA, S.; WHITE, M.G.; ADZIC, R.R. and HRBEK, J., Enhancement in Ethanol Electrooxidation by SnOx Nanoislands Grown on $\mathrm{Pt}(111)$ : Effect of Metal Oxide-Metal Interface Sites. The Journal of Physical Chemistry C, v. 115, n. 33, p. 16467-16473, 2011.

44. VELÁZQUEZ-PALENZUELA, A.; CENTELLAS, F.; BRILLAS, E.; GARRIDO, J.A.; ARIAS, C.; RODRÍGUEZ, R.M. and CABOT, P.-L., Sn- 
modified carbon-supported Pt nanoparticles synthesized using spontaneous deposition as electrocatalysts for direct alcohol fuel cells. International Journal of Hydrogen Energy, v. 38, n. 36, p. 16418-16426, 2013.

45. SILVA, J.C.M.; DE SOUZA, R.F.B.; PARREIRA, L.S.; NETO, E.T.; CALEGARO, M.L. and SANTOS, M.C., Ethanol oxidation reactions using SnO2@Pt/C as an electrocatalyst. Applied Catalysis B: Environmental, v. 99, n. 1-2, p. 265-271, 2010.

46. ZHANG, X.; ZHU, H.; GUO, Z.; WEI, Y. and WANG, F., Design and preparation of CNT@SnO2 core-shell composites with thin shell and its application for ethanol oxidation. International Journal of Hydrogen Energy, v. 35, n. 17, p. 8841-8847, 2010.

47. EL-SHAFEI, A.A. and EISWIRTH, M., Electrochemical activity of Snmodified $\mathrm{Pt}$ single crystal electrodes for ethanol oxidation. Surface Science, v. 604, n. 9-10, p. 862-867, 2010.

48. MAGEE, J.W.; ZHOU, W.-P. and WHITE, M.G., Promotion of Pt surfaces for ethanol electro-oxidation by the addition of small SnO2 nanoparticles: Activity and mechanism. Applied Catalysis B: Environmental, v. 152153, n. 0, p. 397-402, 2014.

49. SPINACE, E.V.; INDELICATO DO VALE, L.A.; OLIVEIRA NETO, A. and LINARDI, M., Preparation of PtRu/C Anode Electrocatalysts using $\mathrm{NaBH} 4$ as Reducing Agent and $\mathrm{OH}$ - ions as Stabilizing Agent. ECS Transactions, v. 5 , n. 1, p. 89-94, 2007.

50. HYUN, M.-S.; KIM , S.-K.; LEE, B.; PECK, D.; SHUL, Y. and JUNG, D., Effect of $\mathrm{NaBH}_{4}$ concentration on the characteristics of PtRu/C catalyst for the anode of DMFC prepared by the impregnation method. Amsterdam, PAYS-BAS: Elsevier. 8, 2008.

51. CHEN, W.X.; LEE, J.Y. and LIU, Z., Microwave-assisted synthesis of carbon supported $\mathrm{Pt}$ nanoparticles for fuel cell applications. Chemical Communications, v., n. 21, p. 2588-2589, 2002.

52. SPINACÉ, E.V.; NETO, A.O.; VASCONCELOS, T.R.R. and LINARDI, M., Electro-oxidation of ethanol using $\mathrm{PtRu} / \mathrm{C}$ electrocatalysts prepared by alcohol-reduction process. Journal of Power Sources, v. 137, n. 1, p. 1723, 2004.

53. WANG, X. and HSING, I.M., Surfactant stabilized Pt and Pt alloy electrocatalyst for polymer electrolyte fuel cells. Electrochimica Acta, v. 47, n. 18, p. 2981-2987, 2002.

54. KIRKLAND, A. and HAIGH, S., Nanocharacterisation. 1 ed.: The Royal Society of Chemistry, 2007. 
55. RADMILOVIC, V.; GASTEIGER, H.A. and ROSS, P.N., Structure and Chemical Composition of a Supported Pt-Ru Electrocatalyst for Methanol Oxidation. Journal of Catalysis, v. 154, n. 1, p. 98-106, 1995.

56. TUSI, M.M.; BRANDALISE, M.; CORREA, O.V.; NETO, A.O.; LINARDI, M. and SPINACÉ, E.V., Preparation of PtRu/C Electrocatalysts by Hydrothermal Carbonization Process for Methanol Electro-oxidation. Portugaliae Electrochimica Acta, v. 27, n., p. 345-352, 2009.

57. BATURINA, O.A.; AUBUCHON, S.R. and WYNNE, K.J., Thermal Stability in Air of Pt/C Catalysts and PEM Fuel Cell Catalyst Layers. Chemistry of Materials, v. 18, n. 6, p. 1498-1504, 2006.

58. OLIVEIRA NETO, A.; GIZ, M.J.; PEREZ, J.; TICIANELLI, E.A. and GONZALEZ, E.R., The Electro-oxidation of Ethanol on Pt-Ru and Pt-Mo Particles Supported on High-Surface-Area Carbon. Journal of The Electrochemical Society, v. 149, n. 3, p. A272-A279, 2002.

59. SPINACÉ, E.V.; OLIVEIRA NETO, A.; FRANCO, E.G.; LINARDI, M. and GONZALEZ, E.R., Métodos de preparação de nanopartículas metálicas suportadas em carbono de alta área superficial, como eletrocatalisadores em células a combustível com membrana trocadora de prótons. Química Nova, v. 27, n., p. 648-654, 2004.

60. BAMBAGIONI, V.; BIANCHINI, C.; FILIPPI, J.; OBERHAUSER, W.; MARCHIONNI, A.; VIZZA, F.; PSARO, R.; SORDELLI, L.; FORESTI, M.L. and INNOCENTI, M., Ethanol Oxidation on Electrocatalysts Obtained by Spontaneous Deposition of Palladium onto Nickel-Zinc Materials. ChemSusChem, v. 2, n. 1, p. 99-112, 2009.

61. ZHANG, G.; SUN, S.; LI, R. and SUN, X., New Insight into the Conventional Replacement Reaction for the Large-Scale Synthesis of Various Metal Nanostructures and their Formation Mechanism. Chemistry - A European Journal, v. 16, n. 35, p. 10630-10634, 2010.

62. BERSANI, M.; CONTE, L.; MARTUCCI, A.; GUGLIELMI, M.; MATTEI, G.; BELLO, V.; ROSEI, R. and CENTAZZO, M., Transmetallation as an effective strategy for the preparation of bimetallic CoPd and CuPd nanoparticles. Nanoscale, v. 6, n. 3, p. 1560-1566, 2014.

63. LEE, K.Y.; LEE, Y.W.; KIM, M. and KIM, T.H., Fabrication of BixPtyPdz alloy nanoporous plates with electro-catalytic activity. Journal of Materials Chemistry A, v. 2, n. 8, p. 2735-2741, 2014.

64. MINTSOULI, I.; GEORGIEVA, J.; VALOVA, E.; ARMYANOV, S.; KAKAROGLOU, A.; HUBIN, A.; STEENHAUT, O.; DILLE, J.; PAPADERAKIS, A.; KOKKINIDIS, G. and SOTIROPOULOS, S., Pt-Ni carbon-supported catalysts for methanol oxidation prepared by $\mathrm{Ni}$ 
electroless deposition and its galvanic replacement by Pt. Journal of Solid State Electrochemistry, v. 17, n. 2, p. 435-443, 2013.

65. MINTSOULI, I.; GEORGIEVA, J.; ARMYANOV, S.; VALOVA, E.; AVDEEV, G.; HUBIN, A.; STEENHAUT, O.; DILLE, J.; TSIPLAKIDES, D.; BALOMENOU, S. and SOTIROPOULOS, S., Pt-Cu electrocatalysts for methanol oxidation prepared by partial galvanic replacement of $\mathrm{Cu} / \mathrm{carbon}$ powder precursors. Applied Catalysis B: Environmental, v. 136-137, n., p. 160-167, 2013.

66. GUO; DAO, J.; JING and ZHI, H., A novel co-precipitation method for preparation of $\mathrm{Pt}$-CeO2 composites on multi-walled carbon nanotubes for direct methanol fuel cells, Elsevier B.V., 2010.

67. LEE, K.-S.; YOO, S.J.; AHN, D.; JEON, T.-Y.; CHOI, K.H.; PARK, I.-S. and SUNG, Y.-E., Surface Structures and Electrochemical Activities of $\mathrm{Pt}$ Overlayers on Ir Nanoparticles. Langmuir, v. 27, n. 6, p. 3128-3137, 2011.

68. COTTON, F.A. and WILKINSON, G., Advanced Inorganic Chemistry (4th ed.). Wiley, Chichester, 1980.

69. WANG, H.; ZHANG, X.; WANG, R.; JI, S.; WANG, W.; WANG, Q. and LEI, Z., Amorphous CoSn alloys decorated by $\mathrm{Pt}$ as high efficiency electrocatalysts for ethanol oxidation. Journal of Power Sources, v. 196, n. 19, p. 8000-8003, 2011.

70. HUANG, M.; DONG, G.; WANG, N.; XU, J. and GUAN, L., Highly dispersive Pt atoms on the surface of RuNi nanoparticles with remarkably enhanced catalytic performance for ethanol oxidation. Energy \& Environmental Science, v. 4, n. 11, p. 4513-4516, 2011.

71. ESPOSITO, D.V.; HUNT, S.T.; STOTTLEMYER, A.L.; DOBSON, K.D.; MCCANDLESS, B.E.; BIRKMIRE, R.W. and CHEN, J.G., Low-Cost Hydrogen-Evolution Catalysts Based on Monolayer Platinum on Tungsten Monocarbide Substrates. Angewandte Chemie International Edition, v. 49, n. 51, p. 9859-9862, 2010.

72. INPI-RJ. SPINACÉ, E.V.; OLIVEIRA, N.A.; VASCONCELOS, T.R.R. and LINARD, M. Pedido de Depósito de Patente. PI0304121-2. 2003.

73. SPINACÉ, E.V.; VALE, L.A.I.D.; DIAS, R.R.; NETO, A.O. and LINARDI, M., $P t S n / C$ electrocatalysts prepared by different methods for direct ethanol fuel cell, M.D.D.E.D.V.S.H.P.A.J.J.A.M. E.M. Gaigneaux and P. Ruiz, Editors, Elsevier, 2006. in Studies in Surface Science and Catalysis, p. 617-624.

74. GAO, H.; LIAO, S.; ZENG, J. and XIE, Y., Platinum decorated Ru/C: Effects of decorated platinum on catalyst structure and performance for the methanol oxidation reaction. Journal of Power Sources, v. 196, n. 1, p. 54-61, 2011. 
75. KOWAL, A.; LI, M.; SHAO, M.; SASAKI, K.; VUKMIROVIC, M.B.; ZHANG, J.; MARINKOVIC, N.S.; LIU, P.; FRENKEL, A.I. and ADZIC, R.R., Ternary $\mathrm{Pt} / \mathrm{Rh} / \mathrm{SnO} 2$ electrocatalysts for oxidizing ethanol to CO2. Nat Mater, v. 8 , n. 4, p. 325-330, 2009.

76. GARCÍA-RODRÍGUEZ, S.; SOMODI, F.; BORBÁTH, I.; MARGITFALVI, J.L.; PEÑA, M.A.; FIERRO, J.L.G. and ROJAS, S., Controlled synthesis of $\mathrm{Pt}-\mathrm{Sn} / \mathrm{C}$ fuel cell catalysts with exclusive $\mathrm{Sn}-\mathrm{Pt}$ interaction: Application in $\mathrm{CO}$ and ethanol electrooxidation reactions. Applied Catalysis B: Environmental, v. 91, n. 1-2, p. 83-91, 2009.

77. BRANDALISE, M.; VERJULIO-SILVA, R.W.R.; TUSI, M.M.; CORREA, O.V.; FARIAS, L.A.; LINARDI, M.; SPINACÉ, E.V. and OLIVEIRA NETO, A., Electro-oxidation of ethanol using PtRuBi/C electrocatalyst prepared by borohydride reduction. Ionics, v. 15, n. 6, p. 743-747, 2009.

78. LÓPEZ-SUÁREZ, F.E.; BUENO-LÓPEZ, A.; EGUILUZ, K.I.B. and SALAZAR-BANDA, G.R., Pt-Sn/C catalysts prepared by sodium borohydride reduction for alcohol oxidation in fuel cells: Effect of the precursor addition order. Journal of Power Sources, v. 268, n., p. 225232, 2014.

79. ZHANG, Y.; HSIEH, Y.-C.; VOLKOV, V.; SU, D.; AN, W.; SI, R.; ZHU, Y.; LIU, P.; WANG, J.X. and ADZIC, R.R., High Performance Pt Monolayer Catalysts Produced via Core-Catalyzed Coating in Ethanol. ACS Catalysis, v. 4, n. 3, p. 738-742, 2014. 